\title{
واقع تحقيق القيادات التربوية للتنمية المهنية لمعلمات الرياضيات من وجهة نظرهن في المدارس الحكومية بمدينة جدة
}

\author{
نوف محمد البادي \\ جامعة دار الحكمة- السعودية
}

حنان عبدالله عبده صميلي

ماجستير في القيادة التربوية

جامعة دار الحكمة- السعودية

seralhaia2015@gmail.com

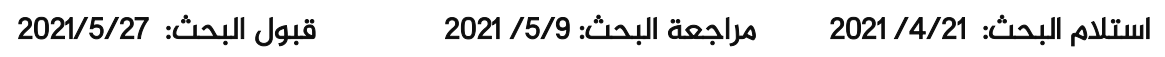


و اقع تحقيق القيادات التربوية للتنمية المهنية لمعلمات الرياضيات من وجهة نظرهن في المدارس

$$
\text { الحكومية بمدينة جدة }
$$

\author{
حنان عبدالله عبده صيميلي \\ ماجستير في القيادة التربوية- جامعة دار الحكمة- السعودية \\ seralhaia2015@gmail.com
}

\author{
نوف محمد البادي \\ جامعة دار الحكمة- السعودية
}

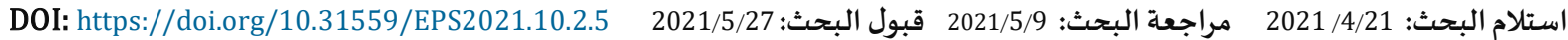

هدفت الدراسة الحالية إلى التعرف على واقع تحقيق القيادات التربوية (قائدة المدرسة، المشرفة التربوية) للتنمية المهنية لمعلمات

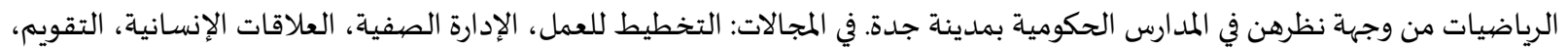
الكتاب المدرسي وطرق التدريس، التخطيط للتدريس. واعتمدت الدراسة على المنهج الوصفي، واستخدمت الاستبانة كأداة للبحث تم تطبيقها

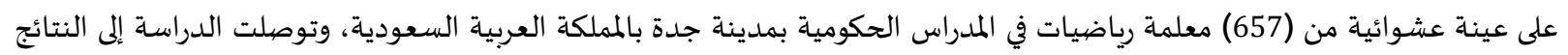

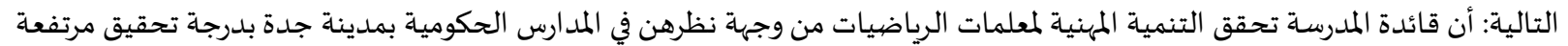

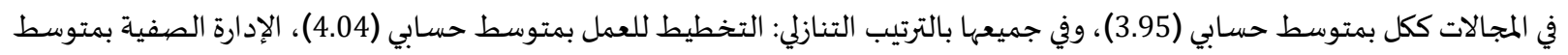
حسابي (4.03)، العلاقات الإنسانية بمتوسط حسابي (3.81)، وأن المشرفة التربوية تحقق التنمية المهنية لمعلمات الرياضيات من وجهاة نظرهن في المدارس الحكومية بمدينة جدة بدرجة تحقيق مرتفعة في المجالات ككل بمتوسط حسابي (3.92)، وفي جميعها بالترتيب التنازلي: التقويم بمتوسط حسابي (4.15)، الكتاب المدرسي وطرق التدريس بمتوسط حسابي (3.88)، التخطيط للتدريس بمتوسط حسابي (3.71).

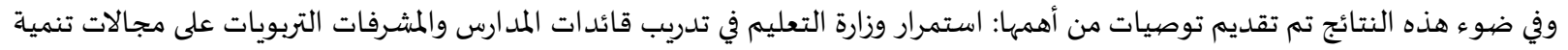

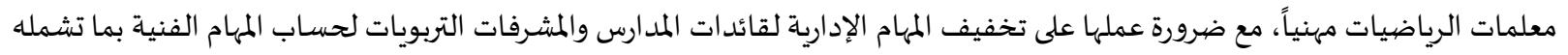
من تنمية معلمات الرياضيات مهنياً. الكلمات المفتاحية: القيادات التربوية؛ قائدة المدرسة؛ المشرفة التربوية؛ التنمية المهنية؛ معلمات الرياضيات.

يشهد العالم منذُ مطلع القرن الحادي والعشرين تطوراً متسارعاً واتجاهاً نحو المنافسة عالمياً في جميع المجالات اقتصادياً، وتكنولوجياً، وسياسياً،

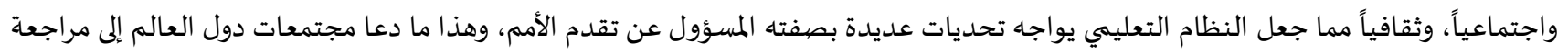

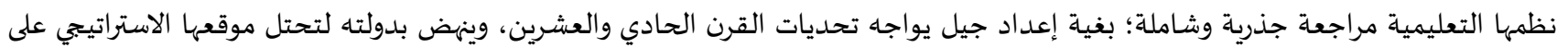
خريطة العولمة. (الذبياني، 2014) 
ولكي تتمكن مجتمعات الدول من مواجهة تلك التحديات، لابد لها من إعداد أفراد مكتسبين مهارات علمية ولغوية وتكنولوجية ومهارات الإنتاج

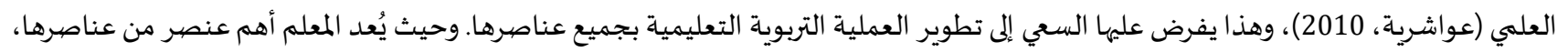

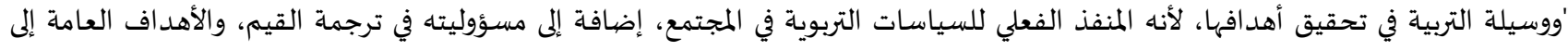

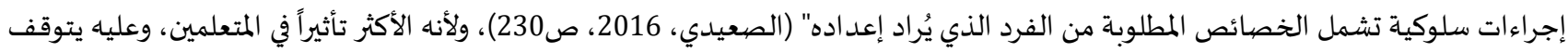

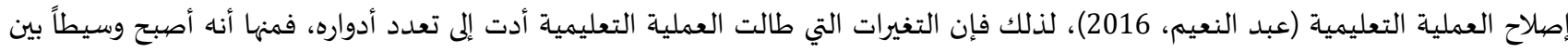

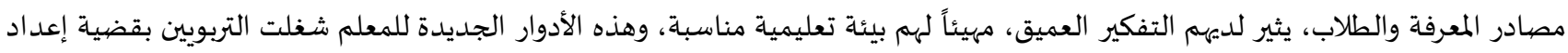
المعلمين وتدريبهم. (الدجاني، 2011)

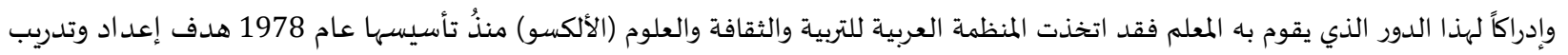

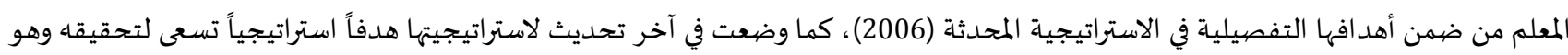

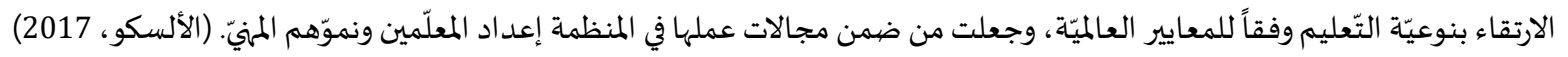

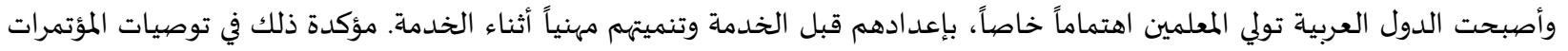

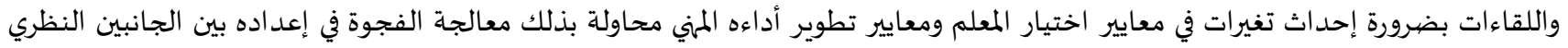

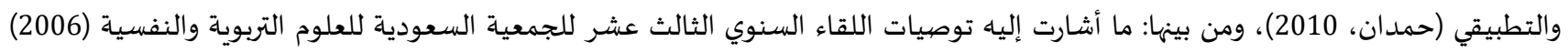

بعنوان" إعداد المعلم وتطويره في ضوء المتغيرات المعاصرة" بضرورة الاهتمام بالمعلم وتطويره مهنياً وتشجيعاه على الأخذ بمبدأ التعلم مدى الحئه الحياة.

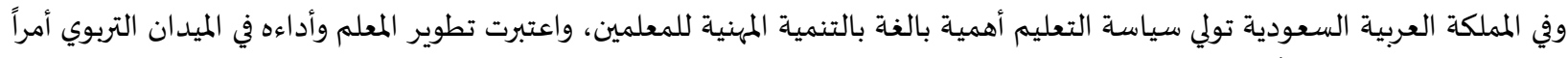

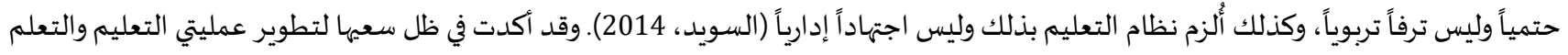

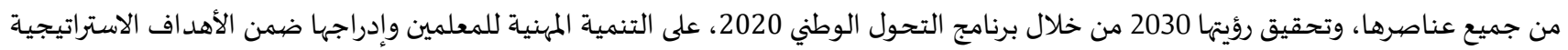

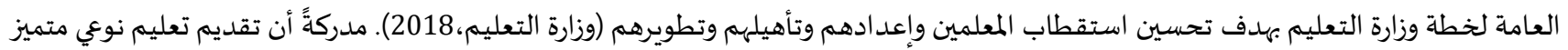

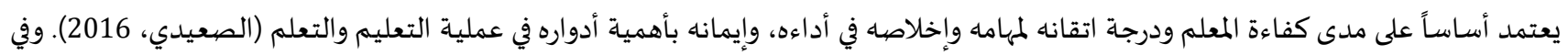

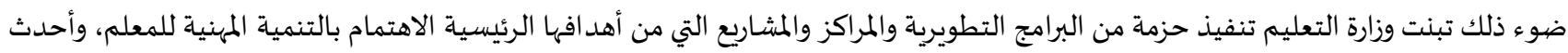

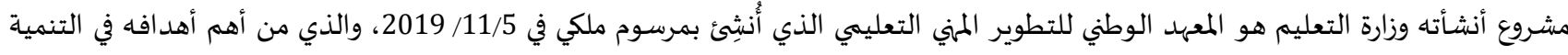

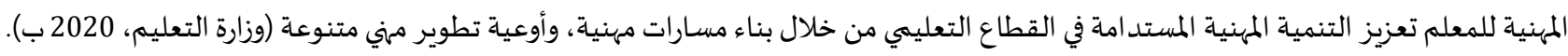

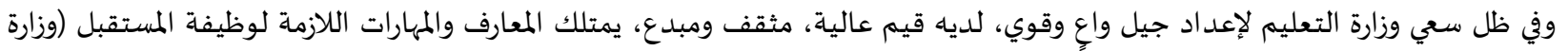

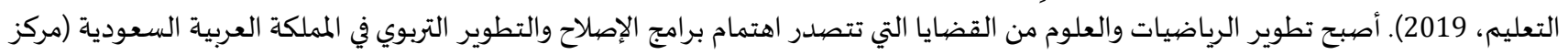

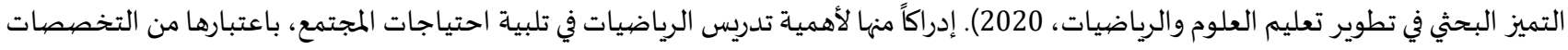

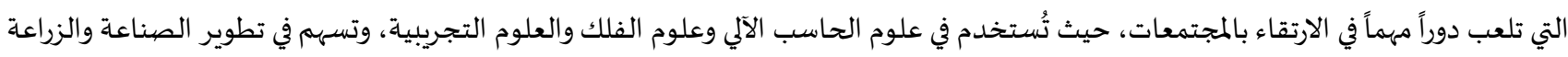

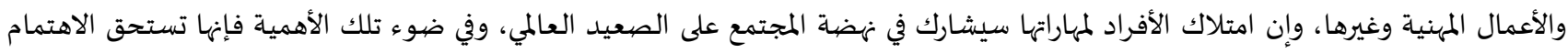

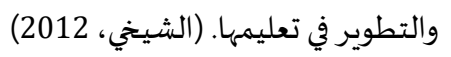

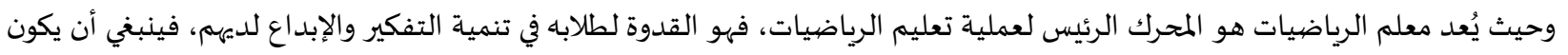

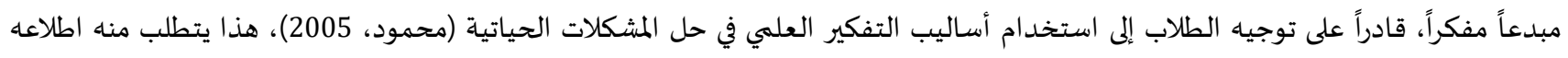

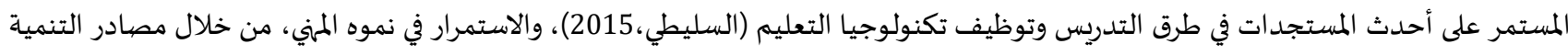

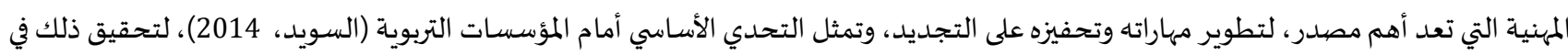

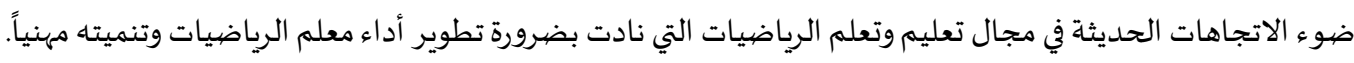

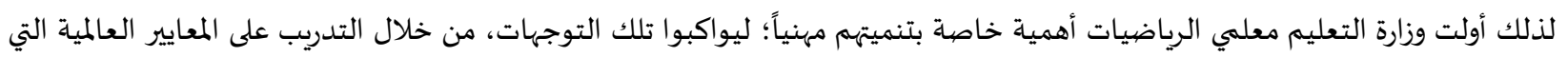

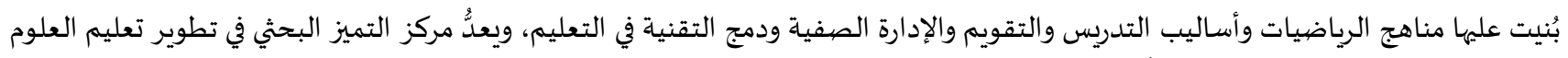

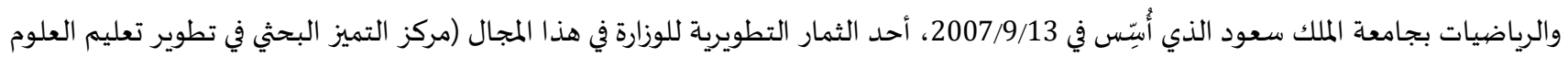

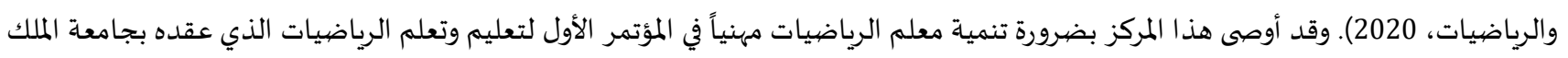

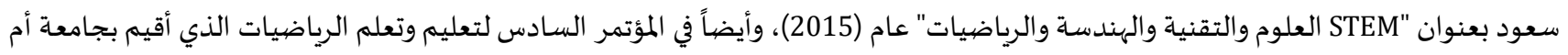

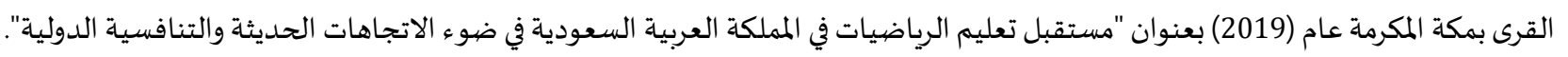

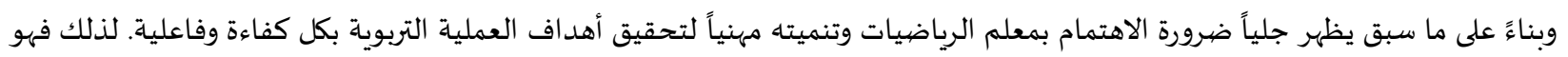

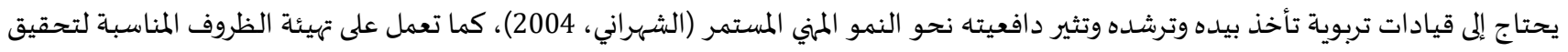

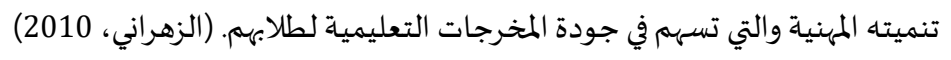


ومن أهم القيادات التربوية التي لها علاقة مباشرة بالمعلمين والتي يحتم علهيا دورها القيادي الاهتمام بتنميتهم مهنياً هي القيادة المدرسية متمثلةً في

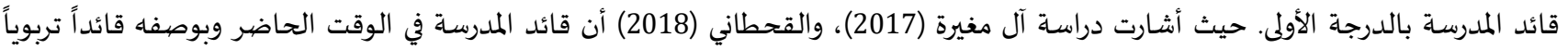

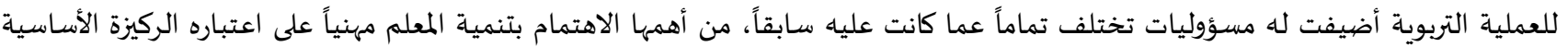
فبتطوير مستواه تتطور مخرجات النظام التربوي. وكذلك يُعد المشرف التربوي قائداً تربوياً، يتابع الميدان التربوي ويشرف على المعلمين ويركز على تحسين أداءهم وتطويره (أبو شاهين، 2011)،

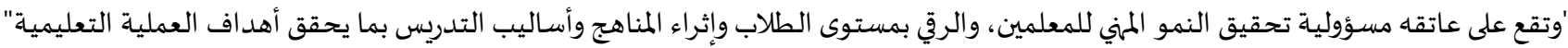

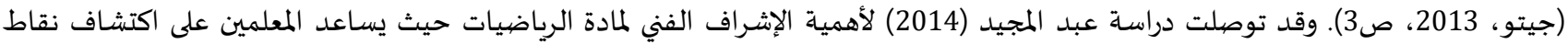

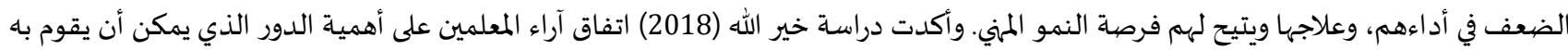

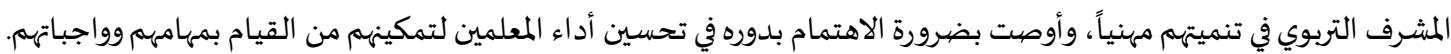

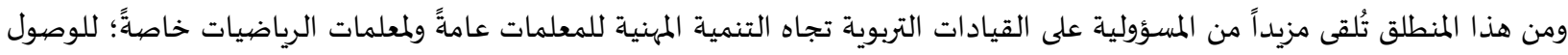

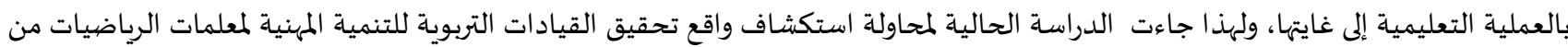
وجهة نظرهن في المدارس الحكومية بمدينة جدة، من خلال المجالات التالية: العلاقات الإنسانية، التخطيط للعمل، الإدارة الصفية، التخطيط للتدريس، الكتاب المدرسي وطرائق التدريس، التقويم.

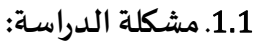
"إن جودة النظام التعليمي من جودة معلميه" (منظمة الأمم المتحدة للتربية والعلوم والثقافة (اليونسكو، 2014، ص235). والتنمية المهنية

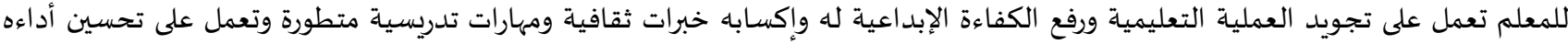

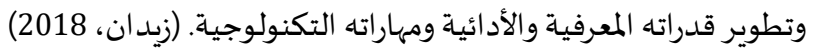

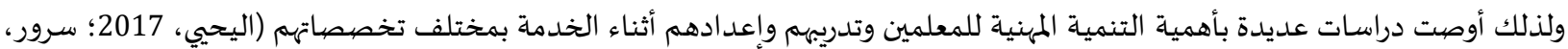

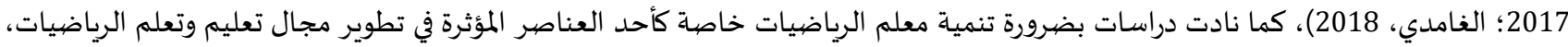

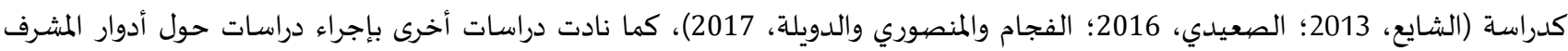

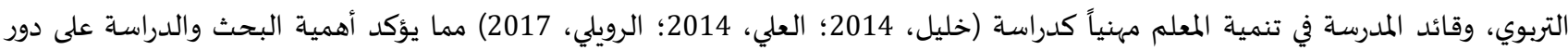

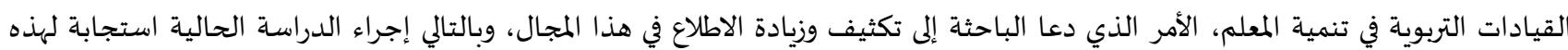

وفي المقابل تعددت الدراسات التي تنادي بضرورة إجراء بحوث علمية في مجال إعداد المعلم وتنميته المهنية لتطوير العملية التعليمية. حيث يأتي

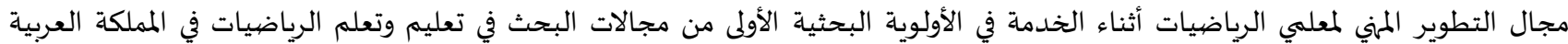

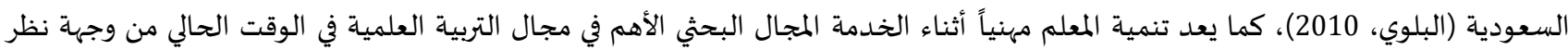

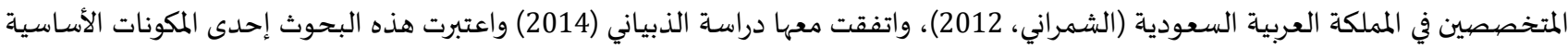

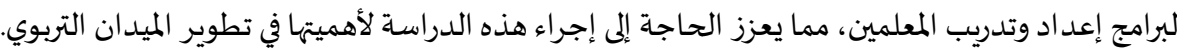

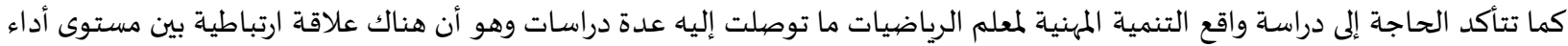

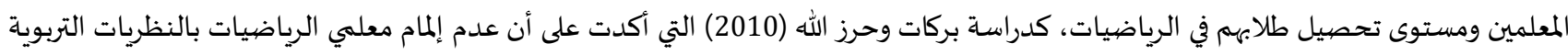

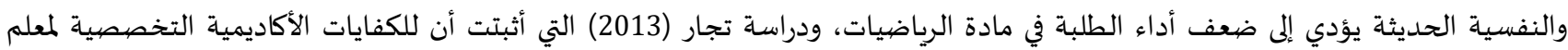

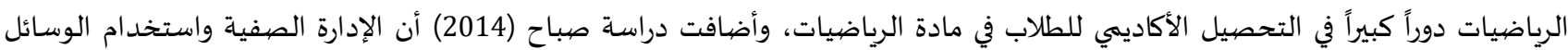

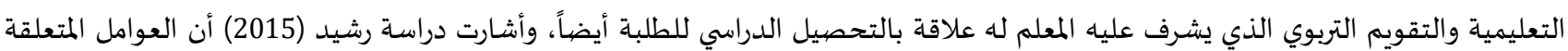

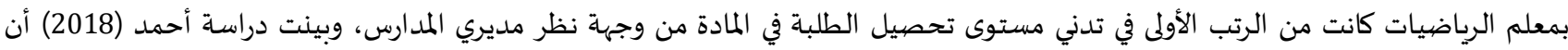

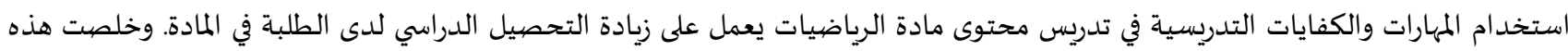

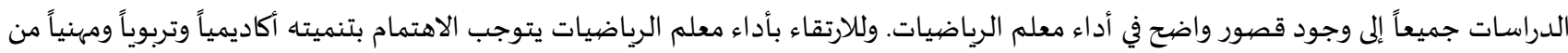
قبل القيادات التربوية المباشرة له على أقل تقدير.

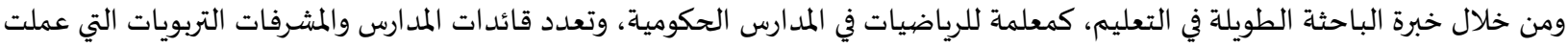

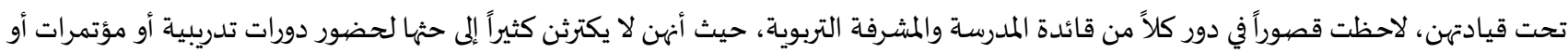

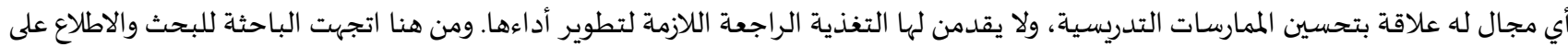

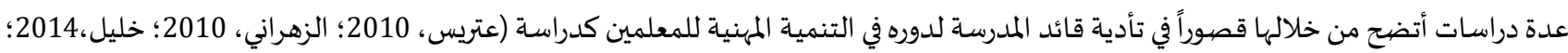

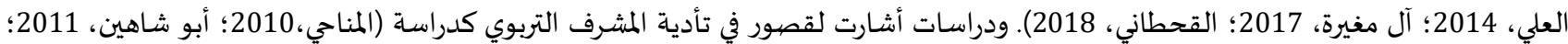


الشديفات، 2014؛ شلش وحرز الله، 2017؛ الرويلي، 2017)، كما بينت دراسات أخرى قصهوراً في دورهما معاً في تنمية المعلمين مهنياً كدراسة (الزهراني،

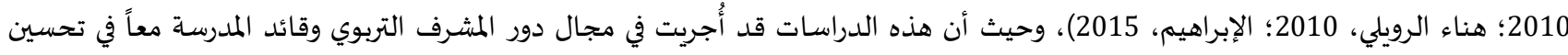

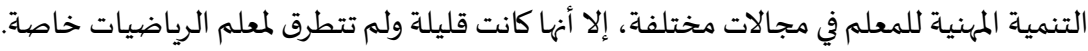

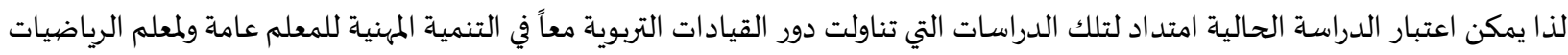

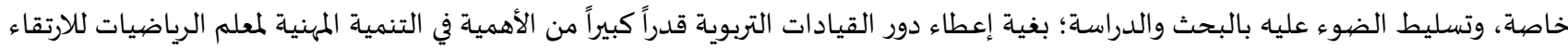

بأدائه وتحسين العملية التعليمية.

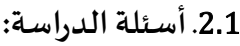

سعت الدراسة الحالية للإجابة على الأسئلة التالية: 1. ما واقع تحقيق قائدة المدرسة للتنمية المهنية لمعلمات الرياضيات من وجهة نظرهن في مجال (العلاقات الإنسانية-التخطيط للعمل-الإدارة

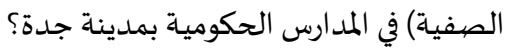
2. ما واقع تحقيق المشرفة التربوية للتنمية المهنية لمعلمات الرياضيات من وجهة نظورية نظرهن في مجال (التخطيط للتدريس -الكتاب المدرسي وطرق التدريس- التقويم) في المدارس الحكومية بمدينة جدة؟ المتربة

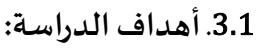

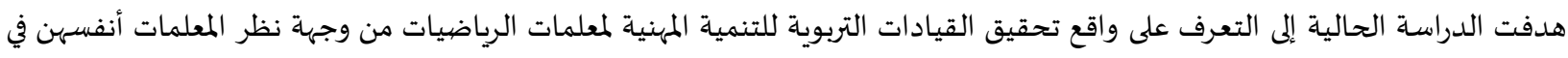

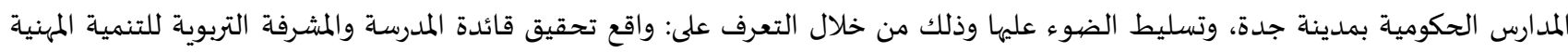
المعلمات من وجهة نظر المعلمات أنفسهن بالمدارس الحكومية بمدينة جدة.

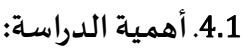

الأهمية النظرية: تكتسب الأهمية النظرية لهذه الدراسة في أنها:

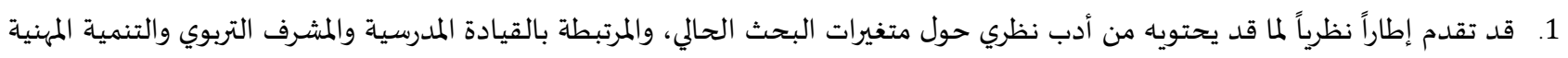

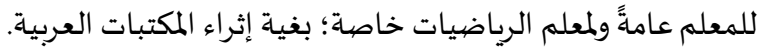

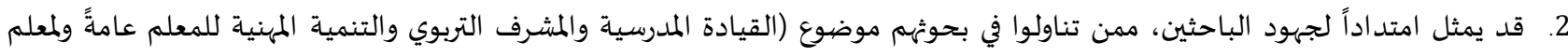

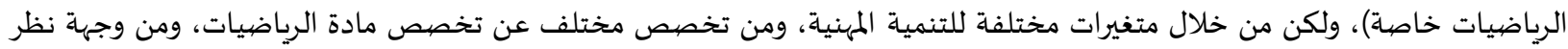

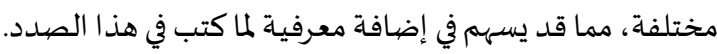

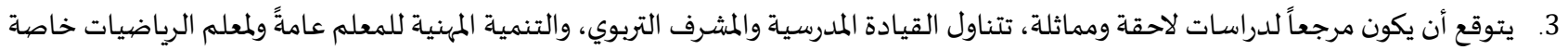

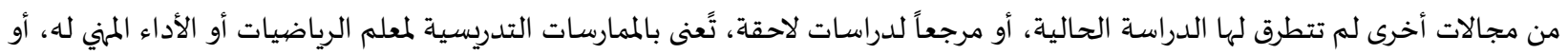
تهتم بمخرجات التعلم من خلال التنمية المهنية للمعلم. الأهمية التطبيقية: وتتلخص الأهمية التطبيقية لهذه النهات الدراسة في أنها:

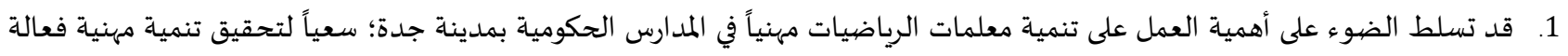

$$
\text { للمعلمات ومخرجات تعلم مجودة. }
$$

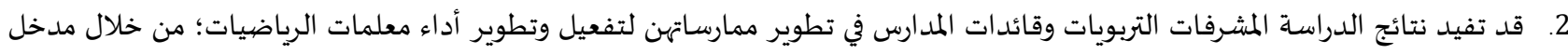

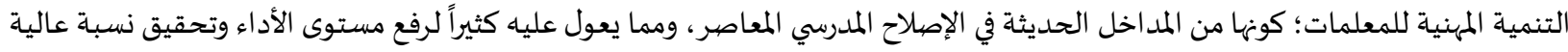
من الإنتاجية في المجال التربوي والتعليمي. 3. قد تزود نتائج الدراسة المسؤولين في إدارة الاشراف التربوي بنقاط القوة، ونقاط الضعف في ممارسات قائدات المدارس والمشرفات التربويات؛ بغية تحسيناه وتطويره.

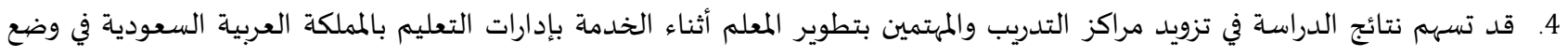

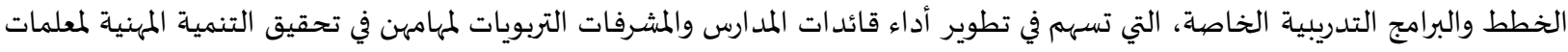

5. قد تفيد نتائج وتوصيات الدراسة، ومقترحاتها صناع القرار، والمهتمين بإعداد وتأهيل المعلم أثناء الخدمة بإدارات التعليم بالمملكة العربية

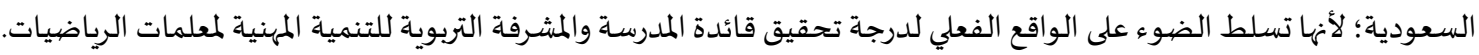


الحدود الموضوعية: اقتصرت على وصف واقع دور: قائدة المدرسة في مجالات (العلاقات الإنسانية- التخطيط للعمل- الإدارة الصفية)، والمشرفة التربوية في مجالات (التخطيط للتدريس-الكتاب المدرسي وطرائق التدريس-التقويم) لتحقيق التنمية المهنية لمعلمات الرياضيات.

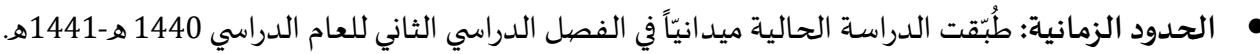

هالحدود المكانية: اقتصرت الدراسة الحالية على المدارس الحكومية (ابتدائي- متوسط - ثانوي) بمدينة جدة في المملكة العربية السعودية. الحـدود البشرية: اقتصرت الدراسة الحالية على عينة عشوائية من معلمات الرياضيات في المدارس الحكومية.

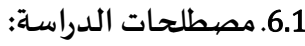

التنمية المهنية للمعلم (Professional Development)

التعريف الاصطلاحي: يُعرّف عامر (2012، ص14) التنمية المهنية بأنها "عملية تفاعل المعلم مع خبرات تعليمية، ومهارات جديدة، من أجل تطوير عاداته، واتجاهاته، وأسلوبه في عمله؛ لجعله قادراً على أداء مهاماه وواجباته التربوية بكفاءة أكثر مع مسايرته لكل جديد التهريد في تخصصيه" كما تعرفها زيدان (2018، صا375) بأها: "عملية نمو مستمرة، شاملة، وطويلة المدى، تهدف إلى تطوير المعلم، وتحسين كفاءته المهنية وأداءه، وذلك من خلال البرامج

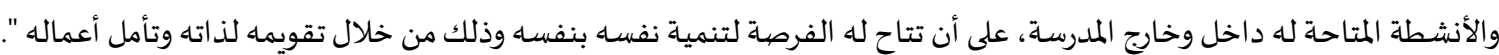
التعريف الإجرائي: وتعرف التنمية المهنية في هذه الدراسة إجرائياً: بأها الجهود المبذولة من قبل قائدة المدرسة والمشرفة التربوية والموجهة إلى معلمة الرياضيات للارتقاء بالعملية التعليمية التعلمية، من خلال زيادة كفاءة عمل المعلمات برفع مستوى ألماتهية أداءهم الوظيفي، وتحسين كفايتهم الإنتاجية، وتنمية قدراتهم وتجديد معلوماتهم لمواجهة المواقف التعليمية بما يتعلق بالمجالات التالية: العلاقات الإنسانية-المتابعة-الإدارة الصفيةالتخطيط للتدريس-التدريب والنمو المهن-المناهج وطرق التدريس-التقويم؛ بغية تحقيق الأهداف التهبية التربوية المنشودة.

(Educational leadership) القيادة التربوية التعريف الاصطلاحي: تُعرّف الشمري (2004، ص.15) بأنها: "القدرة على إدارة التغيير التربوي في المؤسسات التعليمياة، وتنمية روح عمل الفريق، ورفع قدرات الأفراد بما يؤهلهم لتحقيق أهداف المؤسسة التعليمية بفعالية ". التعريف الإجرائي: وتعرف القيادة التربوية في هذه الدراسة إجرائياً بأهها: قائدة المدرسة والمشرفة التربوية المسؤولتان رسمياً من قبل وزارة التعليم عن سير العملية التربوية التعليمية بهدف تحسينها، وتطويرها من خلال الاهتمام بتنمية المعلمة مهنياً. معلمة الرياضيات: وتقصد الدراسـة الحالية بمعمله الرياضيات إجرائياً بأنها المعلمة المؤهلة علمياً، والتي تقوم بتدريس مادة الرياضيات في أي مرحلة من مراحل التعليم بالمدارس الحكومية بمدينة جدة وقت إجراء الدراسـة.

2.

يتناول الإطار النظري المفاهيم والمتغيرات المتصلة بالدراسة والتي تمثلت بالقيادات التربوية التي تناولت القيادة المدرسية من حيث المفهوم،

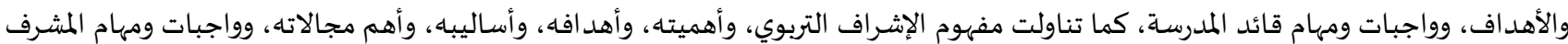
التربوي. ويشمل كذلك على مفهوم التنمية المهنية للمعلمين وأهميتها وأهد افها ومجالاتها.

1.2 القيادات التربوية أولاً: مفهوم القيادات التربوية: "تأثر مفهوم القيادة التربوية بنفس العوامل التي تأثر منها مفهوم القيادة بصورة عامة، من حيث تعدد الزوايا التي نظر منها الباحثون المختلفون

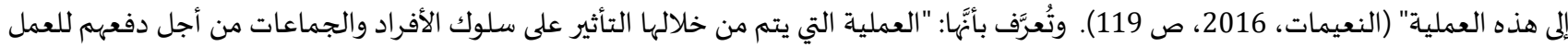

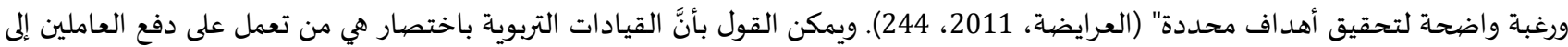
العمل وترغبهم وتشجعهه عليه، وتشرف على ذلك بطريقة مباشرة أو غير مباشرة، وفق خطط مرسومة لتحقيق أهداف معينة.

2.2 القيادة الملدرسية: أولاً: مفهوم القيادة المدرسية: يتحدد مفهوم القيادة المدرسية كما أوضح الشهري (2018) في ضوء المهيه: المهام المنوطة والأعمال الإدارية المترتبة على القائد للقيام بها. وتنبع أهمية هذا المفهوم من أهمية دورها بكونها منظمة ومسيرة للعمل التعليمي. 
وقد عرِفِت جيتو(2013، ص33) القيادة المدرسية بأنَّا: "العمليات والجهود التي تتم من خلال تفاعل فريق العمل داخل المدرسة وإشراك

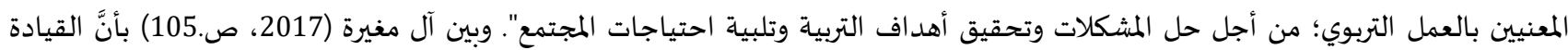

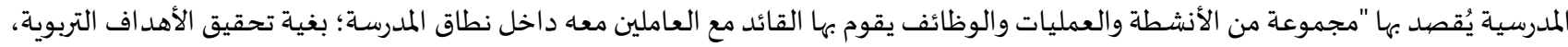

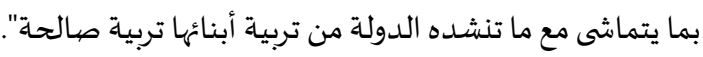

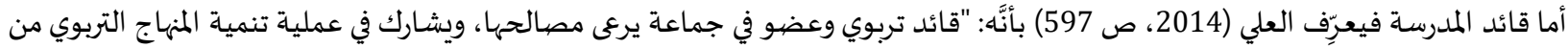

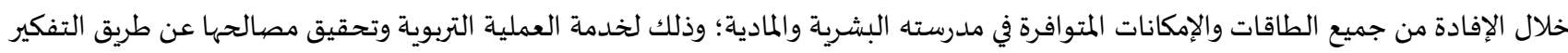

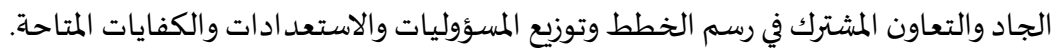

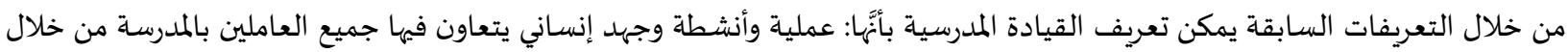

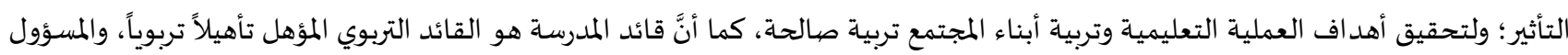

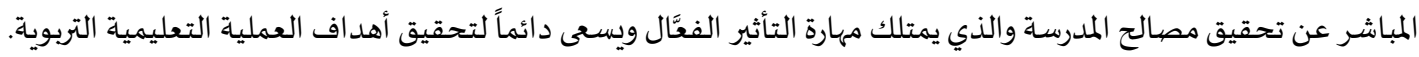
ثانياً: أهداف القيادة المدرسية: تختلف أهداف القيادة المدرسية "وتتفاوت أولوياتها باختلاف المفاهيم والمتغيرات التي تؤثر في العملية التعليمية" (جيتو، 2013، صدادهاء

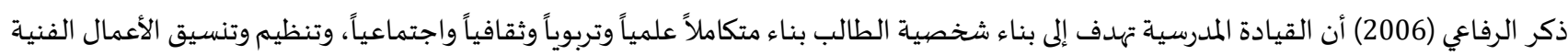

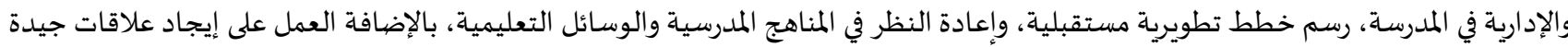

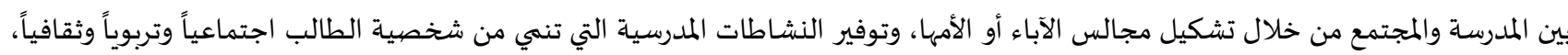

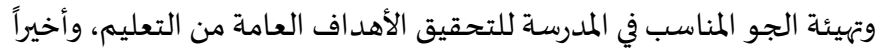
إضافة إلى الأهداف السابقة، يذكر شراحيلي (2020) إنَّ القيادة المدرسية تؤدي دوراً مهماً في العملية التعليمية، فالقائية المائد يقوم بتنظيم وإدارة

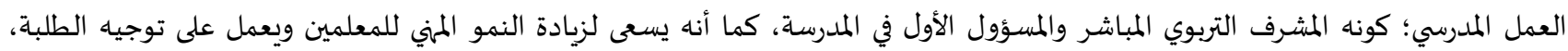
ومساعدتهم للنهوض بهم من جميع النواحي الجسمية والعقلية والانفعالية والروحية.

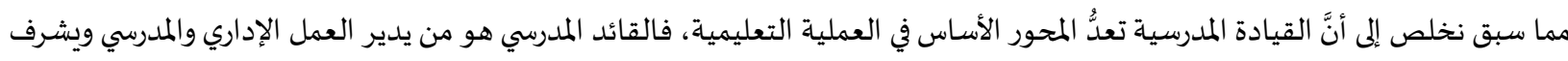

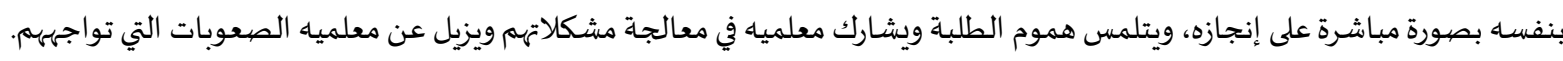

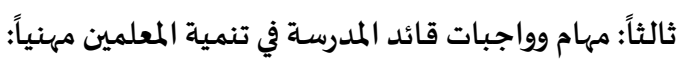

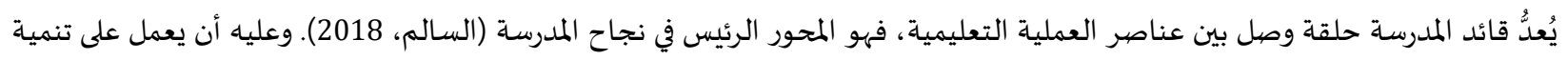

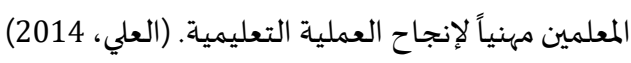

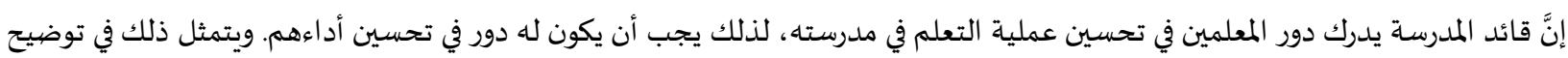

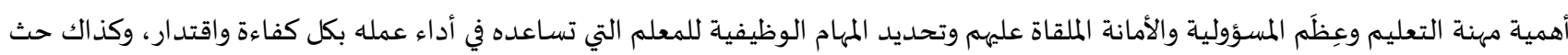

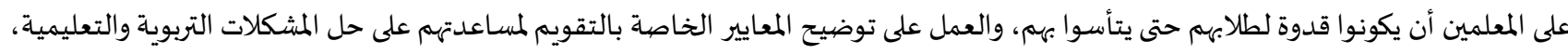

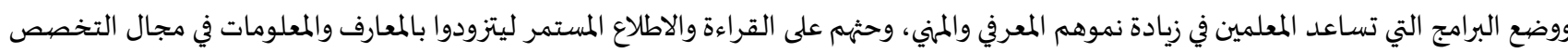

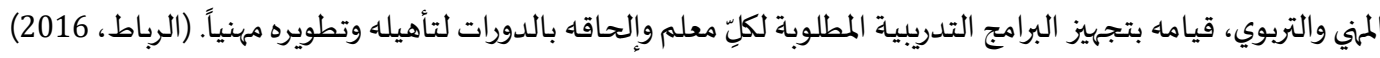

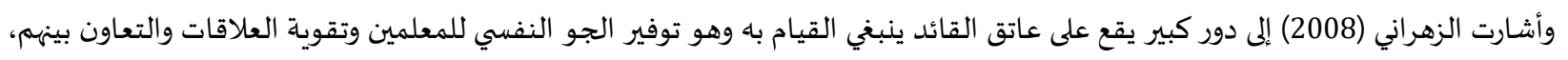

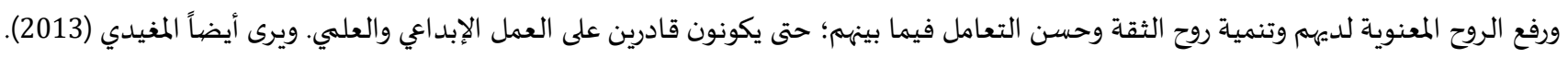

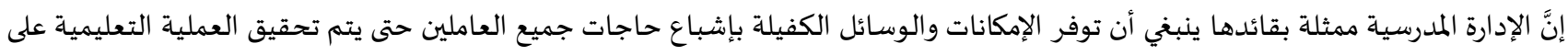
الوجه المطلوب. وفي السياق ذاته، حددت وزارة التعليم في وثيقة الدليل التنظيمي لمدارس التعليم العام (2020-2019 أ، صاب35-34)، واجبات قائد المدرسة تجاه

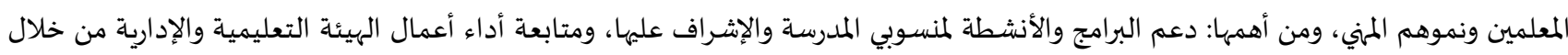

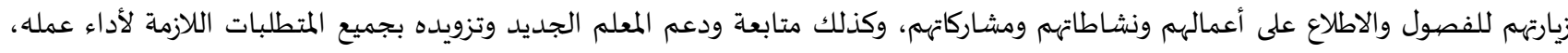

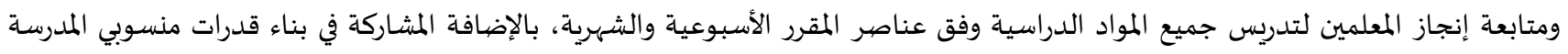

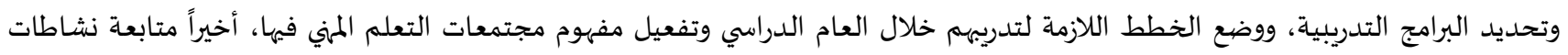

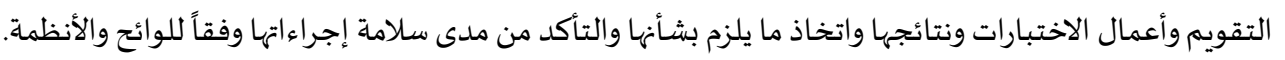


مما سـبق يمكن القول إنَّ واجبـات قائدة المدرسـة تعتمـد في الأسـاس الأول على متابعة أداء أعمال المعلمين من خلال الزيـارات الصهفية ومسـتوى

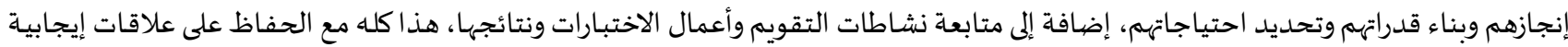
داعمة لسير العمل.

3.2. الإشراف التربوي:

أولاً: مفهوم الإشراف التربوي:

إنَّ مفهوم الإشراف التربوي تطوَّر وتغيَّ متأثراً بالتغيرات التربوية والاجتماعية والاقتصادية (العاجز وحلس، 2009)، وهو يهدف لتحسين الموقف

التعليمي والتعلمي وبيئتهما بالمدرسة، وتطوير العملية التعليمية ضمن أهداف سياسة التعليم (الحربي، 2012). ولقد تعددت تعريفات الإشراف التربوي من قبل المختصين التربويين، فعرفها البدري (2001، ص.18) بأنَّا: "قيادة تربوية هدفها تهيئة الفرص المناسبة لنمو المعلمين وتطويرهم مهنياً؛ بهدف الارتقاء بمستوى التعليم، وذلك عن طريق استخدام الأساليب التربوية الملائمة للاستفادة من التطورات

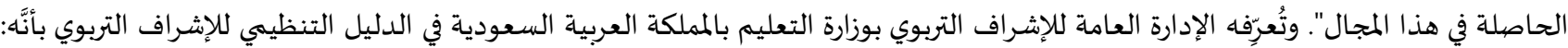

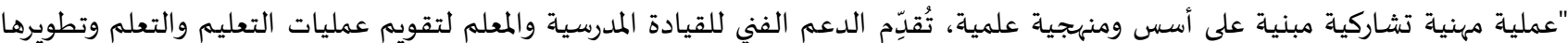

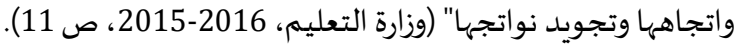

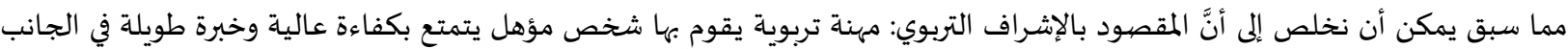
التربوي، يسعى جاهداً إلى توجياء المعلمين من ذوي الاختصاص وإرشادهم في تحسين العملية التعليمية واستخدام أفضل الوسائل والأساليب الحديثة أثناء التدريس. ثانياً: أهمية لإشراف التربوي: يُعدُّ الإشراف التربوي هو الاختيار الأفضل بإجماع الباحثين والمتخصصين للتحسين من أداء المعلمين، ويحتاج المشرفون أثناء العمل الإشرافي إلى قاعدة دينية وأخلاقية تنعكس على أخلاقيات المهنة بحيث يتعاون المشرفون مع المعلمين في توجيههم وإرشادهم (دواني، 2003). لذا ينظر إلى الإشراف التربوي على أنه وسيلة لتطوير البيئة التعليمية. وتبدو أهميته في أنه: عملية منظمة، تسعى إلى الرقي بالمعلم، وهي مكملة

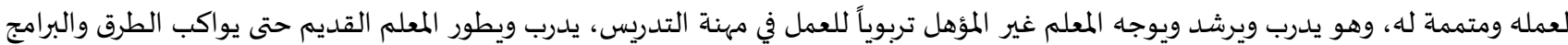
التعليمية الحديثة في عملية التدريس، ويوجه المعلم المبتدئ مهما كان إعداده وتدريبه، ويشرف على المعلم المتميز ولا سيما عند تطبيق أفكار جديدة

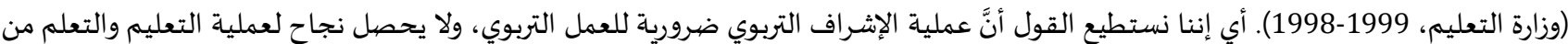
دونها، فمن خلالها يتم تحديد الطرق ورسمها للعاملين في الميدان لتحقيق نموهم المهني بما يخدم الأهداف المنشودة. كما أن الإشراف التربوي يهدف بصورة عامة كما أشار العاجز وحلس (2009) إلى تحسين عمليتي التعليم والتعلم وتحسين بيئتيهما، وذلك من خلال تطويرها والارتقاء بها نحو الأفضل. وههدف الإشراف التربوي في المملكة العربية السعودية بصورة عامة إلى "تحسين عمليتي التعليم التعلم وتحسين

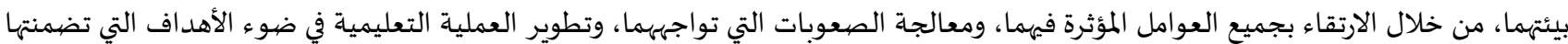

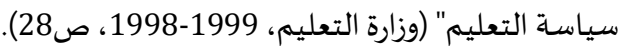

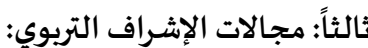

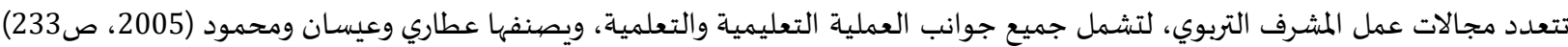

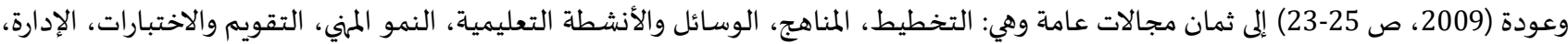
إدارة الصف، العلاقة مع الزملاء والمجتمع. ولذا إنَّ مجالات الإشراف التربوي على تنوعها تسهم جميعها في إنجاح العملية التعليمية، إذا تم تطبيقها

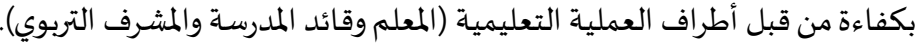
رابعاً: مهام وواجبات المشرف التربوي في تنمية المعلمين مهنياً: إنَّ الإشراف التربوي له أهمية كبيرة في مساعدة المعلمين في تطوير التنمية المهنية لديهم؛ حيث يعمل على تحسين العمل التربوي والتعليمي بوجهاه

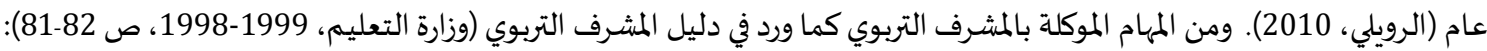
مهام تخطيطية وإدارية ومن أبرزها: إعداد خطة إشرافية شاملة وتنفيذها وتقويمها، الاطلاع على التعليمات واللوائح الإدارية، مساعدة المعلمين على فهم الأهداف التربوية، وتزويد الجدد منهم بالتعليمات، عقد لقاءات معهم لمناقشة كل ما من شأنها رفع مستواهم وتحصيل إديل الطالب، دراسة

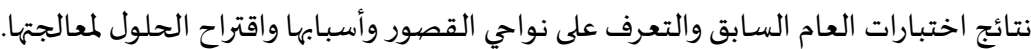
مهام فنية: ومن أبرزها مهام تتعلق بكل من: الطالب من حيث العناية بالنمو المتكامل للطالب ومراعاة الفروق الفردية، المعلم من حيث إعداده

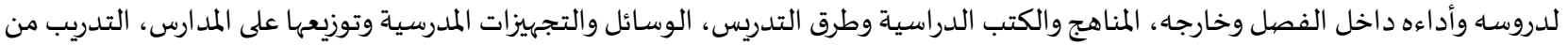


حيث اقتراح البرامج التدرببية وتنفيذها وتقويمها، الأنشطة المدرسية من حيث ضرورتها والتأكد من تنفيذها، الاختبارات من حيث الأساليب المستخدمة ودراسة نتائجها.

وقد جاء في الدليل التنظيمي للإشراف التربوي (وزارة التعليم، 2016-2015، ص 47-45) واجبات المشرف التربوي تجاه المعلمين من أهمها: 1. دعم المعلمين فنياً لتحسين ورفع مستوى عملية تعلم الطلاب. 2. تحليل برامج التنمية المهنية للمعلمين في مجال تخصصيهم والارتقاء بمستوى الأداء وفقاً للتخصص. 3. متابعة توظيف كتاب الطالب ودليل المعلم، وتعليم وتعلم الطلاب الزيارات. 4. دعم المعلمين وتطبيق استراتيجيات التعليم والتعلم والتقويم. 5. دراسة وتحليل مؤشرات التحصيل الدراسي للطلاب وإعداد البرامج الداعمة لتحسينات لتعينه.

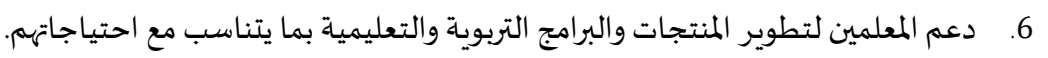

7. بناء مجتمعات التعلم المهني بين المعلمين في مجال تخصصيهم في المدرسة.

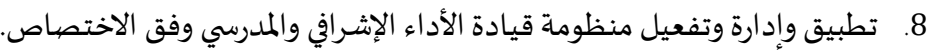

9. تقويم مستوى تطبيق المناهج الدراسية وأدواتها المصاحبة، وتقديم المواد الإثرائية والعلاجية، والتحسينات المقترحة لها.

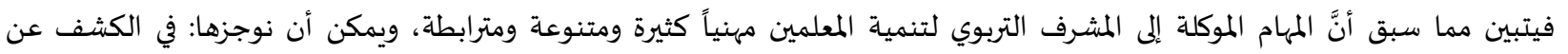
احتياجاتهم مهنياً وأكاديمياً، وتحديد وتنفيذ برامج التنمية المهنية المناسبة لهمه.

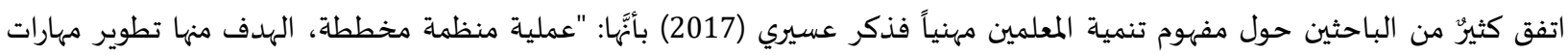

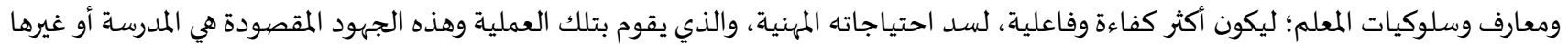

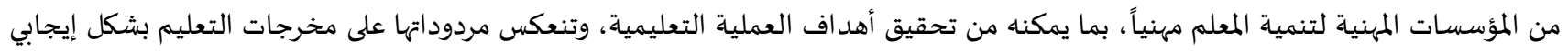
فعَّال" (ص من 154). وبيّن آدم وعثمان وأبكر (2017) بأنَّ مفهوم التنمية المهنية يُقصد به "الخبرات المنظمة التي يتعرض لها المعلم، وتزيد من معلوماته، أو تنمي

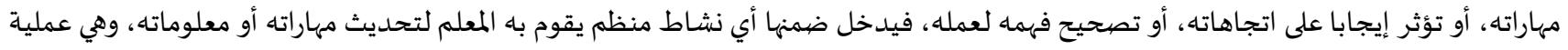

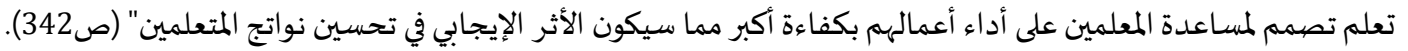

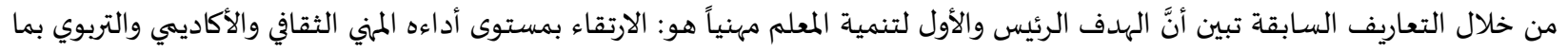
يحقق أهداف العملية التعليمية التعلمية.ومن هنا تتضح أهمية الاهتمام بالتنمية المهنية.

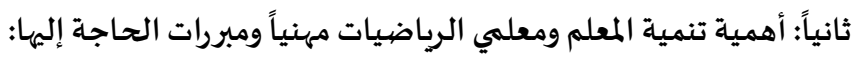
تعدُّ تنمية المعلم مهنياً أمر ضروري، وذلك بتوفير برامج تدريبية له لتأهيله وتطويره في مجال تخصصيه، إضهافة إلى تزويده بطرق وأساليب التدريس التربوية الحديثة (عسيري، 2017).

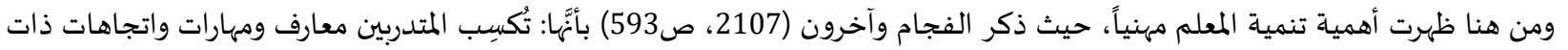

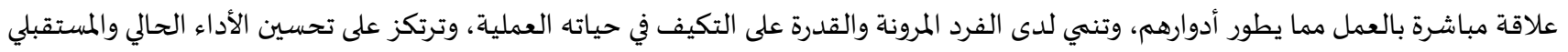
للأفراد والجماعات على حدٍٍ سواء ويقوم على مبدأ التعلم مدى الحياة، وتسهم في تقليل النفقات لزيادة المهارات والكفاءات التي تؤدِّي إلى تقليل نسبة الأخطاء بالعمل. كما أن من أهم المبررات التي تستدعي الاهتمام بالتنمية المهنية لمعلمي الرياضيات خاصيةً هي: تمكينهم من أداء رسالتهم في ضوء التغيرات السريعة

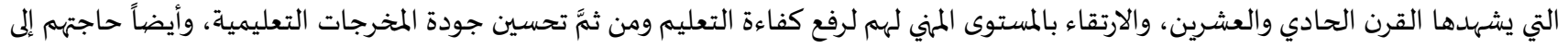

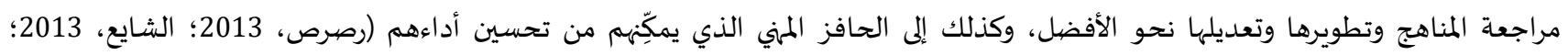
الصعيدي، 2016). ومن خلال مراجعة الدراسات والأبحاث في مجال تعليم وتعلم الرياضيات كدراسة الغامدي (2018)، ودراسة البلوي والراجح (2005) (2012)، ودراسة محمود (2005) يمكن أن نستنتج مبررات أخرى لتنمية معلمات الرياضيات مهنياً وهي:

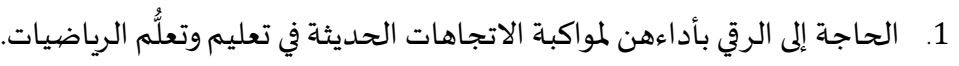
2. الحاجة إلى تجديد معلوماتهن، واطلاعهن على أحدث الطرق والاستراتهاتئجيات والوسائل في تدريس الرياضيات، في ظل تطور مناهج الرياضيات في المملكة العربية السعودية في الفترة الأخيرة. 


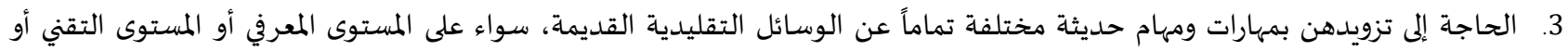

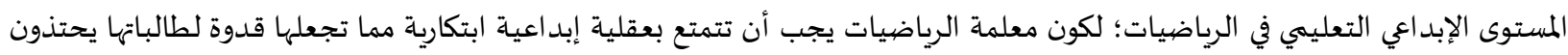

حذوها ويتعلمون منها أساليب التفكير العلمي والإبداعي وكيفية حل مشكلاتهم اليومية أيضاً.

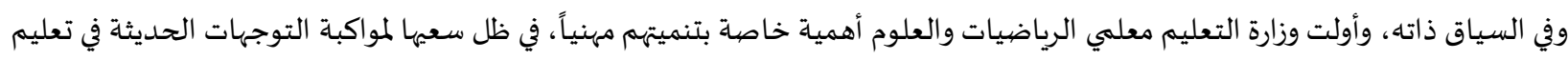

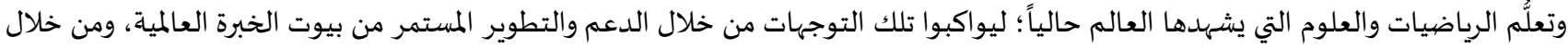

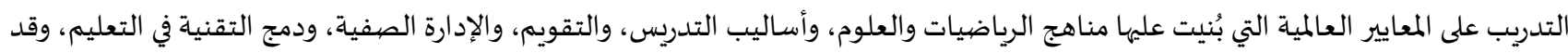

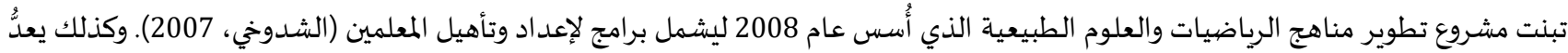

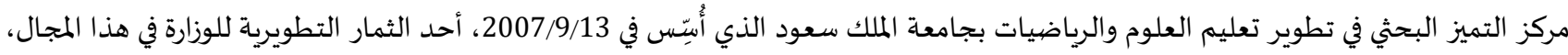

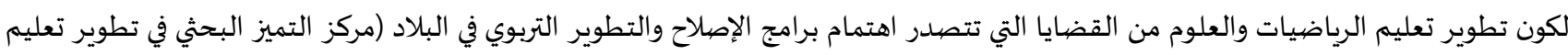

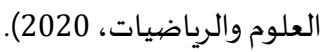

مما ذكر سابقاً يتضح وجود أهداف متنوعة ومتعددة لتنمية المعلم مهنياً من أبرزها: تفير الأساليب والطرق التي يستخدمها المعلم داخل الصف

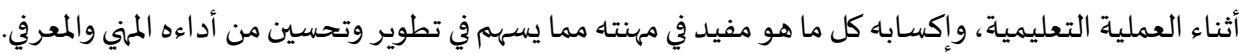

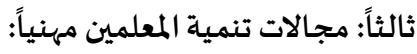
يمكن ربط مجالات التنمية المهنية للمعلم بالكفايات المهنية التي تعدُّ معياراً يقاس بها أداؤه وفق استمارة متابعة تقويم الأداء الصفي للمعاد المعلم (وزارة

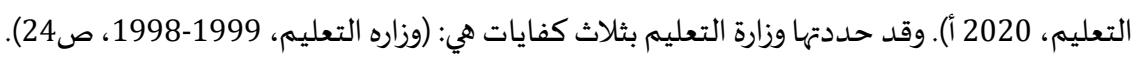

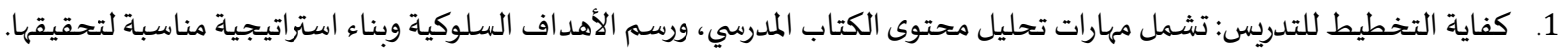
2.

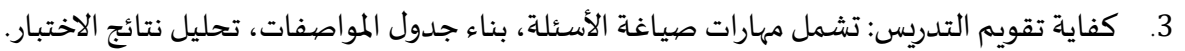

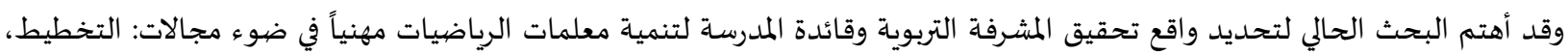

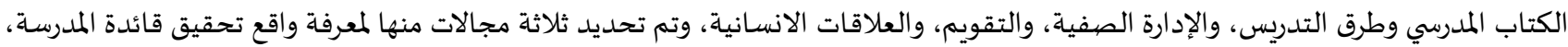

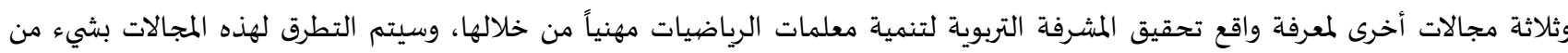

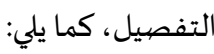

\section{مجال العلاقات الإنسانية "Human Relationships"}

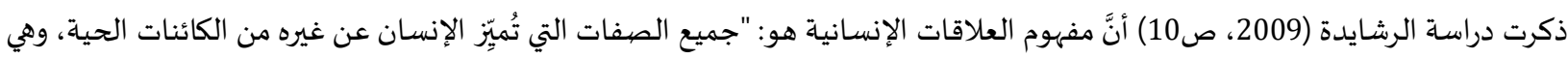

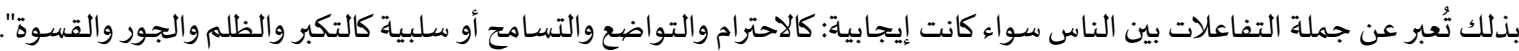

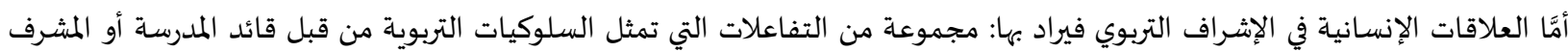

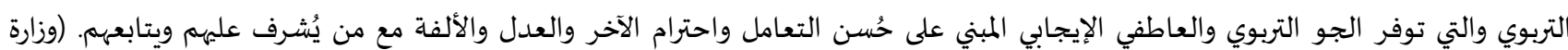
التعليم، 1999-1998)

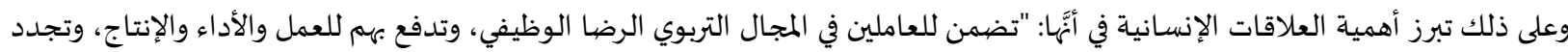

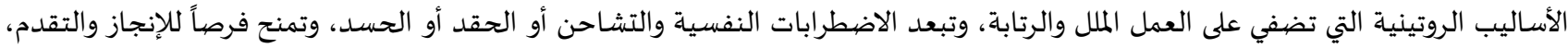

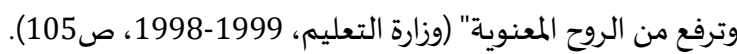

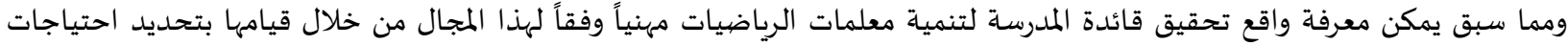

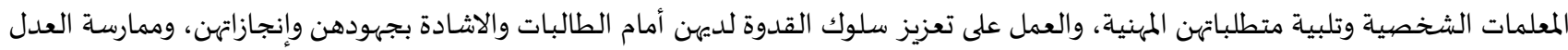

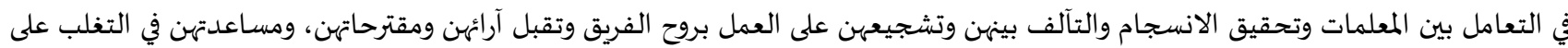
ضغوط العمل التي تواجههن، بالإضافة إلى الحرص على إيجاد علاقات إيجابية مستقرة بين المعلمات ومشرفاتهن.

مجال الإدارة الصفية "Classroom Management":

تُعرَّف بأنَّها: "مجموعاة من الأنماط السلوكية المتعددة التي يستخدمها المعلم لكي يوفر بيئة تعليمية مناسبة، يحافظ على استمرارها بما يمكِّناه من

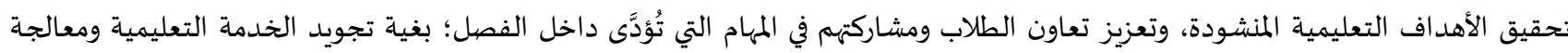

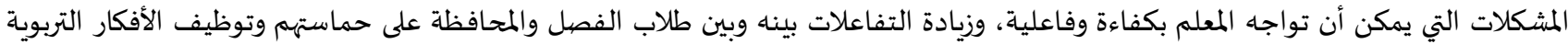

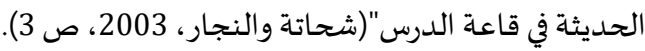


يمكن أن نلّخص التعريف السابق لإدارة الصف في قدرة المعلم على التحكم في تصرفاته وسلوكياته أثناء العلمية التعليمية، وكيف يمكناه أن يوفر

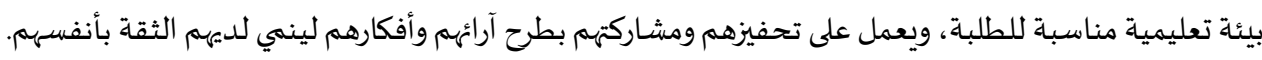

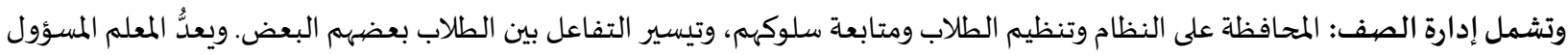

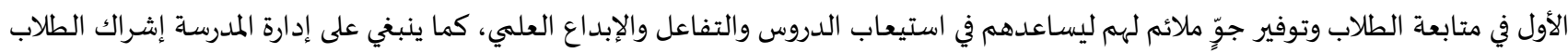

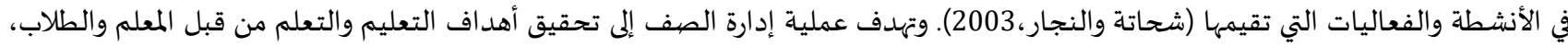

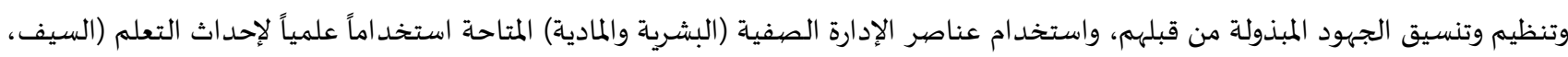

ومما سبق يمكن معرفة واقع تحقيق قائدة المدرسة لتنمية معلمات الرياضيات مهنياً وفقاً لهذا المجال من خلال قيامها حث المعلمات على بناء الماء

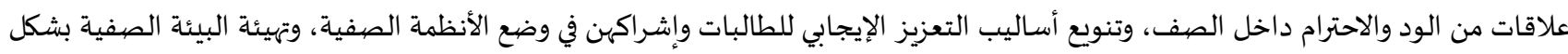

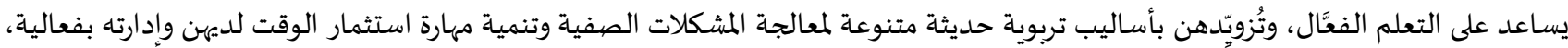

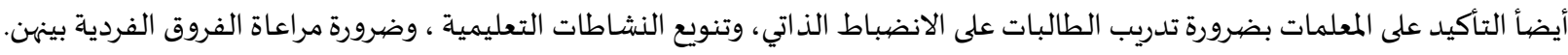

مجال التخطيط "Planning":

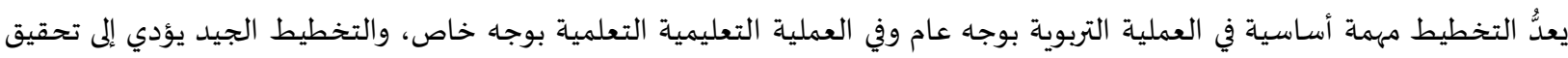

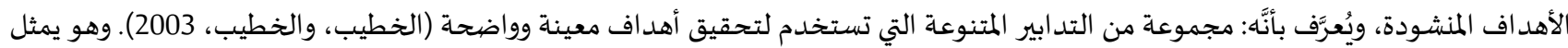

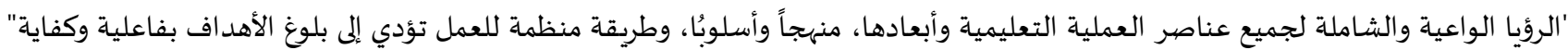

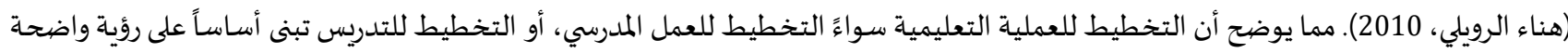
لكأهداف المراد تحقيقها. وينقسم التخطيط التدريسي إلى مرحلتين أساسيتين هي: تخطيط طويل المدى وهو الذي: يتناول مقرراً دراسياً كاملاً، وتخطيط قصير المدىى وهو تخطيط الدروس اليومية (القعود، 2003، صال27). ويوضح الفقيه (2005، ص22) أهمية التخطيط للدروس بأنَّه: يجعل المعلم أكثر تمكناً من المادة المادئ

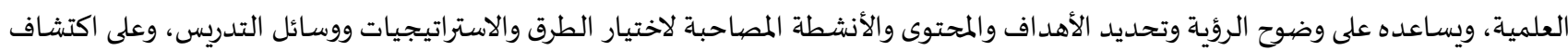

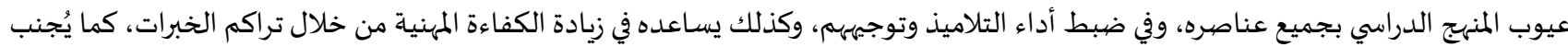

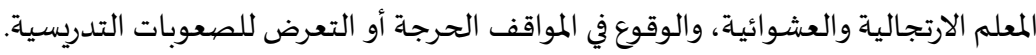

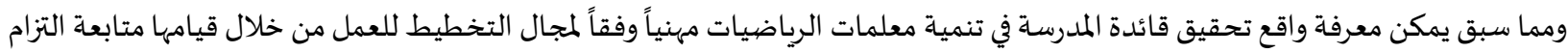

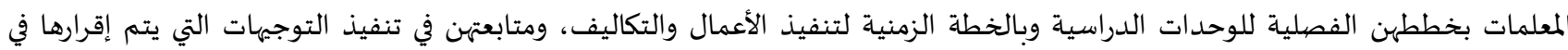

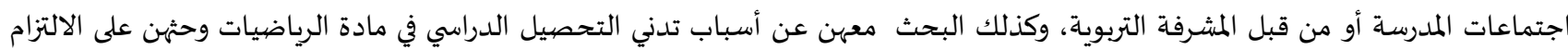

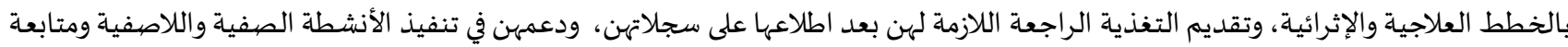
إنجازاتهن التربوية أو المهنية. كما يمكن معرفة واقع تحقيق المشرفة التربوية في تنمية معلمات الرياضيات مهنياً وفقاً لمجال التخطيط للتدريس من خلال قيامها بإشراك

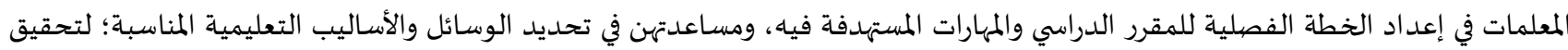

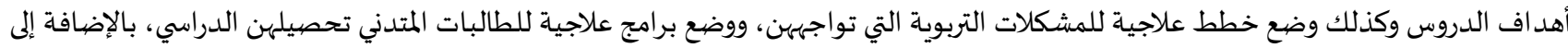

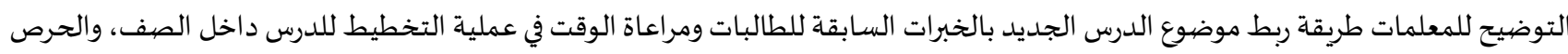
على تبادل الخبرات التعليمية بين المعلمات من خلال الدروس التطبيقية داخل وخارج المدرسة.

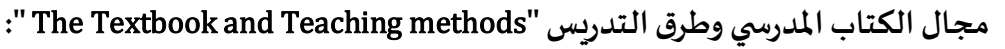

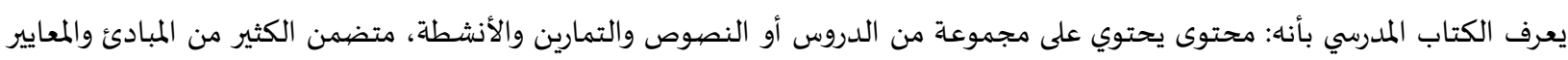

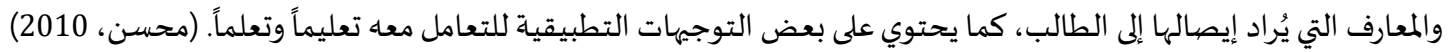

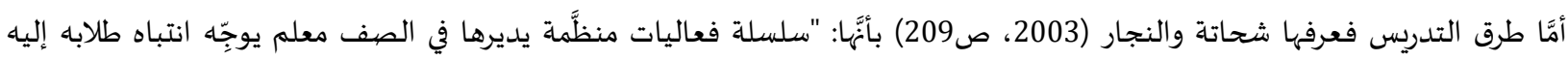

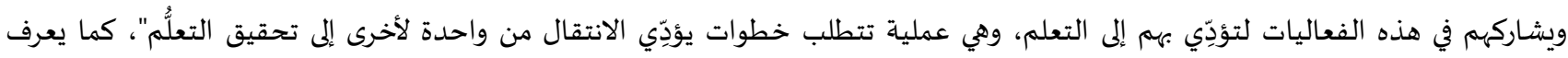

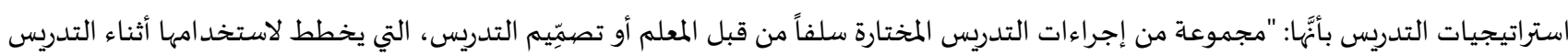

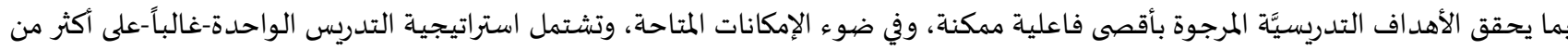
طريقة من طرق التدريس" (ص 40). 
من التعريفات السابقة يتبين لنا بأنَّ طرق التدريس هي الوسائل التي يعتمد علهيا المعلم أثناء تأدية الدرس بما يتناسب مع الموضوع المطروح

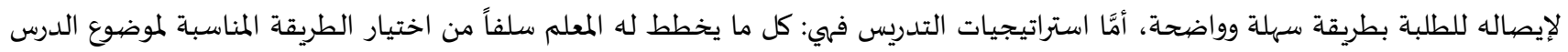
وتحديد الإمكانات المتاحة، وذلك لتحقيق الأهد اف العامة من الدرس.

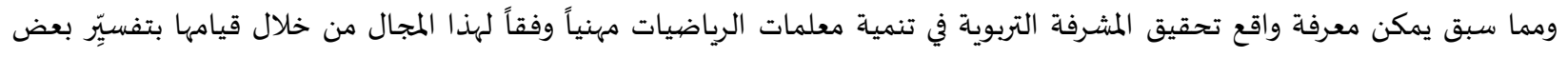

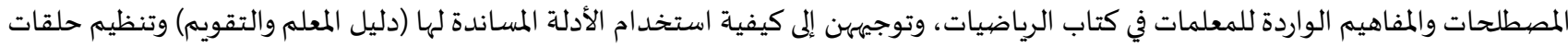

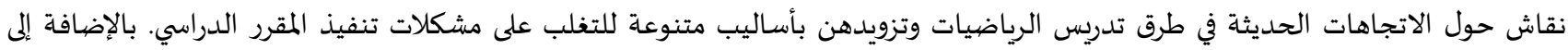

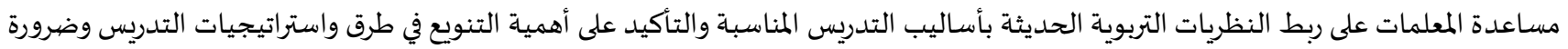

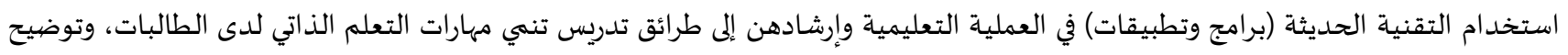

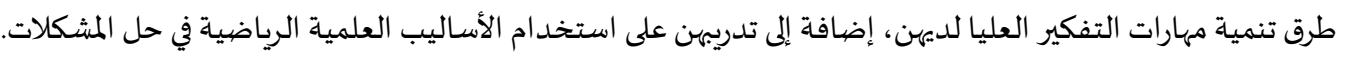

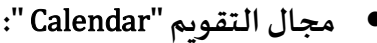

يُقصيد بالتقويم بشكل عام أنَّه: "عملية تقدير قيمة الثيء أو كميته، ويستهدف التقويم إصدار الحكمم أو القرار بقصصد تحسين العمل، كما

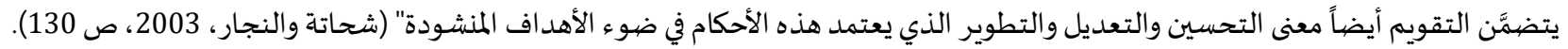

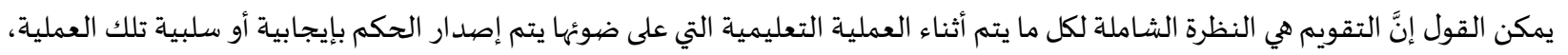

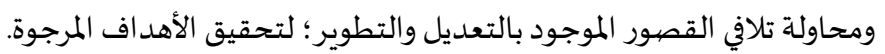

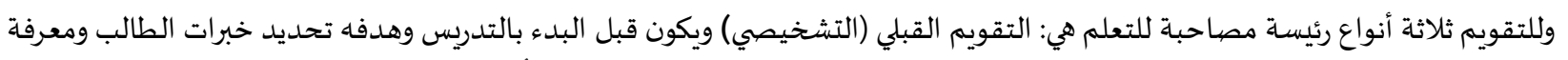

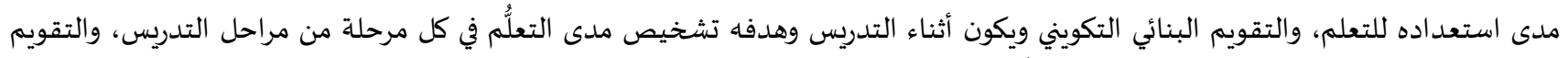

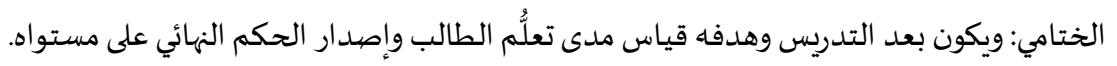

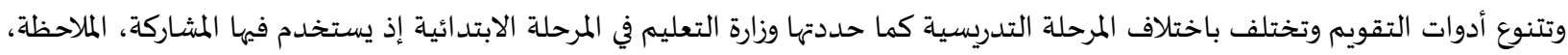

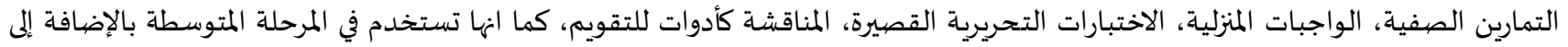

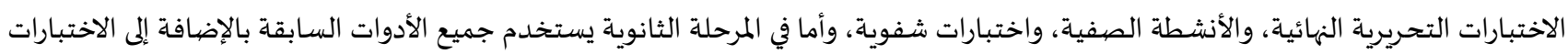

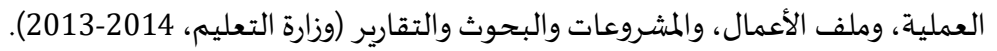

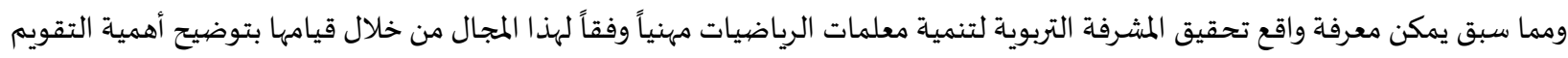

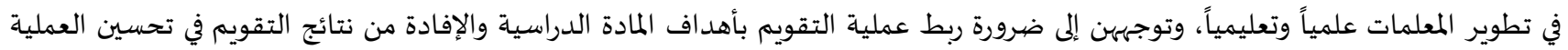

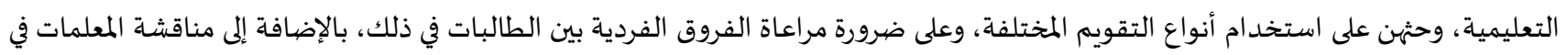

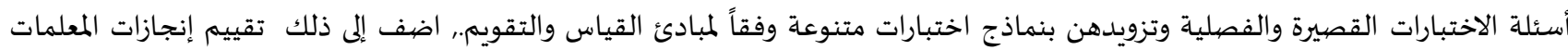
التربوية والتخصصية والاعتماد على مؤشرات قياس الأداء للحكم على أداءهن.

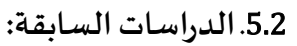

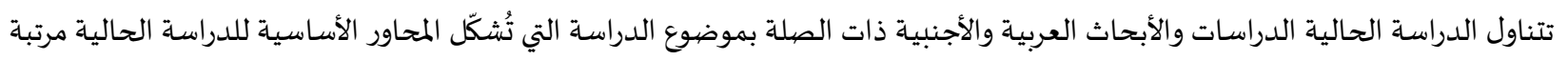

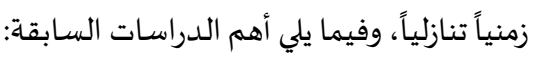
أولاً: دراسات تتعلق بتحقيق قائدة المدرسة للتنمية المهنية للمعلمات:

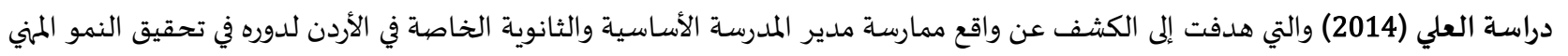

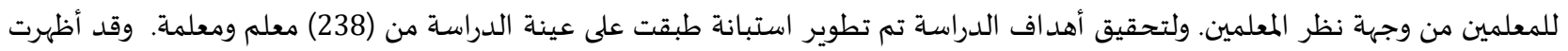

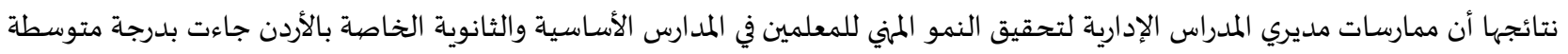

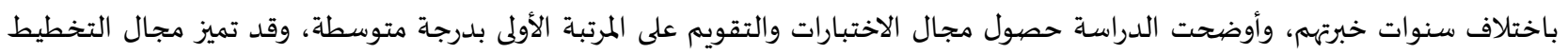

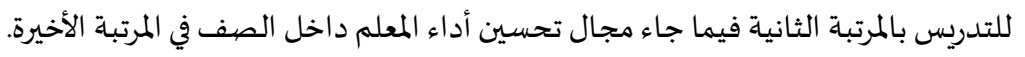

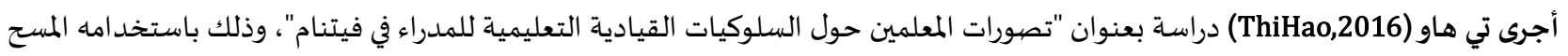

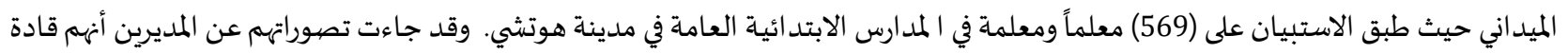

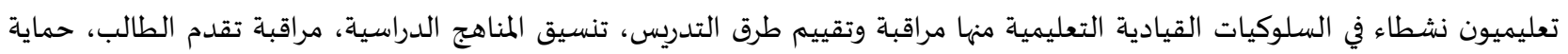

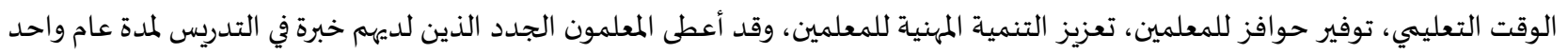

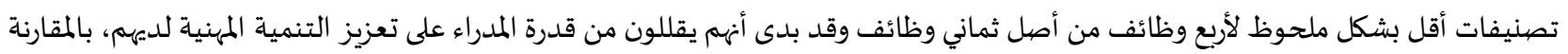

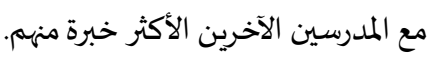


وفي ذات السياق سعت دراسة أجراها مدزوفر (Mudzofir,2017) بعنوان "العلاقة بين الإشراف التربوي والتطوير الملني: تصهورات لمعلمي

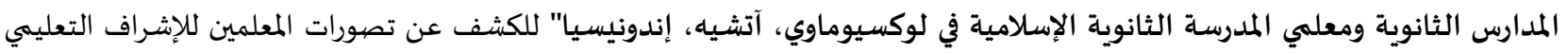
الفعلي والمثالي في المدارس من قبل قائدي المدارس، والعلاقة بينه وبين التطور المهني الشخصي للمعلم، وأوضحت النتائج وجود اختلافات كبيرة في الممارسة الفعلية والمثالية للإشراف التي ينظر إلهها المعلمون. كما أن ممارسة الإشراف التي يقوم بها القائد في إطار التطوير المهني للمعلمين ليس لهاي علاقة كبيرة بالتطور المهني، ولكن لا يزال لدى المعلمين تصورات إيجابية تجاه الإشراف التعليمي. و اتجهت دراسة آل مغيرة (2017) للبحث عن درجة قيام مديري المدارس بواجباتهم نحو المعلمين في الجانبين المعرفي والسلوكي للكفايات التعليمية

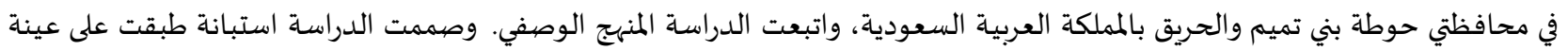

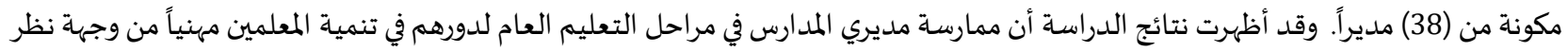

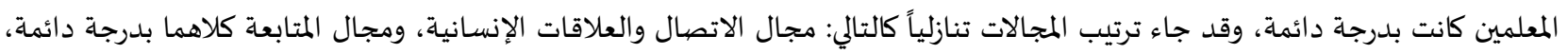

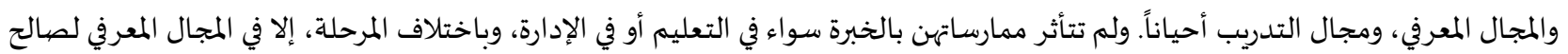
مديري المدارس الابتدائية.

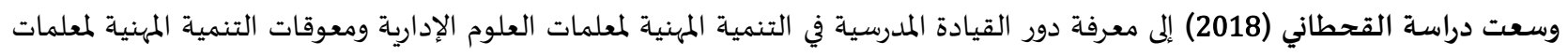
العلوم الإدارية واقتراحات السبل المناسبة لتفعيل دورها في التنمية المهنية للمعلمات، واستخدمت الباحثة المنهج الوصيفي المستحي واستبانة طبقت

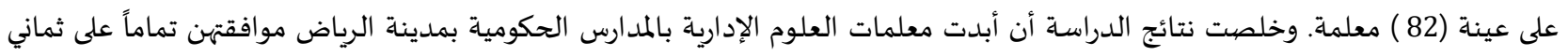

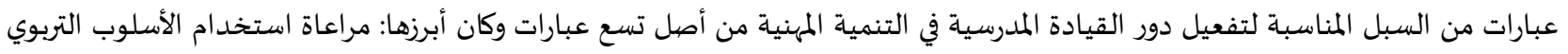

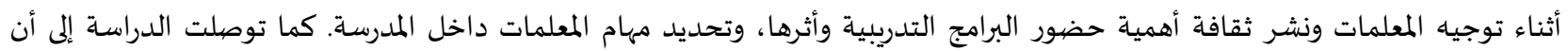

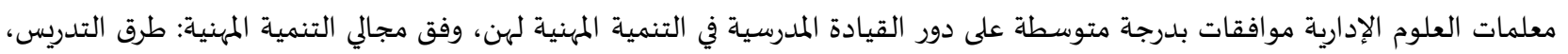

والإدارة الصفية.

في ذات السياق سعت دراسـة السالم (2018) إلى تقصي دور قائدة المدرسة كمشرف تربوي مقيم في التنمية المهنية للمعلمات في مدينة الرياض من وجهة نظرهن. أتبعت الدراسـة المنهج الوصفي التحليلي، واستخدمت لاستبانة لجمع آراء من (142) معلمة. أظهرت النتائج أن دور قائدة المدرسة في في فئي

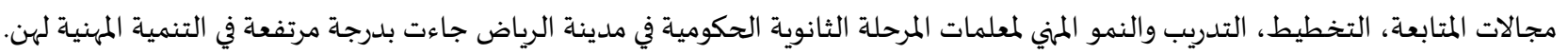

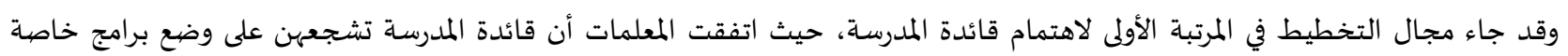

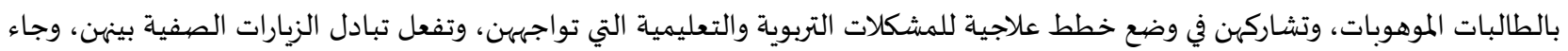

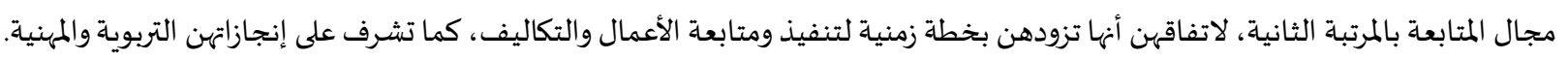
وأخيراً قام زيادين وآخرون دراسـ (Ziyadin, et al.,2018) بعنوان "بيانات عن دور القيادة في تطوير الخبرة في التدريس في الدول النامية"،

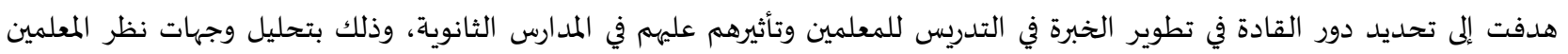

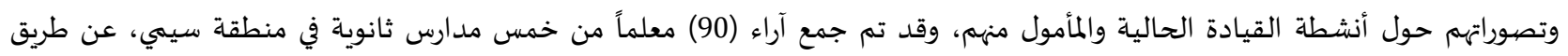

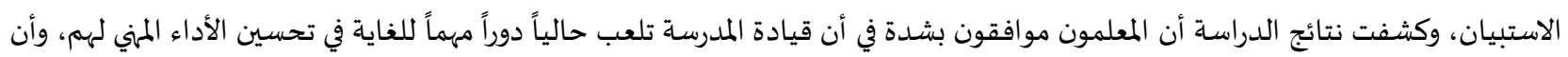

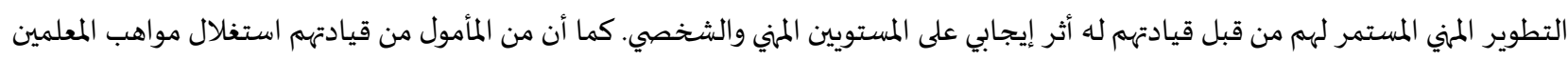

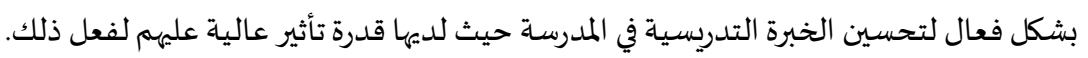
ثانياً: دراسات تتعلق بتحقيق المشرفة التربوية للتنمية المهنية للمعلمات:

دراسة سعود الرويلي (2010) التي سعت لاستكشاف درجة ممارسة المشرف التربوي لمهامه في تطوير النمو المهني لمعلمي الرياضيات في المرحلة

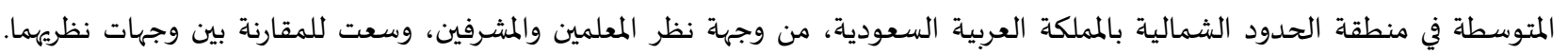
واستخدمت الدراسة المنهج الوصفي واستبانة طبقت على عينة من معلمي الرياضيات البالغ عددهم (74) معلماً. وقد أظهرت نتائج هذه الدراسة أن الن المهات المشرف التربوي يمارس مهامه في تطوير النمو المهني لمعلمي الرياضيات في التخطيط للتدريس والمنهج الدراسي وطرق التدريس والوسائل التعليمية،

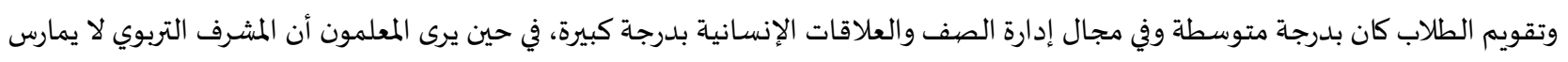

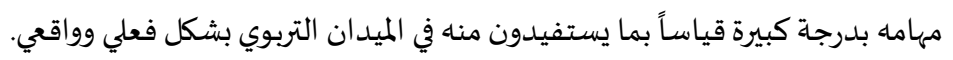
دراسة الشديفات (2014) والتي اختصت بالكشف عن دور المشرفين التربويين في التطوير المهني لمعلمي ومعلمات الدراسات الاجتماعية في محافظة المفرق. اتبعت الدراسة المنهج الوصفي وصهمت استبانة تم تطبيقها على عينة من (99) معلم ومعلماه. وقد خلصت اختص النتائج أن دور المشرفين

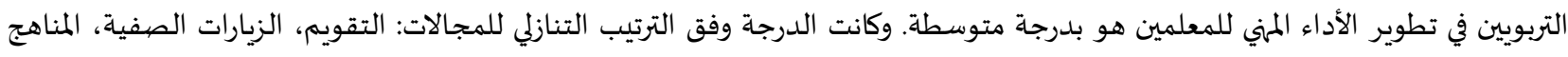
وأساليب التدريس، العلاقة مع الزملاء والمجتمع المحلي، التخطيط، ولصالح المعلمون والمعلمات الجدد والذين تقل خبرتهم عن ست سنوات 
باختلاف مؤهلاتهم ومراحلهم الأساسية والثانوية، ولصالح الدراسات العليا في مجال أساليب التدريس، ولصالح الأقل خبرة من عشر سنوات في مجال التخطيط.

دراسة شلش وحرز الله (2017) التي اختصت بمعلمي ومعلمات الرياضيات في المرحلة الأساسية العليا في محافظتي طولكرم وسلفيت بفلسطين،

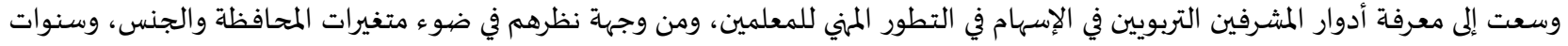

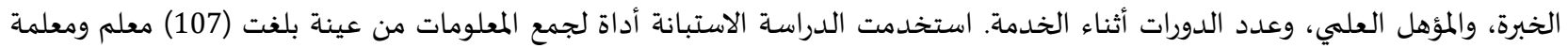

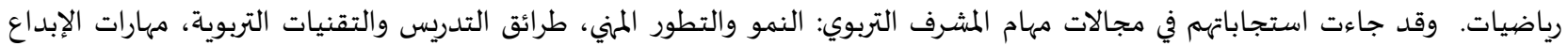

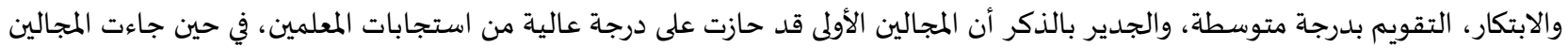
الأخيرة بدرجة متوسطة من إسهام مشرفي الرياضيات. دراسة مدولي ومظفر (Mudawali and Mudzofir,2017) أجريت بمدينة إيشة في إندونيسيا بهدف تقصي تصورات معلمي المدارس الثانوية

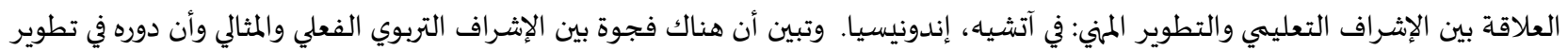

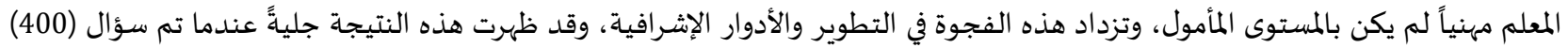

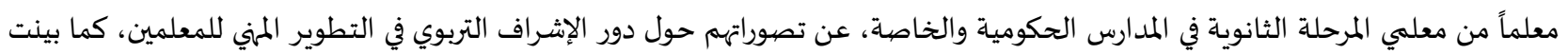
تصوراتهم أن الإشراف له دور هام في تطوير أداءهم والحفاظ على تطوره إذا ما سار إلى المأمول منها.

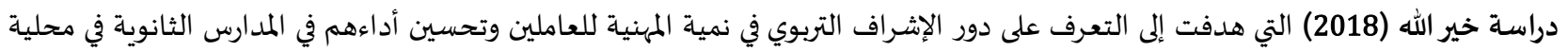

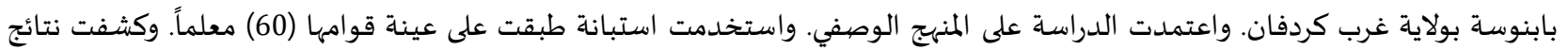

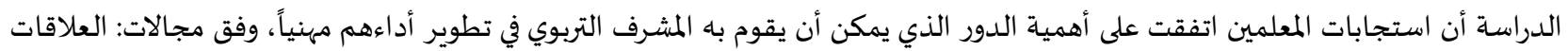
الإنسانية-التخطيط للتدريس-طرق التدريس-تقويم المنهج. دراسة القبلان (2018) عمدت إلى معرفة دور المشرف التربوي في التنمية المهنية لمعلمي العلوم في مدينة حائل، وأظهرت النتائج عند استطلاع آراء

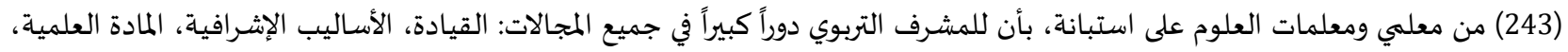

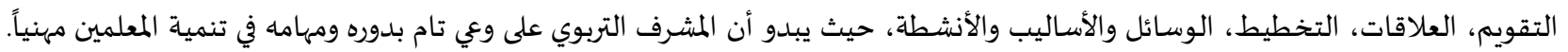

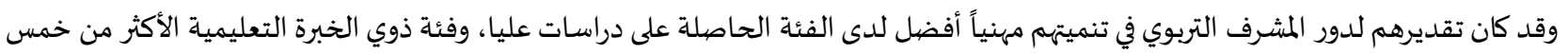
سنوات، ولدى فئة المرحلة الثانوية من فئة المرحلة المتوسطة. دراسة المطيري وسليمان (2019) والتي هدفت إلى معرفة دور الإشراف التربوي في التنمية المهنية لمعلمات المهارات النفسية والاجتماعية من وجهات

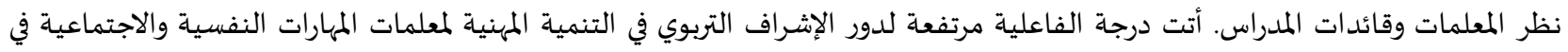

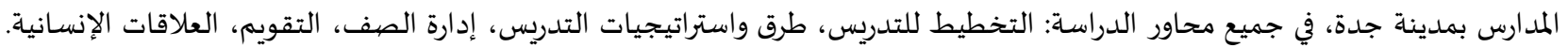

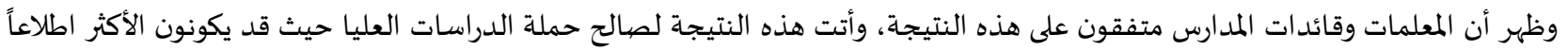

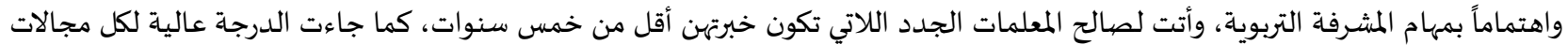
الدراسة.

ثالثاً: دراسات تتعلق بتحقيق قائدة المدرسة والمشرفة التربوبة للتنمية المهنية للمعلمات: دراسة الزهر اني (2010) هدفت إلى تحديد قوة العلاقة الارتباطية بين إسهام كلاً من مدير المدرسة والمشرف التربوي المنسق في النمو المهني

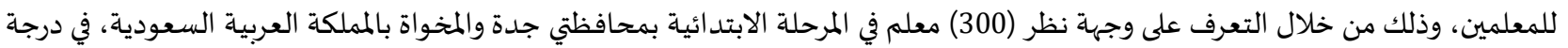

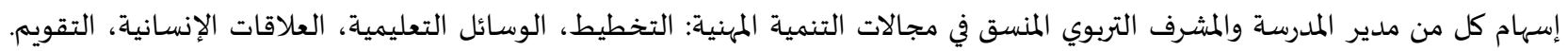

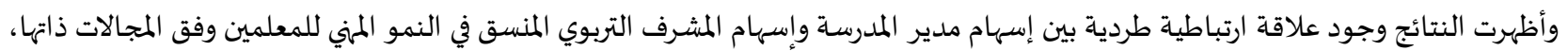

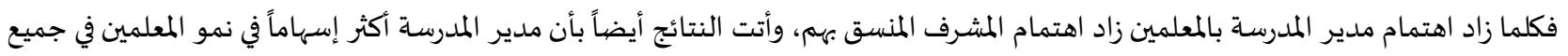

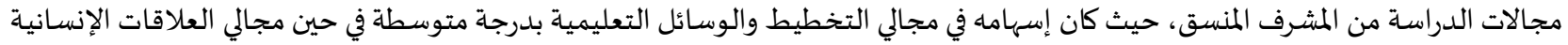

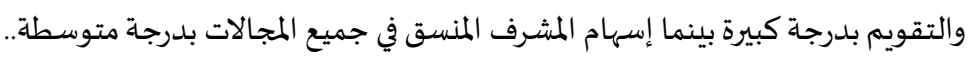
دراسة هناء الرويلي (2010) استهدفت الدراسة معرفة دور المشرفة التربوية الفنية للمواد الدراسية في التنمية المهنية للمعلمات وتُعرِّفهُها بأنها

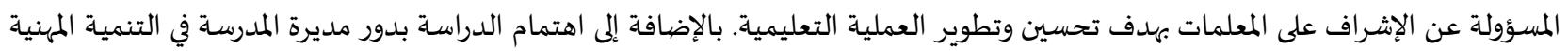

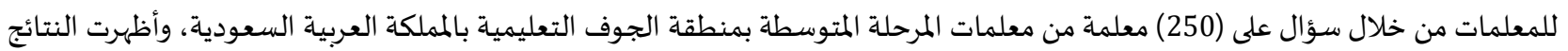
أن ممارسة مديرات المدارس والمشرفات التربويات لأدوارهن في التنمية المهنية للمعلمات جاءت المات بدرجة مرات مرتفعة، مما يلمات يعني أن المديرات والمششرفات

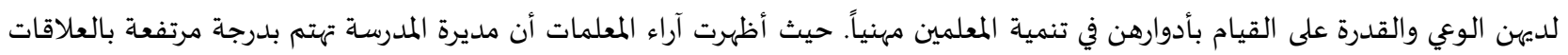




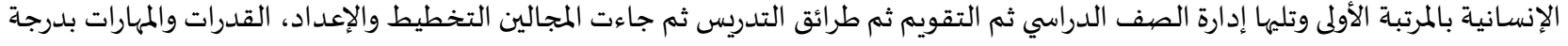

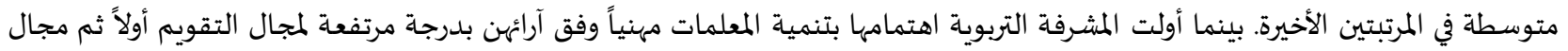

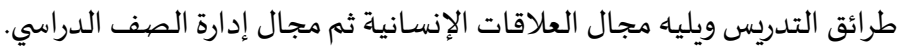

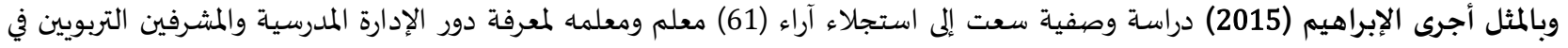

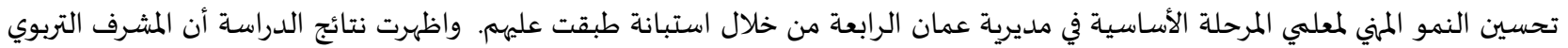

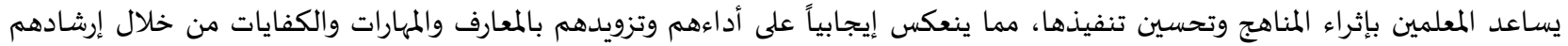

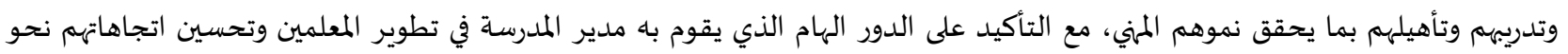

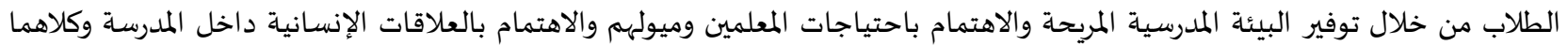

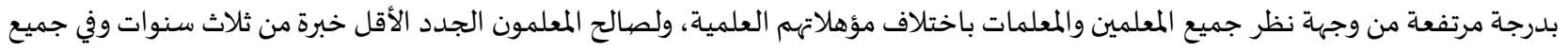

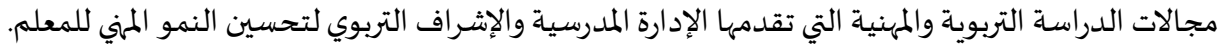
وقد تطرقت دراسة الجريداة (2015) لذات موضوع الدراسة السابقة الذكر ولكن من حيث الكشف عن درجة التنسيق بين أدوار المشرفين

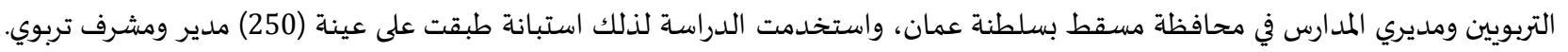

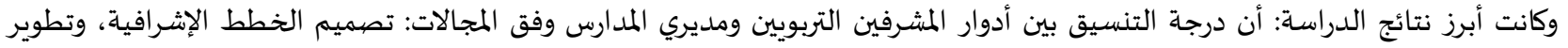

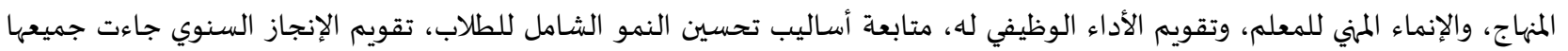
بدرجة متوسطة وفق آراء المديرين والمشرفين ولم تختلف تبعاً لاختلاف جنسهم ولا باختلاف المؤهل العلمي أو سنوات الخبرة. وفي المقابل سعت دراسة اليعربية (2018) لتقديم مقترحات لتفعيل دور المشرف التربوي ومدير المدرسة والتنسيق بين مهامهيما الإشرافية على الماتل

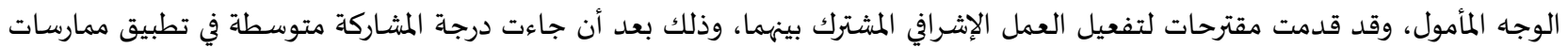
العمل الإشرافي بين المشرفين التربويين ومديري المدارس ومساعديهم في مجالات التخطيط للعملية الإشرافية وتنمية المعلمين مهنياً وتقييم أداءهم،

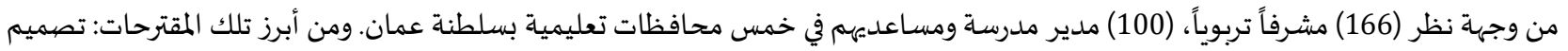

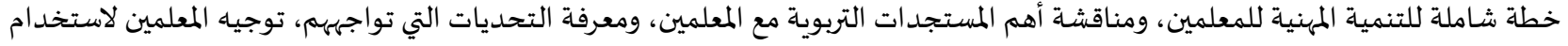

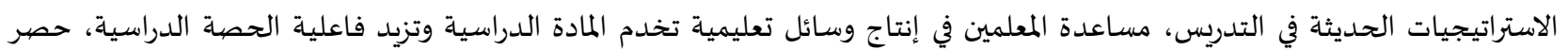
الاحتياجات التدريبية للمعلمين، وتوفير الإمكانات البشرية والمادية لتنميتهم مهنياً. التعقيب على الدراسات السابقة وما يستفاد منها:

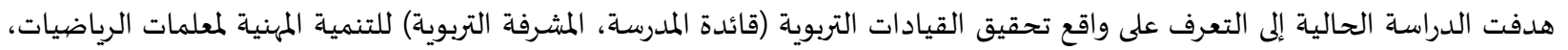

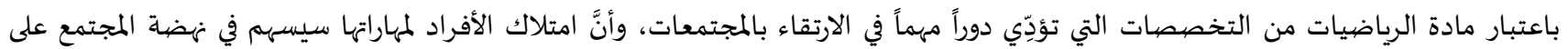

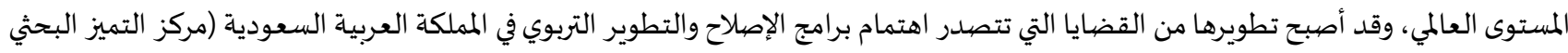

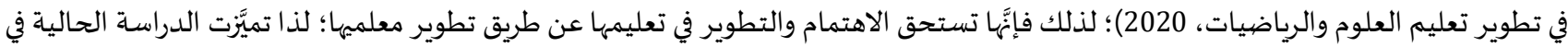

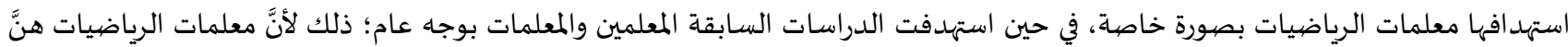

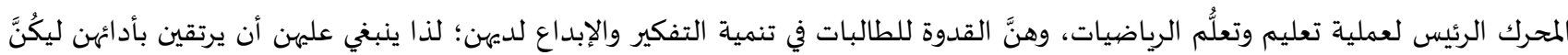

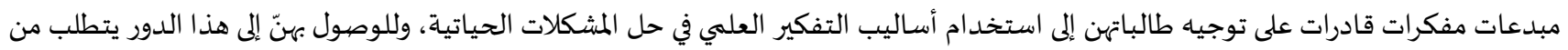

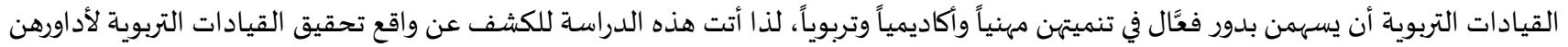

كما تميَّزت الدراسة الحالية في البحث عن دور القيادات التربويات (قائدة المدرسة والمشرفة التربوية) في مجالات التنمية الأقرب إلى عملها، كليّ في

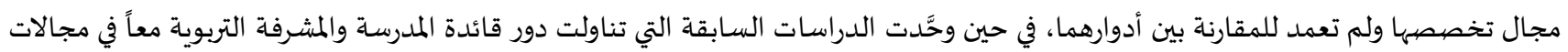
بحثها وقارنت بينهما. واستفادت الدراسة الحالية من الدراسات السابقة في بناء إطارها النظري وتحديد مجالات بحثها، إضافة إلى اعتمادها للمنهج الكمي في الدراسة، وبناء أداتها الميدانية (الاستبانة)، وتفسير نتائجها. 


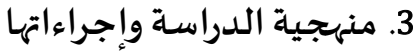

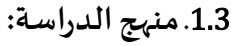

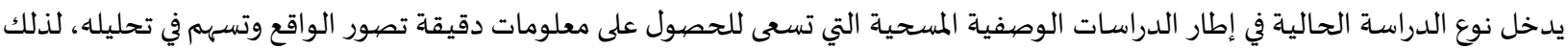

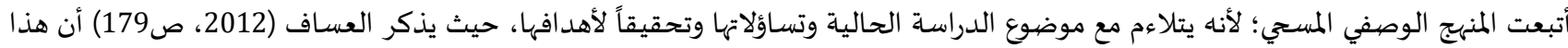

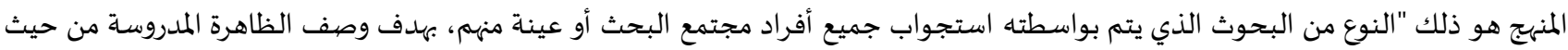
طبيعتها ودرجة وجودها فقط، دون أن يتجاوز ذلك إلى دراسة العلاقة أو استنتاج الأسباب مثلاً".

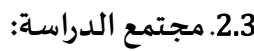

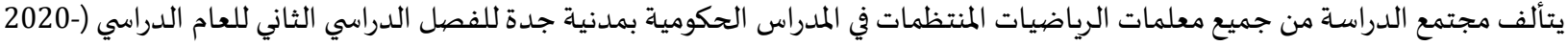

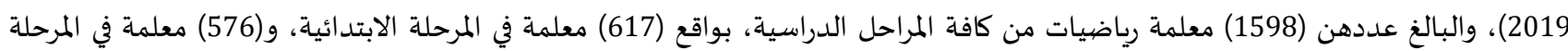
المتوسطة، و(504) معلمة من المرحلة الثانوية وذلك بحسب إحصاءات الموارد البشرية في مكتب تعليم البنات بإدارة تعليم مدينة جدة.

3.3 - 3ينة الدراسة:

تكونت عينة الدراسة الأصلية من (675) معلمة رياضيات من جميع المراحل التعليمية موزعة على جميع المدارس الحكومية في مدينة جدة بطريقة

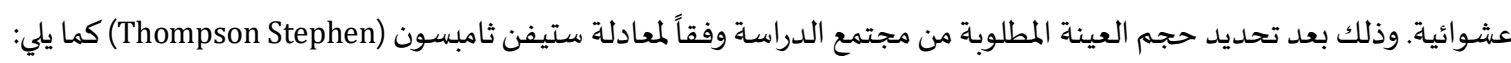

$$
\quad n=\frac{N \times p(1-p)}{\left.\left.\| N-1 \times\left(d^{2} \div z^{2}\right)\right]+p(1-p)\right]}
$$

معادلة ستيفن ثامبسون:

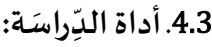

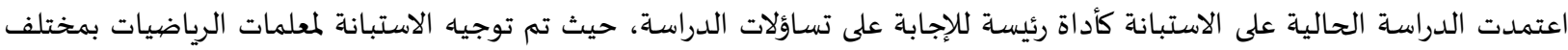

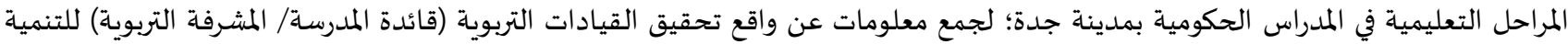

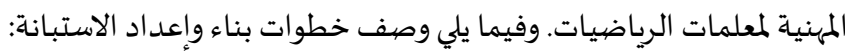
1. تحديد الهدف من الاستبانة: تمثل الهدف في معرفة واقع تحقيق القيادات التربوية (قائدات/ مشرفات) للتنمية المهنية لمعلمات الرياضيات من وجهاة نظرهن في المدراس الحكومية بمدينة جدة.

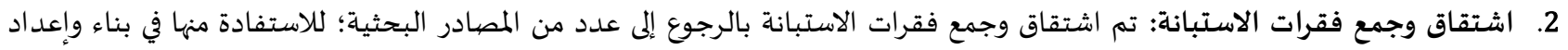

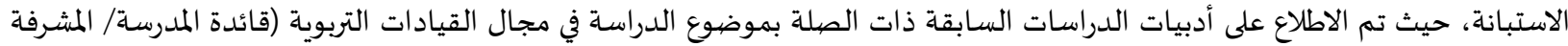

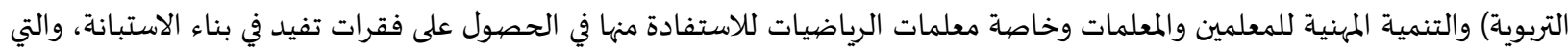
يمكن في ضوئها بناء الاستبانة في صورتها الأولية، ومن هذه الدراسات: دراسة أبو شاهين (2011)، الشديفات (2014)، القحطاني (2018)، خير الله (2018)، السالم (2018). 3. بناء فقرات الاستبانة: تم بناء الاستبانة بصورتها الأولية من خلال تصنيف الاستبانة إلى قسمين، الأول يتضمن البانيات البانيات الأولية الألية لعينة الدراسة،

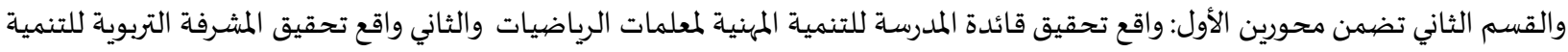

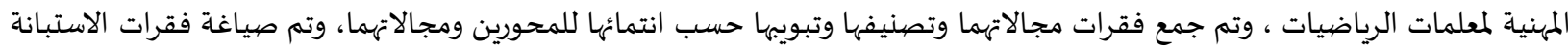
بعبارات واضحة ودقيقة، لها معانٍ محددة، وقد بلغ عدد الفقرات الكلية للاستبانة بصورتها الأولية (63) فقرة.

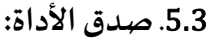

وللتأكد من صدق الاستبانة وأهها تقيس ما أعدت لقياسه، استخدمت الدراسة نوعين من الصدق، وهما:

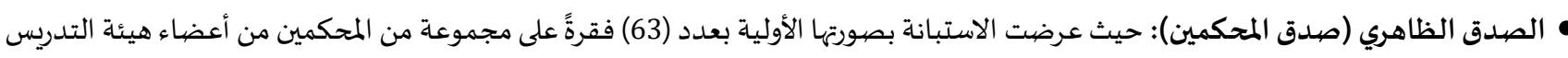

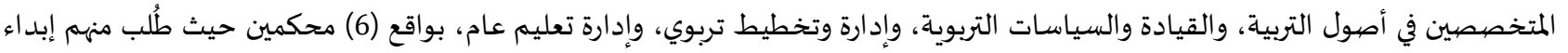

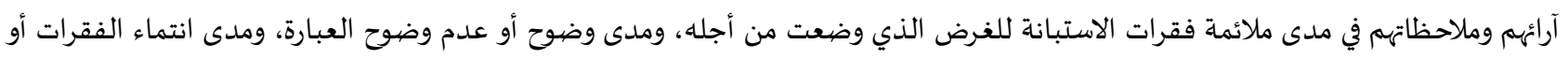

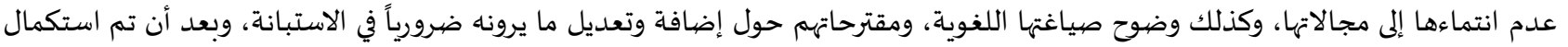

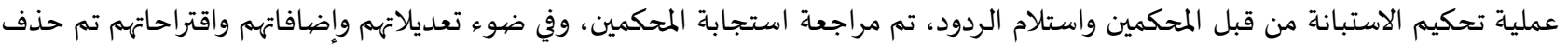
وإضافة بعض الفقرات، وتعديل بعضها لتصبح الاستبانة بصورتها النهائية مكون من (58) فقرةًا. 
درجات تصحيح الإجابة: تم ترتيب استجابة عينة الدراسة في كل فقرة من فقرات الاستبانة وفق مقياس(ليكرت) الخماسي 5-Point Likert Scale) كما

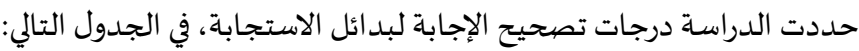
جدول (1): درجات تصحيح الإجابة لبدائل الاستجابة

\begin{tabular}{|c|c|c|c|c|c|}
\hline \multirow[t]{2}{*}{ أبداً } & \multirow[t]{2}{*}{ 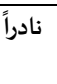 } & \multirow[t]{2}{*}{ أحياناً } & \multirow[t]{2}{*}{ غالباً } & \multirow[t]{2}{*}{ دائماً } & تقوم قائدة المدرسة / المشرفة التربوية بتحقيق التنمية المهنية لمعلمات \\
\hline & & & & & 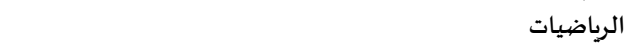 \\
\hline 1 & 2 & 3 & 4 & 5 & 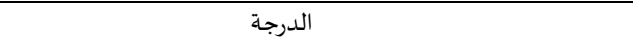 \\
\hline
\end{tabular}

صيدق الاتساق الداخلي: يعتبر صدق الاتساق الداخلي أحد مقاييس صدق الأداة الذي يقيس مدى تحقق الأهداف التي تريد الأداة الوصول

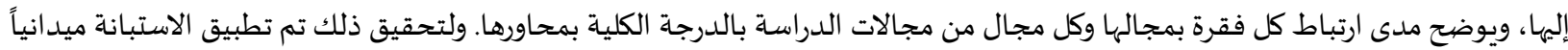

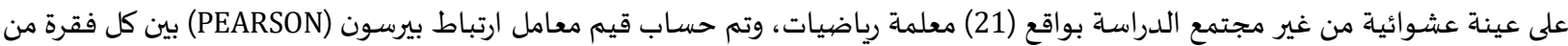
فترات المجال والدرجة الكلية للمجال التابع لها، والجداول التالية توضح نتائج صدق الاتساق الداخلي لفقرات مجالات الاستبانة في كل محور

على حدة، كما يأتي:

جدول (2): معاملات ارتباط درجة كل فقرة بالدرجة الكلية للمجال والمجال بالدرجة الكلية للمحور الأول

\begin{tabular}{|c|c|c|c|c|c|c|c|c|c|c|c|}
\hline \multirow{2}{*}{ معامل ارتباط } & \multicolumn{11}{|c|}{ المحور الأول:و اقع تحقيق قائدة المدرسة للتنمية المهنية لمعلمات الرياضيات } \\
\hline & 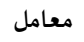 & 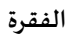 & 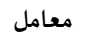 & 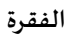 & 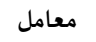 & 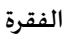 & معامل & 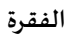 & 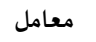 & 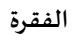 & 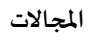 \\
\hline 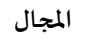 & الارتباط & & 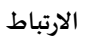 & & 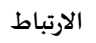 & & الارتباط & & 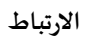 & & \\
\hline 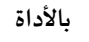 & & & & & & & & & & & \\
\hline \multirow{3}{*}{$0.903^{* *}$} & $0.768^{* *}$ & 5 & $0.751^{* *}$ & 4 & $0.874^{* *}$ & 3 & $0.845^{*}$ & 2 & $0.608^{* *}$ & 1 & 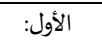 \\
\hline & $0.899^{* *}$ & 10 & $0.948^{* *}$ & 9 & $0.962^{* *}$ & 8 & $0.903^{* *}$ & 7 & $0.927^{* *}$ & 6 & 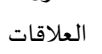 \\
\hline & & & & & & & & & & & الإنسانية \\
\hline \multirow[t]{3}{*}{$0.934^{* *}$} & $0.863^{* *}$ & 5 & $0.880^{* *}$ & 4 & $0.745^{* *}$ & 3 & $0.858^{* *}$ & 2 & $0.658^{* *}$ & 1 & الثاني: \\
\hline & & & $0.654^{* *}$ & 9 & $0.897^{* *}$ & 8 & $0.865^{* *}$ & 7 & $0.780^{* *}$ & 6 & تخطيط \\
\hline & & & & & & & & & & & للعمل \\
\hline \multirow[t]{4}{*}{$0.914^{* *}$} & $0.868^{* *}$ & 5 & $0.766^{* *}$ & 4 & $0.865^{* *}$ & 3 & $0.773^{* *}$ & 2 & $0.867^{* *}$ & 1 & الثالث: \\
\hline & & & $0.854^{* *}$ & 9 & $0.857^{* *}$ & 8 & $0.642^{* *}$ & 7 & $0.909^{* *}$ & 6 & الإدارة \\
\hline & & & & & & & & & & & الصفية \\
\hline & & & & & & & & & $(0.0$ & مستو & *دالة إحصا \\
\hline
\end{tabular}

يتضح من الجدول (2) أن مجالات المحور الأول تتمتع بمعاملات ارتباط طردية قوية ودالة إحصائياً عند مستوى دلالة (0.01)) حيث تراوح قيمة

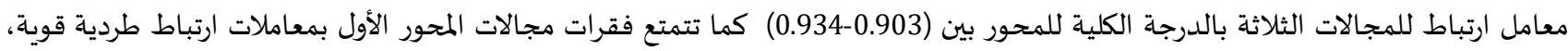
ودالة إحصائياً عند مستوى دلالة (0.01)، عدا الفقرة رقم (2) إذ تتمتع بمعامل ارتباط قوي ودالة إحصائياً بالدرجة الكلية للمجال عند مستوى دلالة

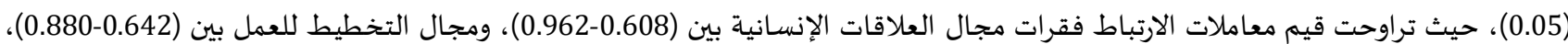
ومجال الإدارة الصفية بين (0.609-0.642)، وتشير هذه المعاملات أن جميع مجالات المحور الأول فقرات مجالاته تتمتع بمعامل صددق عالٍ.

\begin{tabular}{|c|c|c|c|c|c|c|c|c|c|c|c|}
\hline \multirow{2}{*}{ ارتباط معامل } & \multicolumn{11}{|c|}{ المححور الثاني:و اقع تحقيق المشرفة التربوية للتنمية المهنية لمعلمات الرياضيات } \\
\hline & 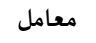 & 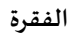 & 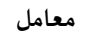 & 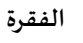 & 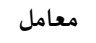 & 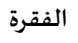 & 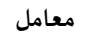 & 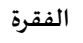 & 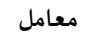 & 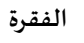 & 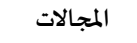 \\
\hline 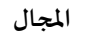 & 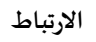 & & 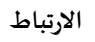 & & 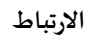 & & 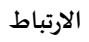 & & 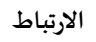 & & \\
\hline \multicolumn{12}{|l|}{ بالمحور } \\
\hline \multirow[t]{3}{*}{$0.819^{* *}$} & $0.796^{* *}$ & 5 & $0.712^{* *}$ & 4 & $0.909^{* *}$ & 3 & $0.911^{* *}$ & 2 & $0.792^{* *}$ & 1 & 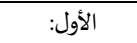 \\
\hline & & & $0.885^{* *}$ & 9 & $0.674^{* *}$ & 8 & $0.928^{* *}$ & 7 & $0.939^{* *}$ & 6 & التخطيط \\
\hline & & & & & & & & & & & 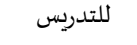 \\
\hline \multirow{3}{*}{$0.974^{* *}$} & $0.797^{* *}$ & 5 & $0.852^{* *}$ & 4 & $0.877^{* *}$ & 3 & $0.807^{* *}$ & 2 & $0.910^{* *}$ & 1 & الثاني: الكتاب \\
\hline & $0.708^{* *}$ & 10 & $0.806^{* *}$ & 9 & $0.949^{* *}$ & 8 & $0.850^{* *}$ & 7 & $0.935^{* *}$ & 6 & المدرسي وطرق \\
\hline & & & & & & & & & & & 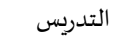 \\
\hline \multirow{2}{*}{$0.863^{* *}$} & $0.689^{* *}$ & 5 & $0.858^{* *}$ & 4 & $0.777^{* *}$ & 3 & $0.719^{* *}$ & 2 & $0.812^{* *}$ & 1 & الثالث: \\
\hline & $0.669^{* *}$ & 10 & $0.631^{* *}$ & 9 & $0.859^{* *}$ & 8 & $0.783^{* *}$ & 7 & $0.832^{* *}$ & 6 & 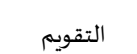 \\
\hline
\end{tabular}

يتضح من الجدول (3) أن مجالات المحور الثاني تتمتع بمعاملات ارتباط طردية قوية ودالة إحصائياً عند مستوى دلالة (0,01) حيث تراوح قيمة

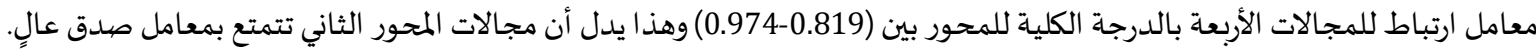


كما تبين أن فقرات مجالات المحور الثاني تتمتع بمعاملات ارتباط طردية قوية ودالة إحصائياً عند مستوى دلالة أقل من (0,01)، حيث تراوحت

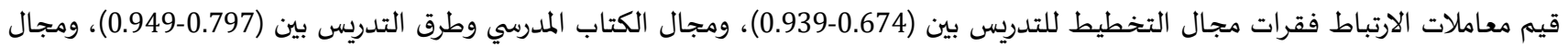

التقويم بين (0.859-0.631)، وهذا يدل على أن مجال التقويم وفقراته يتمتعان بمعامل صدق مجات عالٍ.

وفي ضوء هذه النتائج المتصلة بالتحقق من دلالة الاتساق الداخلي للاستبانة، يتضح تمتع أداة الدراسـة الحالية بمعامل اتساق داخلي لفقراتها.

6.3. ثبات الأداة: يعني الثبات حصول المقاييس على نفس الدرجة إذا ما تكرر تطبيقه مرّات عديدة على نفس الأفراد، وفي ظروف متشابهة، وللتحقق من

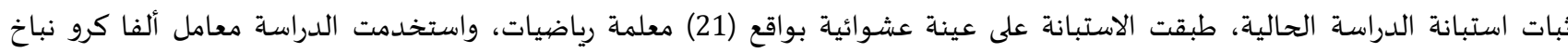
(Cronbach s Alpha)

جدول (4): معامل ألفا كرونباخ لمحاور أداة الدراسة وللأداة ككل

\begin{tabular}{|c|c|c|c|c|c|}
\hline \multicolumn{3}{|c|}{ مجالات و اقع تحقيق قائدة المدرسة للتنمية المهنية لمعلمات الرياضيات } & \multicolumn{3}{|c|}{ مججالات و اقع تحقيق المشرفة التربوية للتنمية المهنية لمعلمات الرياضيات } \\
\hline معامل ألفا كرونباخ & 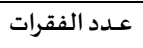 & 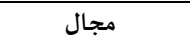 & معامل ألفا كرونباخ & 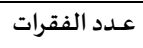 & مجال \\
\hline 0.942 & 11 & العلاقات الإنسانية & 0.943 & 9 & التخطيط للتدريس \\
\hline 0.925 & 9 & التخطيط للعمل & 0.956 & 10 & الكتاب المدرسي وطرق التدريس \\
\hline 0.939 & 9 & 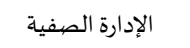 & 0.911 & 10 & 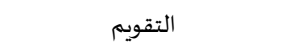 \\
\hline 0.973 & 29 & المحور الأول ككل & 0.976 & 29 & المحور الثاني ككل \\
\hline 0.987 & 58 & \multicolumn{4}{|c|}{ 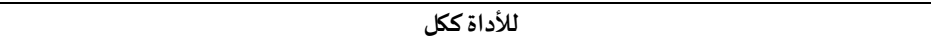 } \\
\hline
\end{tabular}

يتضيح من نتائج الجدول (4) أن معامل الثبات ألفا كرونباخ للأداة ككل بلغ (0.987) وهو معامل ثبات مرتفع ومقبول تربوياً، وبالنسبة عن ثبات

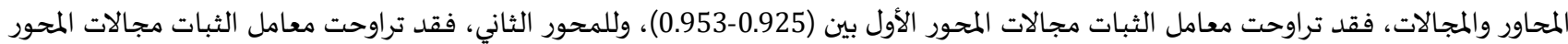
الأول بين (0.956-0.976) وهي معاملات ثبات مرتفعة ومقبولة تربوياً. وهذه تشير إلى يعني أن صلاحية الأداة لتحقيق هدف الدراسة الحالية وتطبيقها ميدانياً على عينة الدراسـة.

7.3. الأسـاليب الإحصيائية: استعانت الدراسة ببرنامج الحزم الإحصائية للعلوم الاجتماعية والإنسانية (SPSS) في معالجة بيانات استجابة عينة الدراسة على الاستبانة لإجراء

التحليلات الإحصائية المناسبة لطبعة الدراساة، وقد استخدمت الدراسة لتحليل بياناتها الأساليب الإحصائية الآتياة: 1. معامل ارتباط بيرسون؛ للتحقق من صداق الاتساق الداخلي لفقرات ومجالات الاستبانة (كما تم إيضاحها سابقاً).

2. معادلة ألفا كرونباخ؛ للتحقق من ثبات فقرات ومحاور الاستبانة (كما تم إيضاحها سابقاً).

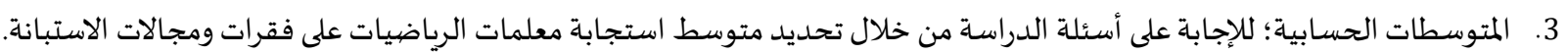
4. الانحراف المعياري: لمعرف تبيان واختلاف استجابات عينة الدراسة تجاه كل فقرة من فقرات المجالات.

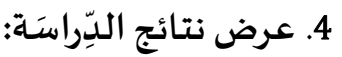
التقديرات الوزنية المحكية في الدراسـة: استندت الدراسة على تقديرات وزنية معينة لمتوسطات استجابة عينة الدراسـة؛ للحكم على درجة تحقيق القيادات التربوية للتنمية المهنية لمعلمات الرياضيات، كما يلي: جدول (5): التقديرات الوزنية والدرجة لبدائل الإجابة

\begin{tabular}{|c|c|c|c|c|c|}
\hline دائماً & غالباً & أحياناً & 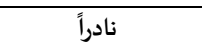 & أبداً & مقياس و اقع تحقيق القيادات التربوية \\
\hline مرتفعة جداً & مرتفعة & متوسطة & منخفضية & منخفضة جداً & درجة التحقيق \\
\hline $4.20-5.0$ & 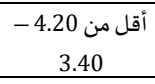 & أقل من 3.40- & أقل من 2.60- 1.80 & 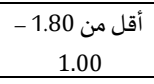 & مدى المتوسطات \\
\hline
\end{tabular}

1.4. نتائج السؤال الأول: للإجابة على السؤال الأول الذي نصها: ما و اقع تحقيق قائدة المدرسة للتنمية المهنية لمعلمات الرياضيات من وجهة

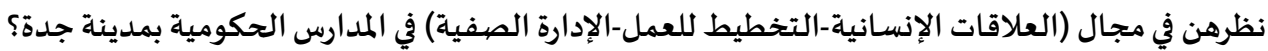

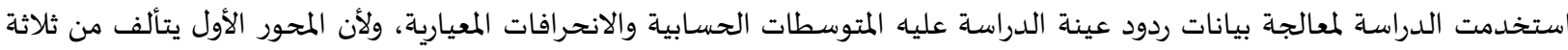
مجالات، تم عرض النتائج بشكل موجز وحسب المجالات الثلاثة كما يلي: 
النتائج العامة للسؤال الأول:

جدول (6): المتوسطات الحسابية، والانحر افات المعيارية ودرجة تحقيق قائدة المدرسة لجميع مجالات المحور الأول مرتبة تنازلياً

\begin{tabular}{|c|c|c|c|c|c|}
\hline درجة تحقيق قائدة المدرسة & الترتيب & الانحراف المعياري & المتوسط الحسابي & المجالات & الرقم \\
\hline مرتفعة & 1 & 0.803 & 4.04 & التخطيط للعمل & 2 \\
\hline مرتفعة & 2 & 0.884 & 4.03 & الإدارة الصفية & 3 \\
\hline مرتفعة & 3 & 0.911 & 3.81 & العلاقات الإنسانية & 1 \\
\hline مرتفعة & & 0.803 & 3.95 & لمدرسة للمحور الأول & 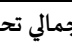 \\
\hline
\end{tabular}

يتضح من بيانات الجدول (6) أن متوسط تحقيق قائدة المدرسة للتنمية المهنية لمعلمات الرياضيات لإجمالي المحور الأول بلغ (3.95) وانحراف

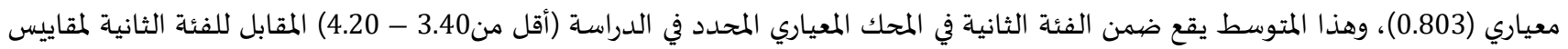

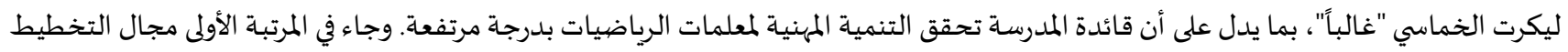

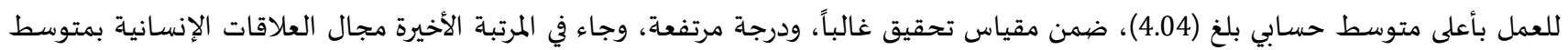
حسابي (3.81)، ضمن مقياس تحقيق غالباً، وبدرجة تحقيق مرتفعة.

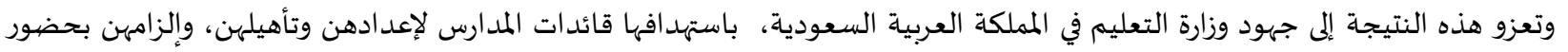

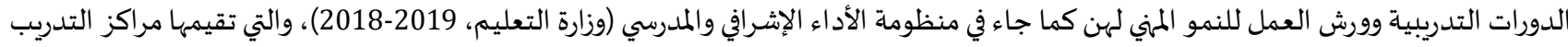

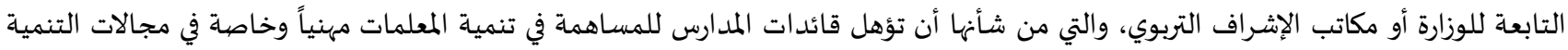

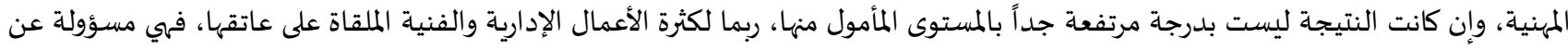

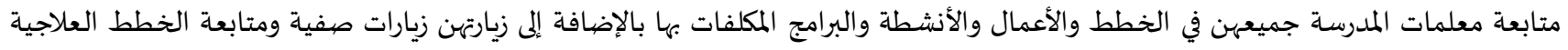
والإثرائية للجميع، بالإضافة إلى الأعمال المكتبية التي قد تعيقها عن متابعة تنمية معلمات الرياضيات مهنياً مهنياً باستمرار بالوجها المأمول منها.

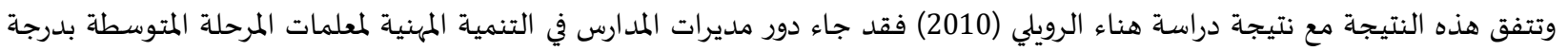

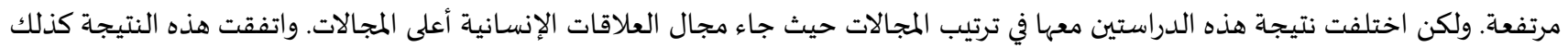

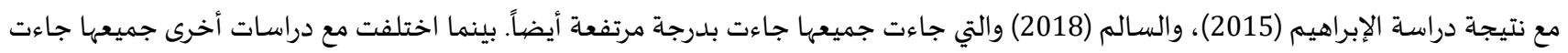

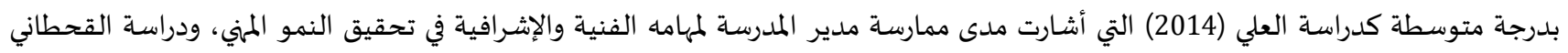
(2018) في دور القيادة المدرسية في التنمية المهنية لمعلمات العلوم الإدارية. • النتائج التفصيلية للسؤال الأول وفقاً للترتيب التنازلي للمجالات في نتائج الدراسة: 1. 1 . مجال التخطيط للعمل:

جدول (7): المتوسطات الحسابية والانحر افات المعيارية ودرجة التحقيق قائدة المدرسة لفقرات مجال التخطيط للعمل مرتبة تنازلياً

\begin{tabular}{|c|c|c|c|c|c|}
\hline التحقيق & الترتيب & المعياري & المستوسطي & 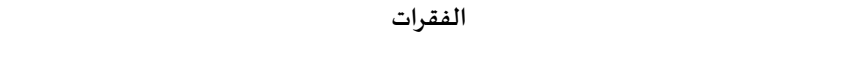 & م \\
\hline مرتفعة جداً & 1 & 0.896 & 4.28 & تحث قائدة المدرسة معلمات الرياضيات على الالتزام بالخطط العلاجية والإثرائية. & 4 \\
\hline مرتفعة جداً & 2 & 0.879 & 4.27 & تحرص قائدة المدرسة على التزام معلمات الرياضيات بخطة زمنية لتنفيذ الأعمال والتكاليف. & 2 \\
\hline مرتفعة جداً & 3 & 0.900 & 4.23 & تتابع قائدة المدرسة التزام معلمات الرياضيات بخططهن الفصلية للوحدات الدراسية. & 1 \\
\hline مرتفعة & 4 & 1.016 & 4.07 & تتابع قائدة المدرسة تنفيذ توصيات وتوجهات المشرفة التربوية لمعلمات الرياضيات. & 9 \\
\hline مرتفعة & 5 & 0.972 & 4.05 & تبحث قائدة المدرسة عن أسباب تدني التحصيل الدراسي للطالبات في مادة الرياضيات. & 3 \\
\hline مرتفعة & 6 & 1.015 & 4.00 & تتابع قائدة المدرسة تنفيذ معلمات الرياضيات التوصيات التي يتم إقرارها في اجتماعات المدرسة. & 8 \\
\hline مرتفعة & 7 & 1.037 & 3.97 & تتابع قائدة المدرسة الانجازات التربوية أو المهنية لمعلمات الرياضيات. & 7 \\
\hline مرتفعة & 8 & 1.095 & 3.83 & (التحضير، الرصدة، المتابعة،ة...). & 5 \\
\hline مرتفعة & 9 & 1.220 & 3.65 & تدعم قائدة المدرسة معلمات الرياضيات في تنفيذ الأنشطة الصفية واللاصفية. & 6 \\
\hline لمعة & & 0.803 & 4.04 & 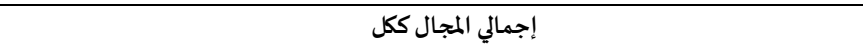 & \\
\hline
\end{tabular}

يتضح من بيانات الجدول (7) أن متوسط تحقيق قائدة المدرسة للتنمية المهنية لمعلمات الرياضيات في مجال التخطيط للعمل بلغ (4.04)

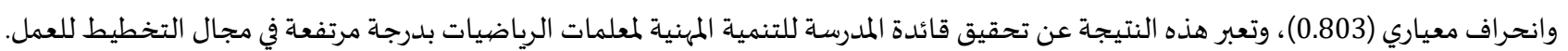
وتعزى هذه النتيجة ربما لاهتمام قائدة المدرسة بتأدية واجباتها المكلفة بها وفق الدليل التنظيمي لمدارس التعليم العام (وزارة التعليم، -2019 التهات

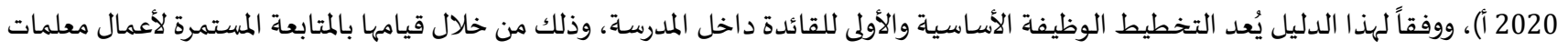
الرياضيات المكلفات بها والاطلاع على دفاتر التحضير وتزويدهن بالتخذية الراجعة، مدركة لأهمية التخطيط في ضبط وتهن وتنظيم العمل المدرسي عامة 


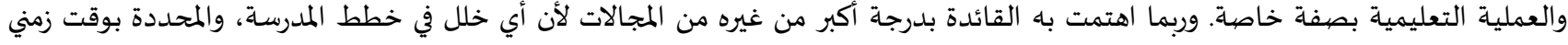

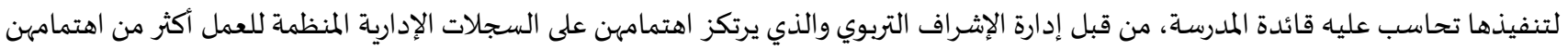

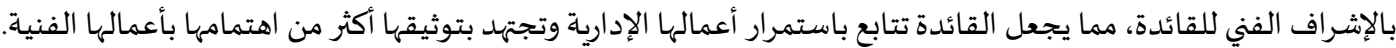

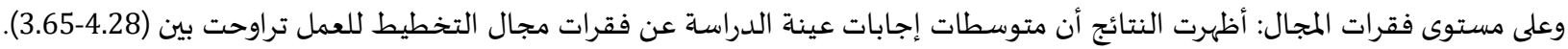

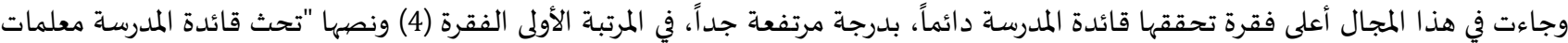
الرياضيات على الالتزام بالخطط العلاجية والإثرائية" بمتوسط حسابي (4.28) وانحراف معياري (0.896).

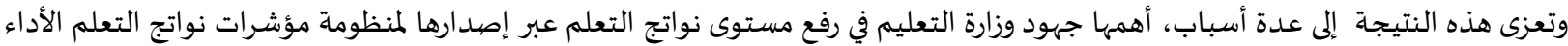

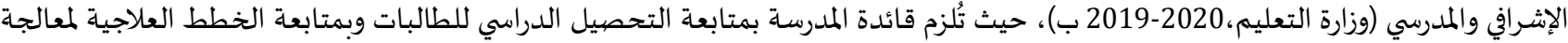

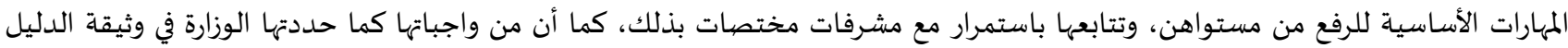

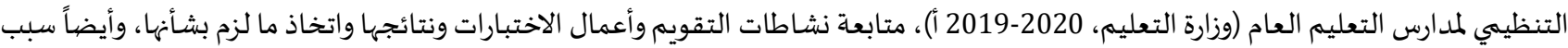

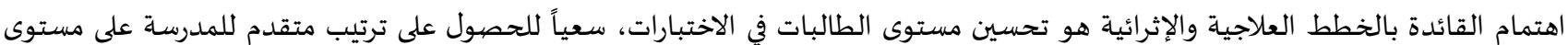

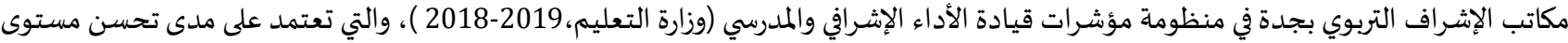

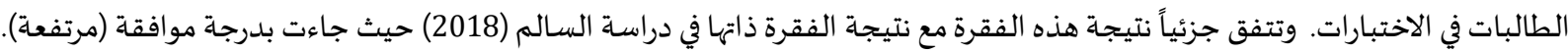

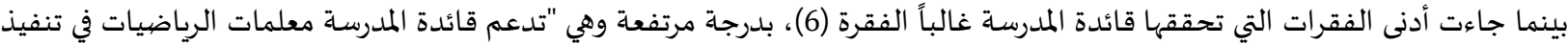
الأنشطة الصفية واللاصفية" بمتوسط حسابي (3.65) وانحراف معياري (1220). ويمكن إرجاع الفاع هذه النتيجة إلى تعميم وزارة التعليم بتاريخ

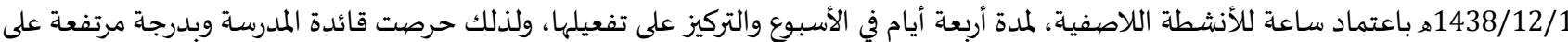

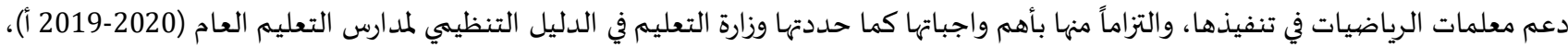

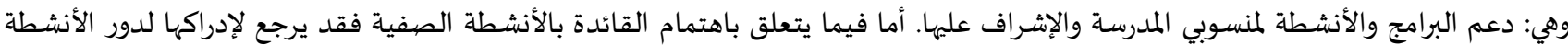

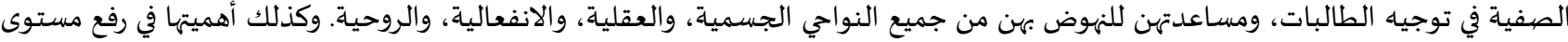

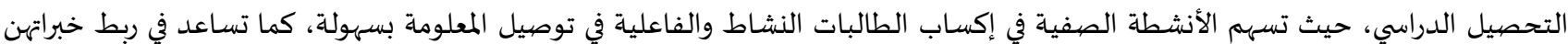

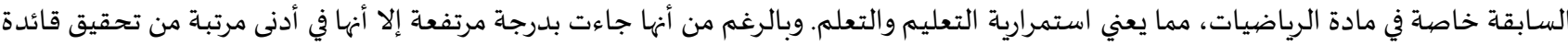

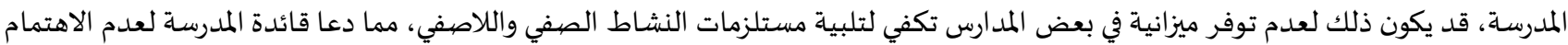

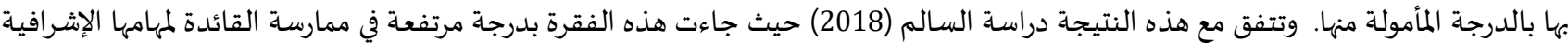
كمشرفة مقيمة في النمو المنفي لمعلمات المرحلة الثانوية.

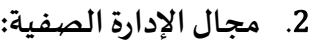

جدول (8): المتوسطات الحسابية والانحر افات المعياربة ودرجة تحقيق قائدة المدرسة لفقرات مجال الإدارة الصفية مرتبة تنازلياً

\begin{tabular}{|c|c|c|c|c|c|}
\hline التحقيق & الترتيب & المعياري & المستوسط & 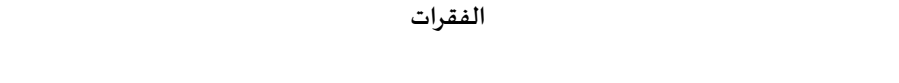 & م \\
\hline مرتفعة & 1 & 0.891 & 4.35 & تحث قائدة المدرسة معلمات الرياضيات على بناء علاقات من الود والاحترام داخل الصف. & 1 \\
\hline مرتفعة & 2 & 0.942 & 4.31 & تؤكد قائدة المدرسة على معلمات الرياضيات بضرورة مراعاة الفروق الفردية بين الطالبات. & 5 \\
\hline مرتفعة & 3 & 0.932 & 4.30 & تحث قائدة المدرسة معلمات الرياضيات على تنويع أساليب التعزيز الإيجابي للطالبات. & 2 \\
\hline مرتفعة & 4 & 0.980 & 4.18 & تؤكد قائدة المدرسة على معلمات الرياضيات بضرورة تنويع النشاطات التعليمية داخل الصف. & 6 \\
\hline مرتفعة & 5 & 1.030 & 4.16 & تؤكد قائدة المدرسة على معلمات الرياضيات بضرورة تدريب الطالبات على الانضباط الذاتي داخل & 4 \\
\hline مرتفعة & 6 & 1.050 & 4.07 & تحث قائدة المدرسة معلمات الرياضيات على تهيئة البيئة الصفية بشكل يساعد على التعلم الفعال. & 7 \\
\hline 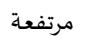 & 7 & 1.146 & 3.88 & تحث قائدة المدرسة معلمات الرياضيات على اشراك الطالبات في وضع الأنظمة الصفية. & 3 \\
\hline مرتفعة & 8 & 1.235 & 3.56 & تنمي قائدة المدرسة لدى معلمات الرياضيات مهارة استثمار الوقت وإدارته بفعالية داخل الصف. & 9 \\
\hline مرتفعة & 9 & 1.284 & 3.46 & تزود قائدة المدرسة معلمات الرياضيات بأساليب تربوية حديثة متنوعة لمعالجة المشكلات الصفية داخل & 8 \\
\hline & & 0.884 & 4.03 & إجمالي المجال ككل & \\
\hline
\end{tabular}


يتضح من بيانات الجدول (8) أن متوسط تحقيق قائدة المدرسة للتنمية المهنية لمعلمات الرياضيات في مجال الإدارة الصفية بلغ (4.03)،

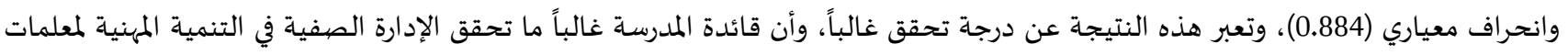

الرياضيات بدرجة مرتفعة.

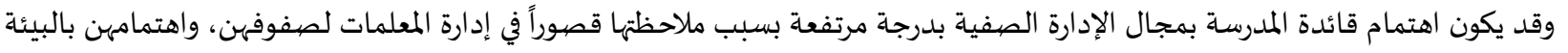

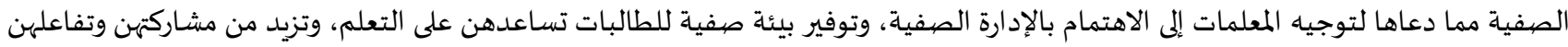

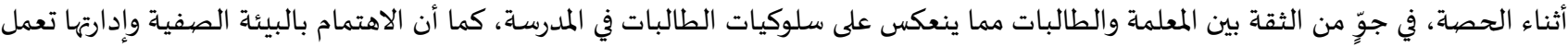

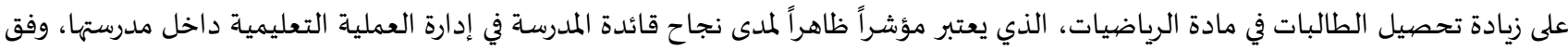

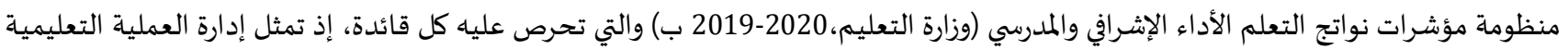
داخل الصف مفتاح النجاح للقيادة المدرسية. وعلى مستوى فقرات المجال: أظهرت نتائج الدراسة أن متوسطات إجاباتهم عن فقرات مجال الإدارة الصفية تراوحت بين (4.35-3.46). كما

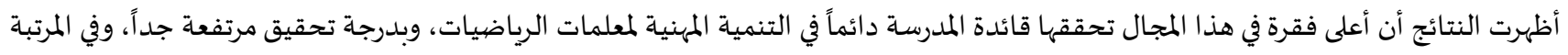

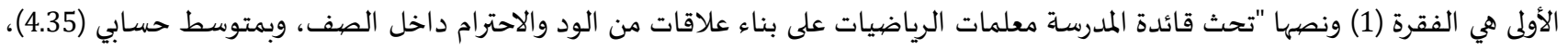

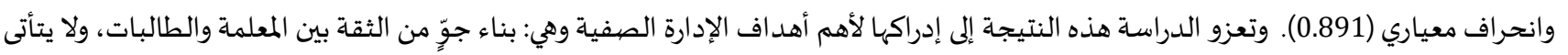

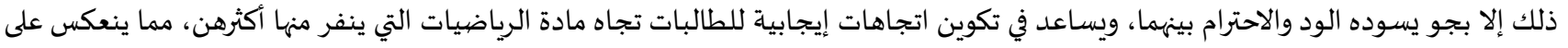

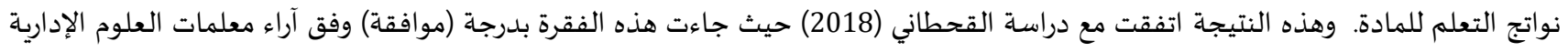
لدور القيادة المدرسية في التنمية المهنية لهن.

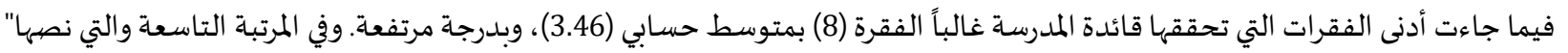

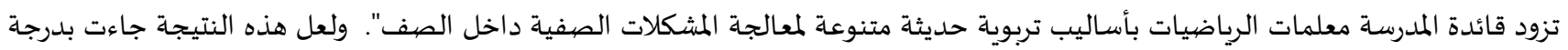

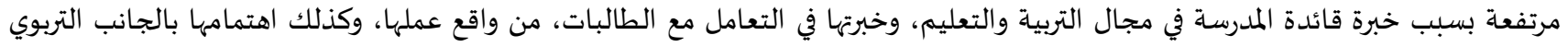

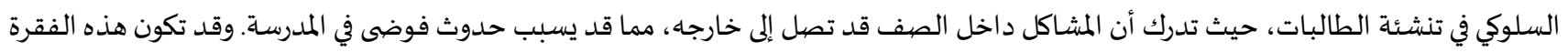
أدنى عبارة في هذا المجال بسبب قناعة بعض القائدات للمدارس بأن حل المشككلات الصفية من مهام وكيلة الشؤون الطابلابية والمرشدة الطابلابية،

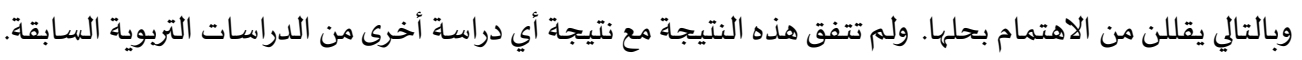

3. - مجال العلاقات الإنسانية:

جدول (9): المتوسطات الحسابية والانحر افات المعيارية ودرجة تحقيق قائدة المدرسة لفقرات مجال العلاقات الإنسانية مرتبة تنازلياً

\begin{tabular}{|c|c|c|c|c|c|}
\hline التحقيق & الترتيب & المعياري & الحسابي & 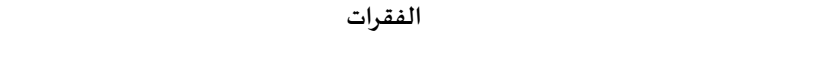 & م \\
\hline مرتفعة & 1 & 1.054 & 4.06 & تشجع قائدة المدرسة العمل بروح الفريق بين معلمات الرياضيات. & 3 \\
\hline 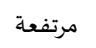 & 2 & 1.104 & 4.02 & تعزز قائدة المدرسة سلوك القدوة لدى معلمات الرياضيات أمام الطالبات. & 5 \\
\hline 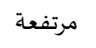 & 3 & 1.122 & 4.00 & تحرص قائدة المدرسة على إيجاد علاقات إيجابية مستقرة بين معلمات الرياضيات ومشرفاتهن. & 10 \\
\hline 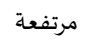 & 4 & 1.075 & 3.94 & تَعدِل قائدة المدرسة في التعامل بين معلمات الرياضيات. & 4 \\
\hline 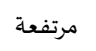 & 5 & 1.132 & 3.91 & تشجع قائدة المدرسة العلاقات الإيجابية بين معلمات الرياضيات والأسرة. & 9 \\
\hline 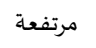 & 6 & 1.110 & 3.89 & تحقق قائدة المدرسة الانسجام والتآلف بين معلمات الرياضيات. & 8 \\
\hline 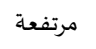 & 7 & 1.167 & 3.82 & تشيد قائدة المدرسة بجهود معلمات الرياضيات وانجازاتهم. & 6 \\
\hline 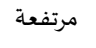 & 8 & 1.060 & 3.74 & تتقبل قائدة المدرسة آراء ومقترحات معلمات الرياضيات. & 7 \\
\hline 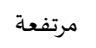 & 9 & 1.062 & 3.53 & تراعي قائدة المدرسة الاحتياجات الشخصية لمعلمات الرياضيات. & 1 \\
\hline 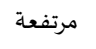 & 9 & 1.026 & 3.53 & تلبي قائدة المدرسة المتطلبات المهنية لمعلمات الرياضيات. & 2 \\
\hline 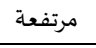 & 10 & 1.276 & 3.46 & تساعد قائدة المدرسة معلمات الرياضيات في التغلب على ضغوط العمل التي تواجههن. & 11 \\
\hline \multicolumn{2}{|c|}{ 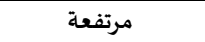 } & 0.911 & 3.81 & 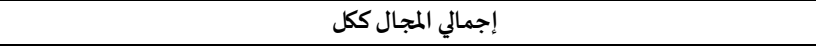 & \\
\hline
\end{tabular}

يتضح من بيانات الجدول (9) أن متوسط تحقيق قائدة المدرسة للتنمية المهنية لمعلمات الرياضيات في مجال العلاقات الإنسانية بلغ (3.81)

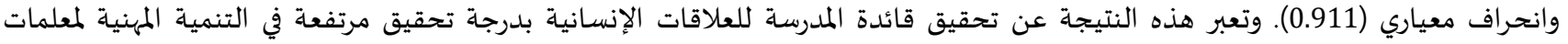

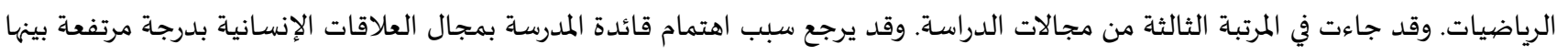

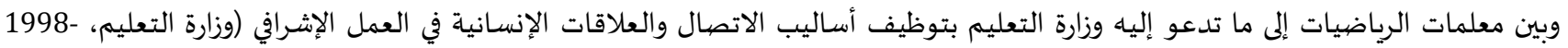

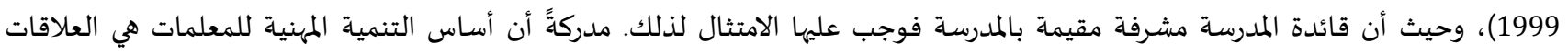

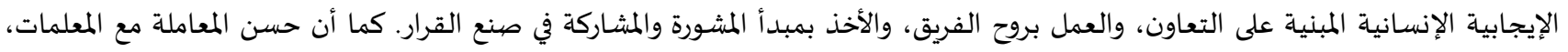




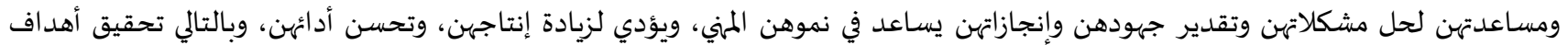

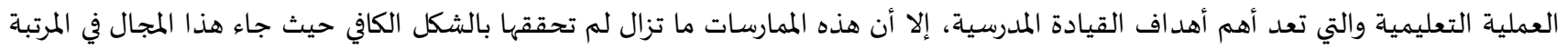

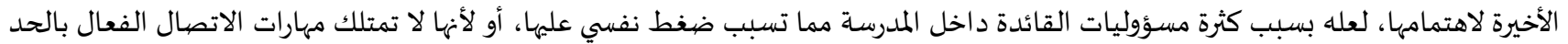

وعلى مستوى فقرات المجال: أظهرت النتائج أن متوسطات إجابات عينة الدراسة لفقرات مجال العلاقات الإنسانية تراوحت بين (4.06-3.46).

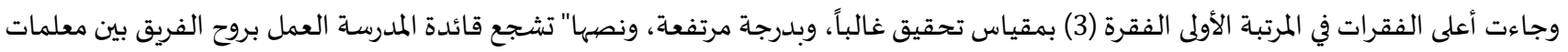

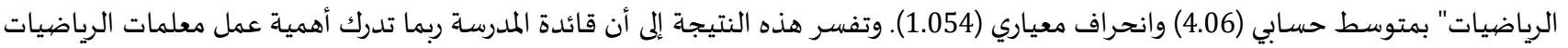

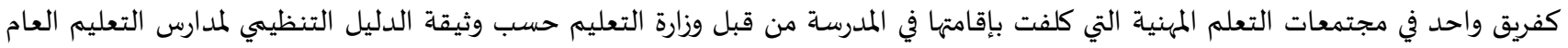

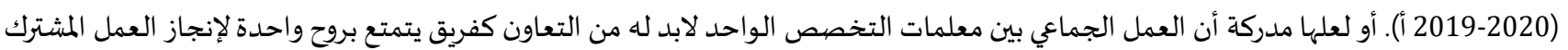

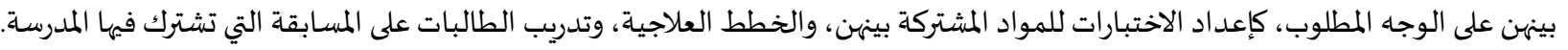

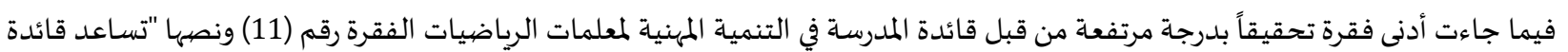

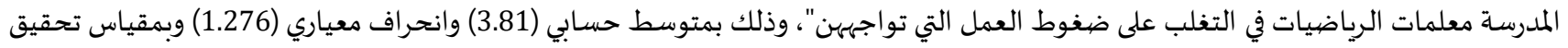

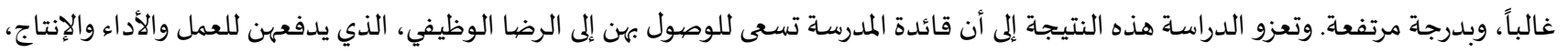

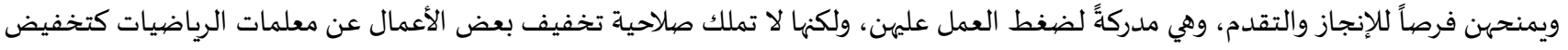

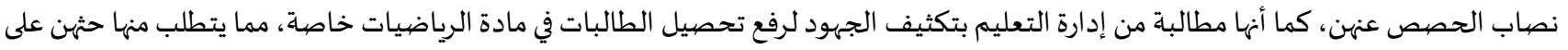

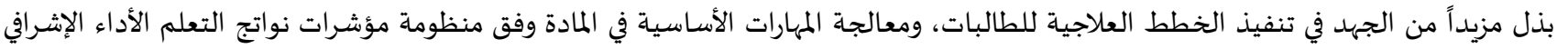

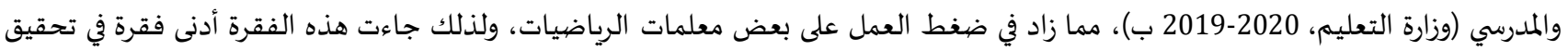

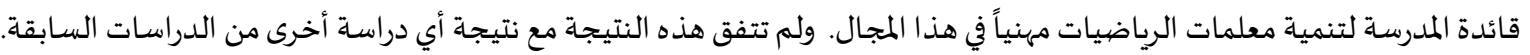

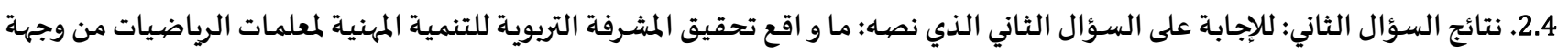

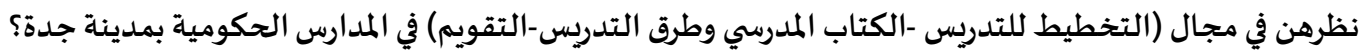

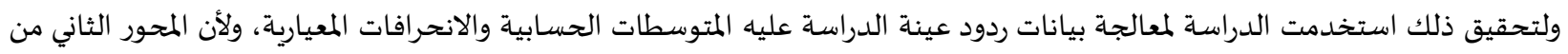

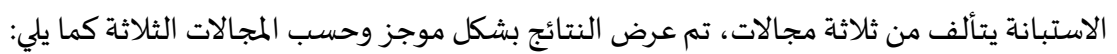
النتائج العامة للسؤال الثاني:

\begin{tabular}{|c|c|c|c|c|c|}
\hline درجة تحقيق المشرفة التربوية & الترتيب & الانحراف المعياري & المتوسط الحسابي & المجالات & 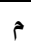 \\
\hline مرتفعة & 1 & 0.796 & 4.15 & التقويم & 3 \\
\hline مرتفعة & 2 & 0.942 & 3.88 & الكتاب المدرسي وطرق التدريس & 2 \\
\hline مرتفعة & 3 & 0.982 & 3.71 & التخطيط للتدريس & 1 \\
\hline مرتفعة & & 0.837 & 3.92 & المحور الثاني ككل & \\
\hline
\end{tabular}

يتضح من بيانات الجدول (10) أن متوسط تحقيق المشرفة التربوية للتنمية المهنية لمعلمات الرياضيات لإجمالي المحور الأول بلغ (3.92) وانحراف

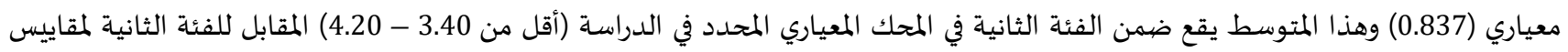

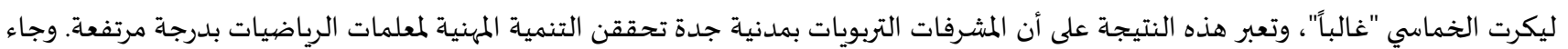

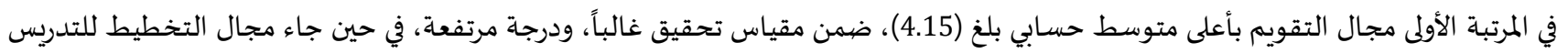

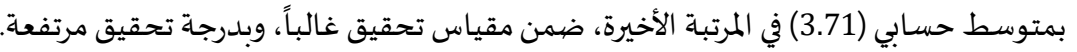

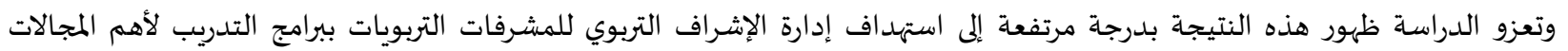

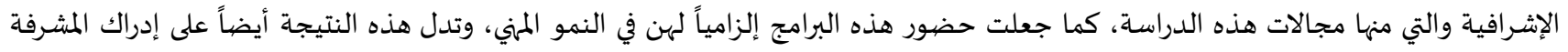

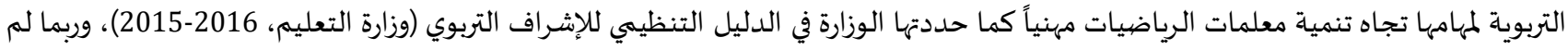

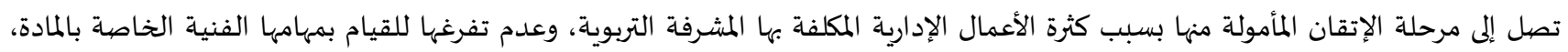

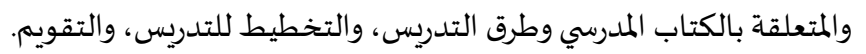


وتتفق هذه النتيجة مع نتيجة كلا من دراسة الإبراهيم (2015) في دور المشرفيين التربويين لتحسين النمو المهني لمعلمي المرحلة الأساسية، ودراسة

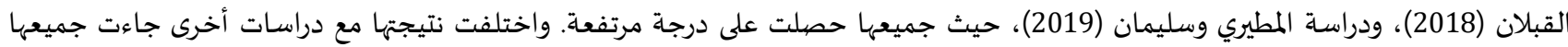

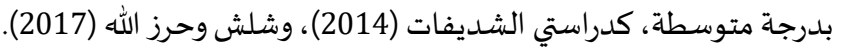
• النتائج التفصيلية للسؤال الثاني وفقاً للترتيب التنازلي للمجالات في نتائج الدراسـة:

1

\begin{tabular}{|c|c|c|c|c|c|}
\hline التحقيق & الترتيب & المعياري & الحسابي & 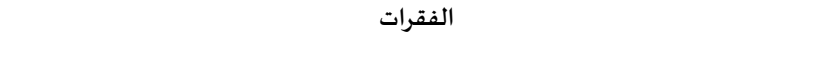 & م \\
\hline مرتفعة جداً & 1 & 0.873 & 4.39 & تحث المشرفة التربوية المعلمات على ضرورة مراعاة الفروق الفردية بين الطالبات. & 5 \\
\hline مرتفعة جداً & 2 & 0.899 & 4.31 & توجه المشرفة التربوية المعلمات بضرورة ربط عملية التقويم بأهداف المادة الدراسية. & 2 \\
\hline مرتفعة جداً & 3 & 0.915 & 4.28 & تحث المشرفة التربوية المعلمات على استخدام أنواع التقويم (التشخيصي-البنائي-الختامي). & 3 \\
\hline مرتفعة جداً & 4 & 0.917 & 4.26 & توضح المشرفة التربوية للمعلمات أهمية التقويم في تطوير العملية التعليمية. & 1 \\
\hline مرتفعة جداً & 5 & 0.973 & 4.25 & تناقش المشرفة التربوية المعلمات في أسئلة الاختبارات القصيرة والفصلية التي يُعدونها. & 6 \\
\hline مرتفعة & 6 & 0.927 & 4.17 & تعتمد المشرفة التربوية على مؤشرات قياس الأداء للحكم على أداء المعلمات. & 10 \\
\hline مرتفعة & 7 & 1.024 & 4.09 & مثل (المشاريع الأدائية، تقويم أقران، المعلي).. & 4 \\
\hline 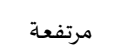 & 8 & 1.034 & 4.08 & تُقييم المشرفة التربوية إنجازات المعلمات التربوية التخصصية. & 9 \\
\hline مرتفعة & 9 & 1.045 & 4.01 & توجه المشرفة التربوية المعلمات للإفادة من نتائج التقويم في تحسين العملية التعليمية. & 8 \\
\hline مرتفعة & 10 & 1.294 & 3.68 & تزود المشرفة التربوية المعلمات بنماذج اختبارات متنوعة وفقاً لمبادئ القياس والتقويم. & 7 \\
\hline تفعة & & 0.796 & 4.15 & 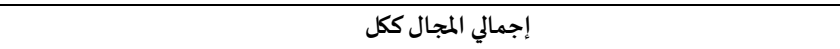 & \\
\hline
\end{tabular}

يتضح من بيانات الجدول (11) أن متوسط تحقيق المشرفة التربوية للتنمية المهنية لمعلمات الرياضيات في مجال التقويم بلغ (3.15) وانحراف معياري (0.796)، وتعبر هذه النتيجة عن تحقيق المشرفة التربوية لفقرات التقويم بدرجة تحقيق مرتفعة في التنمية المهنية لمعلمات الرياضيات. وتعزو مجات الدراسـة هذه النتيجة إلى جهود وزارة التعليم في رفع مستوى نواتج التعلم عبر إصدارها لمنظومة مؤشرات نواتج التعلم الأداء الإشرافي والمدرسي (وزارة

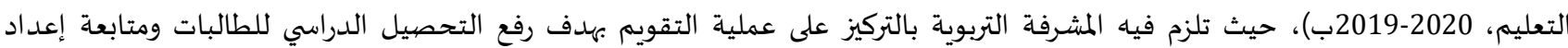
الاختبارات، وكل ما من شأنه تحسين نواتج التعلم. وعلى مستوى فقرات المجال: أظهرت النتائج أن متوسطات إجابات عينة الدراسة عن فقرات مجال مات التقويم تراوحت بين (4.39-3.68). وجاءت

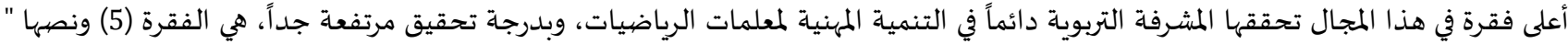

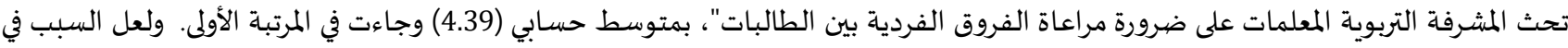

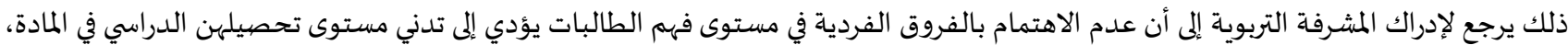
مما يجعلها تحث المعلمات باستمرار على الاهتمام بها لتحسين نواتج التعلم وفقُا لاتجاهات الوزارة في التركيز عليها، أو قد يكون بسبب ظهوري قصور قصور

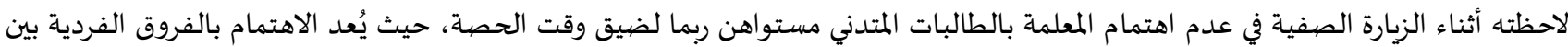
الطالبات من أهم بنود استمارة متابعة تقويم الأداء الصفي للمعلمة (وزارة التعليم، 2020 أ). وتختلف نتيجة هذه الدراسـة مع نتيجة دراسة الشديفات (2014) حيث جاءت هذه الفقرة بدرجة متوسطة. بينما جاءت أدني الفقرات التي تمارسها المشرفات التربويات بدرجة تحقيق غالباً وبدرجة مرتفعة الفقرة (7) ونصها "تزود المشرفة التربوية

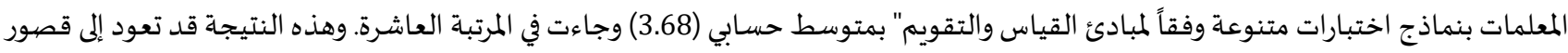
في معرفة المعلمات لطريقة إعداد الاختبارات وفقاً لمبادئ التقويم والقياس، مما دعا المشرفة التربوية إلى تزويدهن بنماذج للاختبارات إدراكاً منها لمهامها

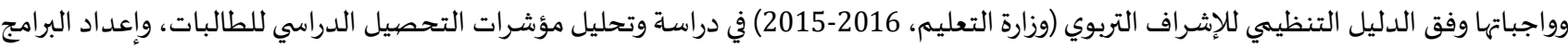

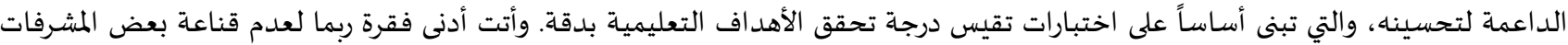

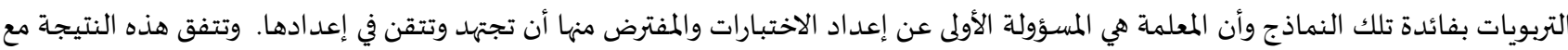
نتيجة دراسة خير الله (2018) في هذه الفقرة حيث جاءت بدرجة موافقة (مرتفعة). 


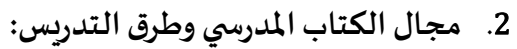

\begin{tabular}{|c|c|c|c|c|c|}
\hline التحقيق & الترتيب & 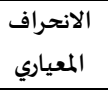 & الحتوسط المسابي & الفقرات & م \\
\hline مرتفعة & 1 & 0.960 & 4.24 & تأتعليمية. المشرفة التربوية على المعلمات ضرورة استخدام التقنية الحديثة (برامج وتطبيقات) في العملية & 5 \\
\hline مرتفعة & 2 & 0.975 & 4.14 & التعليمية. & 9 \\
\hline 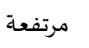 & 3 & 1.054 & 4.03 & توضح المشرفة التربوية للمعلمات طرق تنمية مهارات التفكير العليا للطالبات. & 6 \\
\hline 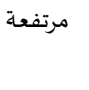 & 4 & 1.110 & 4.00 & التقويم،...) & 10 \\
\hline 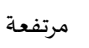 & 5 & 1.132 & 3.85 & ترشد المشرفة التربوية المعلمات إلى طرق تدريس تنهي مهارات التعلم الذاتي لدى الطالبات. & 2 \\
\hline 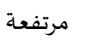 & 6 & 1.143 & 3.81 & تدرب المشرفة التربوية المعلمات على استخدام الأساليب العلمية الرياضية في حل المشكلات. & 7 \\
\hline 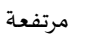 & 7 & 1.175 & 3.72 & تنظم المشرفة التربوية للمعلمات حلقات نقاش حول الاتجاهات الحديثة في مجال تدريس الرياضيات. & 8 \\
\hline 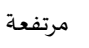 & 8 & 1.188 & 3.62 & تزود المشرفة التربوية المعلمات بأساليب متنوعة للتغلب على مشكلات تنفيذ المقرر الدراسي. & 4 \\
\hline 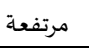 & 9 & 1.276 & 3.56 & تفسر المشرفة التربوية للمعلمات بعض المصطلحات والمفاهيم الواردة في الكتاب المدرسي. & 3 \\
\hline
\end{tabular}

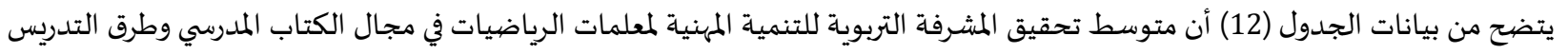

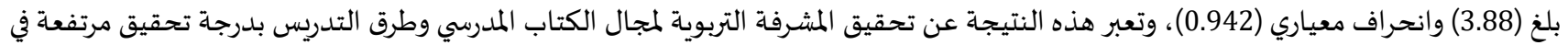

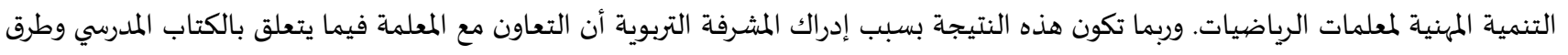

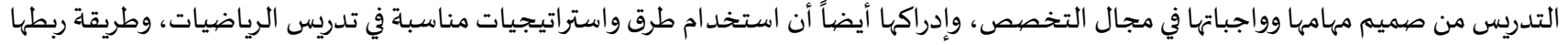

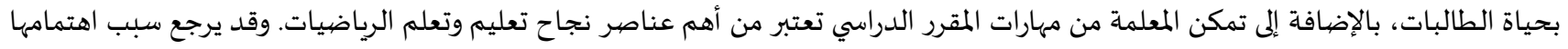

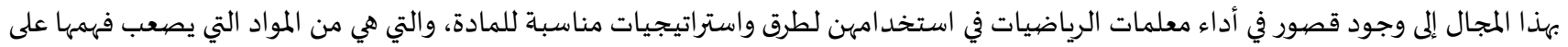

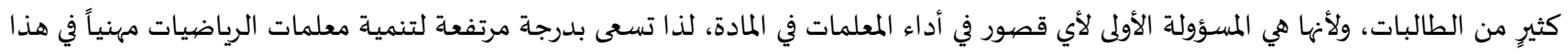

وعلى مستوى فقرات المجال: أظهرت نتائج عينة الدراسة أن متوسطات إجاباتهم عن فقرات مجال الكتاب المدرسي وطرق التدريس تراوحت بين

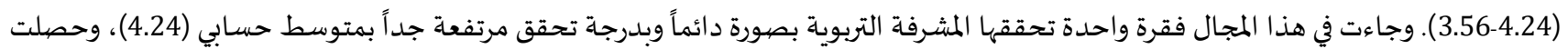

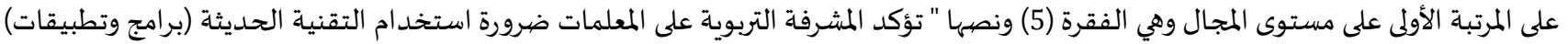

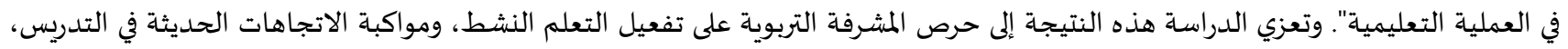

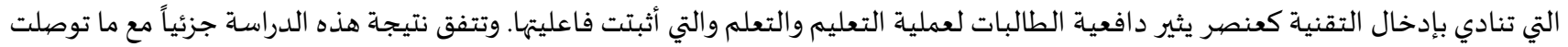

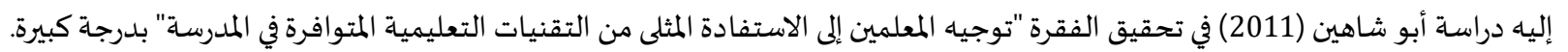

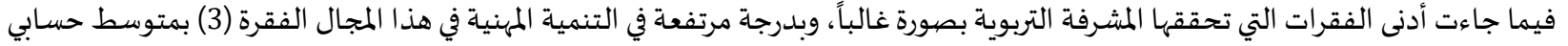

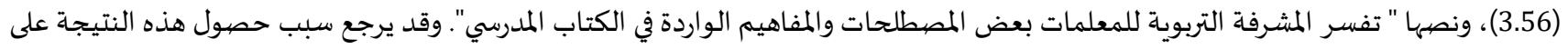

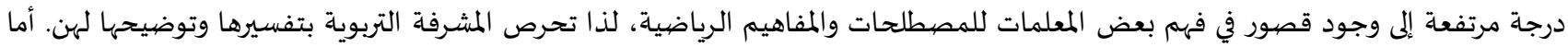

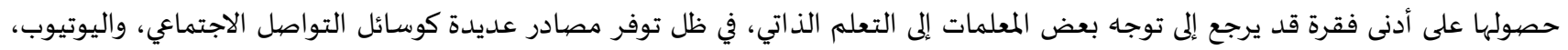

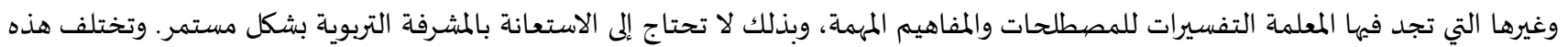
النتيجة مع نتيجة دراسة الشديفات (2014) في هذه الفقرة حيث جاءت بدرجات المهات متوسطة. 3. مجال التخطيط للتدريس:

\begin{tabular}{|c|c|c|c|c|c|}
\hline التحقيق & الترتيب & المعياري & المسابي & 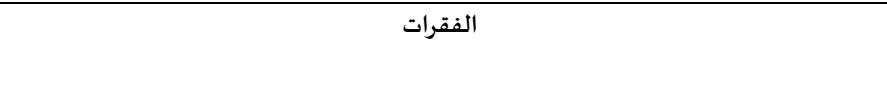 & م \\
\hline مرتفعة & 1 & 0.891 & 4.35 & تركز المشرفة التربوية على مراعاة المعلمة للوقت في عملية التخطيط للدرس داخل الصف & 8 \\
\hline مرتفعة & 2 & 1.168 & 3.78 & تخطط المشرفة التربوية آلية لتنفيذ الدروس التطبيقية للمعلمات داخل المدرسة أو خارجها. & 4 \\
\hline مرتفعة & 3 & 1.188 & 3.75 & تساعد المشرفة التربوية المعلمات في بناء برامج تعليمية علاجية خاصة بالطالبات المتدني تحصيلهن & 9 \\
\hline
\end{tabular}

$$
\text { الدراسي. }
$$




\begin{tabular}{|c|c|c|c|c|c|}
\hline مرتفعة & 4 & 1.211 & 3.74 & توضح المشرفة التربوية للمعلمات طريقة ربط موضوع الدرس الجديد بالخبرات السابقة للطالبات. & 5 \\
\hline 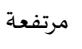 & 5 & 1.214 & 3.70 & تساعد المشرفة التربوية المعلمات في وضع خطط علاجية للمشكلات التربوية التي تواجههن. & 3 \\
\hline 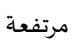 & 6 & 1.177 & 3.67 & تساعد المشرفة التربوية المعلمات في اختيار الأساليب التعليمية المناسبة لطبيعة مادة الرياضيات. & 7 \\
\hline 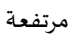 & 7 & 1.244 & 3.59 & تساعد المشرفة التربوية المعلمات في تحديد الوسائل التعليمية المناسبة لتحقيق أهداف الدروس. & 6 \\
\hline 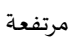 & 8 & 1.345 & 3.56 & تشرك المشرفة التربوية المعلمات في عملية التخطيط للمهارات المستهدفة في المادة. & \\
\hline 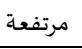 & 9 & 1.497 & 3.46 & تشرك المشرفة التربوية المعلمات في إعداد الخطة الفصلية للمقرر الدراسي. & \\
\hline \multicolumn{2}{|c|}{ مرتفعة } & 0.982 & 3.71 & 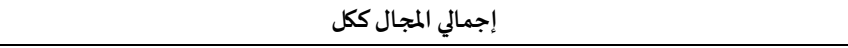 & \\
\hline
\end{tabular}

يتضح من بيانات الجدول (13) أن متوسط تحقيق المشرفة التربوية للتنمية المهنية لمعلمات الرياضيات في مجال التخطيط للتدريس بلغ (3.71) وانحراف معياري (0.982). وتعبر هذه النتيجة عن تحقيق المشرفة التربوية للتخطيط للتدريس بدرجة تحقيق مرتفعة في التنمية المهنية لمعلمات

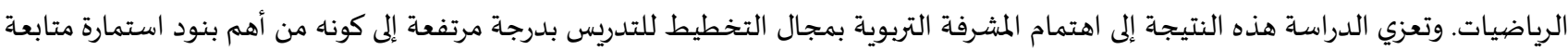
تقويم الأداء الصفي للمعلمة (وزارة التعليم، 2020 أ). مدركةً مدى أهميته لنجاح العملية التعليمياة، فكلما كانت المعلمة مهتمة بالتخطيط الجيد

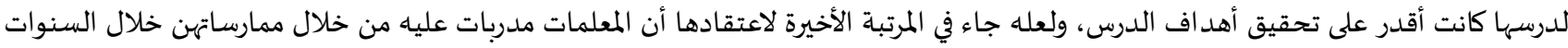
الماضية، وأنه قد أصبح للمعلمات من البديهيات.

وعلى مستوى فقرات المجال: أظهرت نتائج عينة الدراسة أن متوسطات إجاباتهم عن فقرات مجال التخطيط للتدريس تراوحت بين (4.35-3.46).

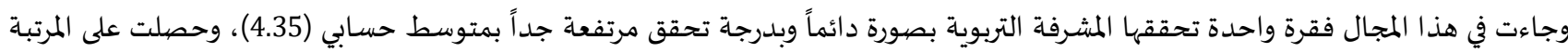

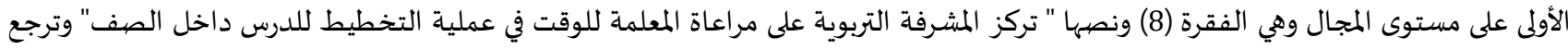

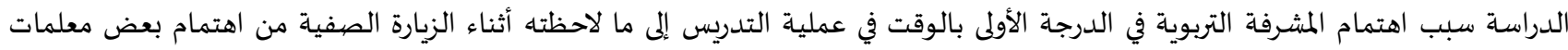
الرياضيات بتقديم كل ما لديهن من طرق تدريس، واستراتيجيات، وأنشطة تعليمية مما يؤدي إلى انتهاء زمن الحصة قبل فيل الوصهول لمرحلة التقييم

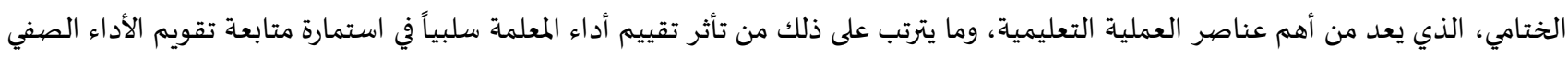

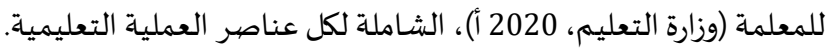
أما أدني فقرات المجال التي تحققها غالباً المشرفات التربويات وجاءت الفاء في المتربة التاسعة، هي الفقرة رقم (1) بمتوسط حسابي (3.46)، وبدرجة مرتفعة أيضاً "تشرك المشرفة التربوية المعلمات في إعداد الخطة الفصلية للمقرر الدراسي". وقد يعود سبب هذه النتيجة إلى اهتمام المشرفة التربوية

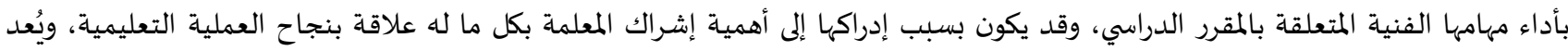

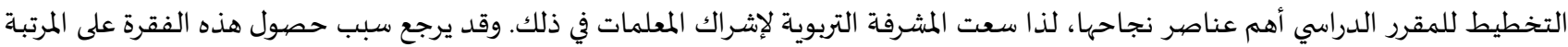

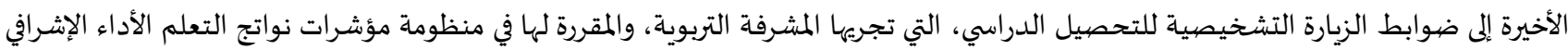

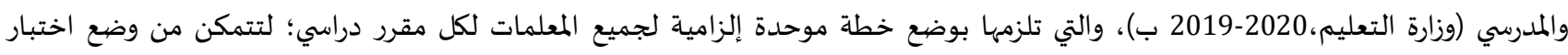
تشخيصي للمهارات الأساسية التي سبقت دراستها في المقرر الدراسي وفق هذه الخطة، واختبار الطالبات فيه بهدف الوقوف على مدى تمكنهن من اتقان

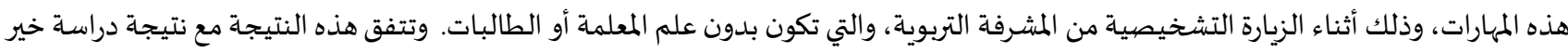
الله (2018) وفق الفقرة "يساعد في إعد اد الخطة الفصلية" في حصولها على درجة مرتفعة، بينما تختلف مع نتيجة دراسـة الشديفات (2014) التي بينت

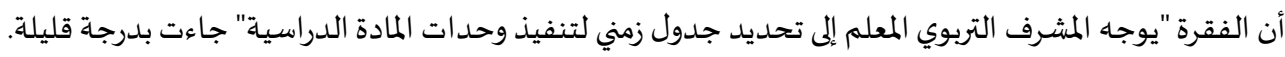

3.4 توصيات الدراسة:

بناء على نتائج الدراسة الحالية، يمكن تقديم بعض التوراهي التوصيات التي قد تسهم في تحقيق القيادات التربوية للتنمية المهنية لمعلمات الرياضيات وهي: استمرار المسؤولين بمكاتب الإشراف التربوي بوزارة التعليم في تدريب قائدات المدارس والمشرفات التربويات على مجالات التنمية المهنية، لما ظهر

لهذا التدريب من أثر إيجابي في ممارسات القائدات والمشرفات لتحقيق التنمية المهنية لمعلمات الرياضيات المرات ضرورة عمل وزارة التعليم على تخفيف المهام الإدارية لقائدات المدارس والمشرفات التربويات، لحسـاب المهام الفنية، ليتسنى لهن القيام بمهامهن الفنية في متابعة معلمات الرياضيات، وتنميتهن مهنياً بما يخدم نجاح العملية التعليمية. متابعة وزارة التعليم في التركيز على نواتج التعلم للعملية التعليمية في المدارس، وفقاً للأدلة المنظمة للعمل، لما لها من أثر في تفاعل القائدات والمشرفات التربويات في القيام بمهامهن لرفع نواتج التعلم. منح وزارة التعليم لقائدات المدارس بعض الصلاحيات لتخفيف الأعمال عن معلمات الرياضيات، للوصول بهن إلى الرضيا الوظيفي، الذي يدفعهن

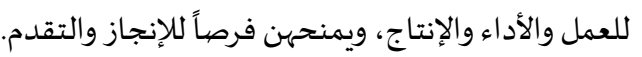

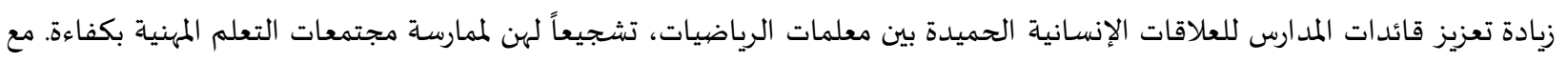
اهمية استمرار قائدات المدارس في حث معلمات الرياضيات على بناء هذه العلاقات الإنسانية الحميدة داخل الصفئ. 
ضرورة زيادة اهتمام قائدات المدارس بالأنشطة الصفية واللاصفية؛ لما لها من أثر في إثراء الخبرة للطالبات، وإكسابهن مهارات متعددة تخدم

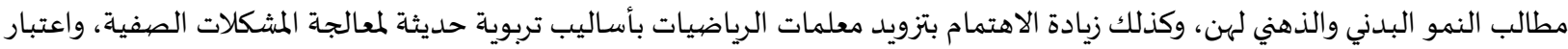
ذلك من واجباتهن الأسـاسية، للحفاظ على استقرار الجو التربوي داخل المدرسة. زيادة اهتمام المشرفات التربويات بتدريب المعلمات على إعداد الاختبارات وفق مبادئ القياس والتقويم، وتزويدهن بنماذج اختبارات متنوعة، ليتسنى للمعلمات وضع اختبارات تقيس مدى تحقق أهداف العملية التعليمية بدقة. تعزيز المشرفات التربويات لثقافة التعلم الذاتي والمسؤولية المهنية بين معلمات الرياضيات، ليرتقين بأدائهن مهنياً وعلمياً، مع زيادة المتابعة لهن في مدىى تمكنهن من المادة العلمية للرياضيات، بالإضافة إلى استمرار في حث المعلمات على استخد ام التقنية في التدريس، وتدريبهن عليها. زيادة اشراك المشرفات التربويات لمعلمات الرياضيات في وضع الخطة الفصلية للمقرر الدراسي، لأنهُنَّ أكثر ممارسة له، ولديهن المعرفة التامة

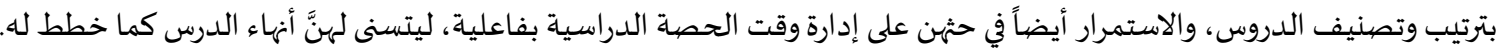
استمرار المشرفات التربويات في التركيز على حث معلمات الرياضيات بمراعاة الفروق الفردية بين الطالبات، حرصاً على استمرارية التعليم والتعلم للطالبات.

9.4 0.4 مقترحات الدراسة:

تقديم تصور مقترح لتحقيق القيادات التربوية (قائدة المدرسة- المشرفة التربوية) للتنمية المهنية لمعلمات الرياضيات باستخدام أسلوب التخطيط الاستراتيجي (التحليل الرباعي SWOT). إجراء دراسات مماثلة لهذه الدراسة تهتم بالتعرف على أثر متغير المرحلة الدراسية، سنوات الخبرة في التدريس، والمؤهل العلمي على تنمية معلمات

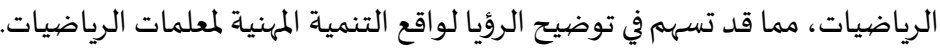

المراجع: 1. الإبراهيم، افتكار (2015). دور الإدارة المدرسية والمشرفين التربويين في تحسين النمو المهني لمعلمي المرحلة الأساسية في مديرية عمان الرابعة. مجلحة دراسات عربية في التربية وعلمم النفس: (59): 172-149. 2. أحمد، ياسر (2018). تقويم واقع أداء معلمي الرياضيات وأثره على تنميه التحصيل والاتجاه لدى طلاب الصف الأول الثانوي بالمملكة العربية السعودية. مجلة تربويات الرياضيات. 21(4): 127-86. 3. آدم، محمد؛ عثمان، إبراهيم؛ وأبكر ، صديق (2017). دور مدير المدرسية في تحقيق اتهات التنمية المهنية لمعلمي مرحلة التعليم الأساسي والمعوقات التي

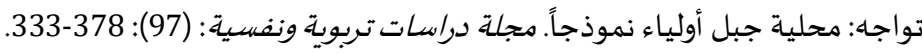

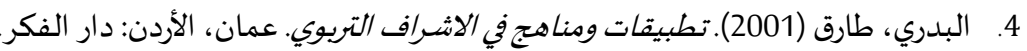

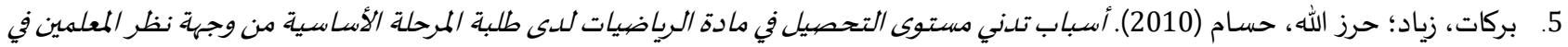

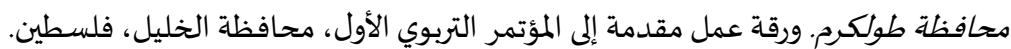

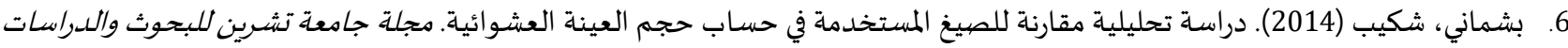

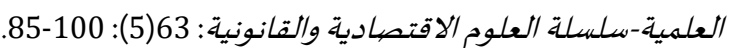
7. البلوي، عبد الله (2010). أولويات البحث في مجال تعليم وتعلم الرياضيات في المملكة العربية السعودية. مجلة دراسيات في المناهج وطرق التدريس بجامعة عين شمس: (155): 142-90. 8. البلوي، عبد الله؛ والراجح، نوال (2012). واقع التطور المهني لمعلمي ومعلمات الرياضيات في المملكة العربية السعودية. مجلة رسالة التربية وعلم النفس بجامعة الملك سعود: (38): 9 9 تجار، صباح (2013). عوامل تدني التحصيل الأكاديهي لمادة الرياضيات للصف الرابع بمرحلة الأساس من وجهة نظر المعلمين (رسالة ماجستير

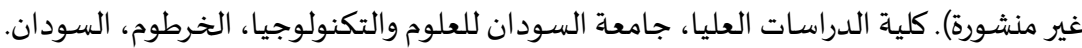

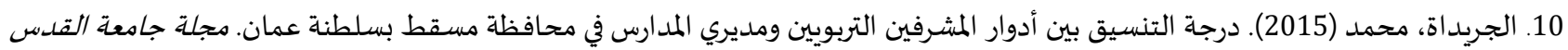
المفتوحة للأبحاث والدراسات التويوية والنفسية: 3(9): 176-148. 11. جيتو، عبد الحق (2013). مشاركة المشرف التويوي لملدير الملدرسة في تحسين الأداء الملمرسي (رسالة ماجستير غير منشورة). كلية التربية، جامعة 
12. الحربي، عبد الله (2012). دور الكفايات الأسـاسية للمشرف التربوي في تطوير النمو المهني لمعلم العلوم. مجلة دراسات عربية في التربية وعلم النفس: 1(32): $193-210$.

13. حمدان، محمد (2010). التنمية المهنية للمعلم التدريب لمجتمع المعرفة. المؤتمر الدولي الخامس-مستقبل إصلاح التعليم العربي لمجتمع المعرفة

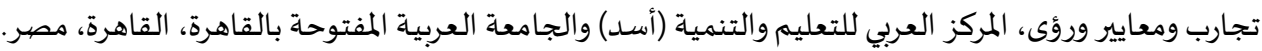

14. الخطيب، إبراهيم؛ والخطيب، أمل (2003). الإشراف التريوي-فلسفته-أساليبه-تطبيقاته. عمان، الأردن: دار قنديل للنشر والتوزيع. 15. خليل، عصام (2014). درجه تقدير معلمي المرحلة الاساسية الاولى لفاعلية الأدوار التي يقوم بها مدير المدرسة الحكومية في محافظة رام الله الهابه والبيرة في ضوء بعض المتغيرات. مجله التربية بجامعة الأزهر: 2(158): 169-135. 16. خير الله، مطر (2018). دور المثرف التوبوي في التنمية المهنية للمعلمين بالموحلة الثانوية بولاية غرب كردفان: دراسة ميدانية محلية بابنوسة (رسالة ماجستير غير منشورة). كلية التربية، جامعة النيلين، الخرطوم، السودان.

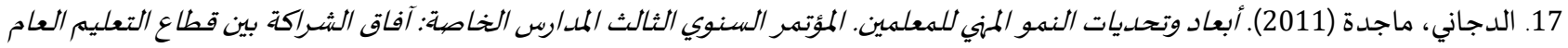
والخاص، مركز ديبونو لتعليم التفكير ونقابة أصحاب المدارس الخاصة الأردنية وشركة طيف للخدمات التحات التعليمية، عمان، الأردن. 18. دواني، كمال (2003). الإششراف التربوي (مفاهيمروآفاق). عمان، الأردن: دار وائل للطباعة والنشر.

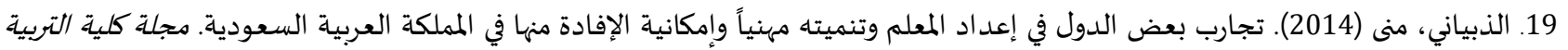
بالزقازيق: (85): 172-103. 20. الرباط، بهيرة (2016). الإشسراف المهني التريوي. الرياض، السعودياة: دار الزهراء للنشر والتوزيع.

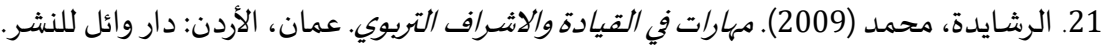

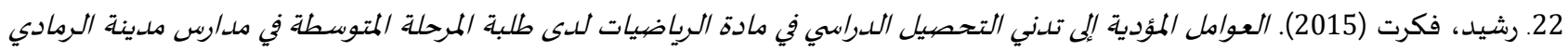

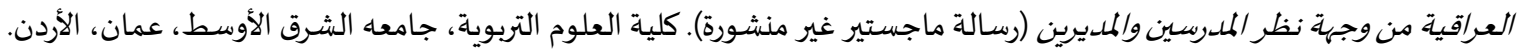
23. رصرص، حسن (2013). تصور مقترح لتطوير اداء معلمي الرياضيات بمدارس غزه في ضوء المعايير المهنيه المعاصرة. مجلة الجامعة الإسلامية

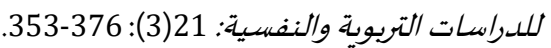

24. الرفاعي، سعد (2006). إجراء/ت الإدارة الممرسية في المملكة العربية السعودية (ط.2). جدة، السعودية: دار خوارزم العلمية للنشر والتوزيع.

25. الرويلي، سعود (2010). مهام المشرف التربوي في تطوير النمو المهني لمعلمي الرياضيات في المرحلة المتوسطة. عالم التوبية: (30): 396-334. 26. الرويلي، سعود (2017) دور المشرف التربوي في عصر المعرفة كما يدركه المعلمون والمعلمات في مدينة عرعر، مجلة جامعة الحداود الشمالية للعلوم الإنسانية: 2(1): 55-27. 27. الرويلي، هناء (2010). دور ملديرات المدارس والمشَفات التويويات في التنمية المهنية لمعلمات المرحلة المتوسطة من وجهة نظر معلمات منطقة

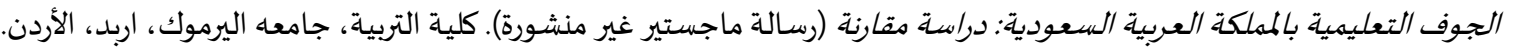

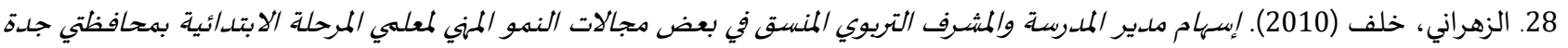
والمخواة (رسالة ماجستير غير منشورة). كلية التربية، جامعة أم القرى، مكاة المكرمة، السعودية.

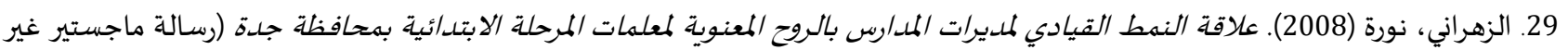
منشورة). كلية التربية، جامعة ام القرى، مكاة المكرمة، السعودية.

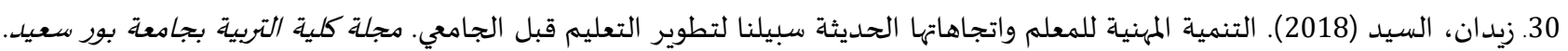
.370-410:24) 31. السالم، هديل (2018). دور قائدة المدرسة كمشرف تربوي مقيم في التنمية المهنية للمعلمات في مدينة الرياض. مجلة البحث العملي في التوبية بجامعة عين شمس: 4 (19): 153-117.

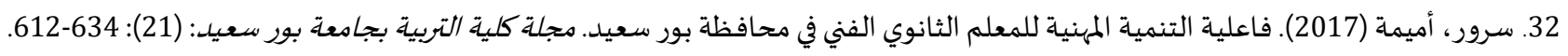
33. السليطي، ظبياه (2015). تصور مقترح لمهارات معلم القراءة في ضوء متطلبات القرن الحادي والعشرين في المدارس المستقلة بدوله قطر. مجلة

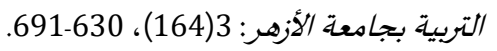
34. السويد، محمد (2014). بناء مصفوفة الخيارات الاستراتيجية للتنمية المهنية للمعلمين بالمملكة العربية السعودية باستخدام أسلوب SWOT.

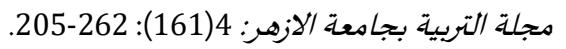
35. السيف، عادل (2005). الحاجات التدريبية في مهام الإدارة الصفية لمعلمي الصيفوف الأولية من المرحلة الابتدائية (رسالة ماجستير غير منشورة). كلية التربية، جامعة الملك سعود، الرياض، السعودية. 
36. أبو شاهين، دلال (2011). دور الموجاه التربوي في النمو المهني لمعلمي الحلقة الأولى من مرحلة التعليم الأساسي. مجلة جامعة دمشق: 27: -279

37. الشايع، فهد (2013). واقع التطور المهني للمعلم المصاحب لمشروع تطوير الرياضيات والعلوم الطبيعية في التعليم العام في المملكة العربية

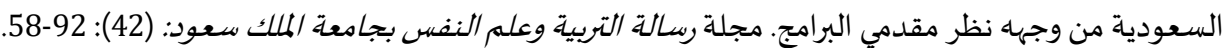

38. شحاتة، حسن؛ النجار، زينب (2003). معجم المصطلحات التوبوية والنفسية. القاهرة، مصر: الدار المصرية اللبنانية.

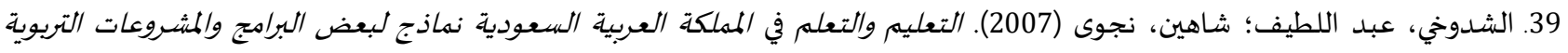
التطويرية. المؤتمر العلمي الحادي عشر التربية العلمية إلى أين، الجمعية المصيرية للتربية العلمية، القاهرة. 40. الشديفات، باسل (2014). دور المشرفيين التربويين في تطوير الأداء المهني لمعلمي الدراسات الاجتماعية في مديرية التربية والتعليم للواء البادية

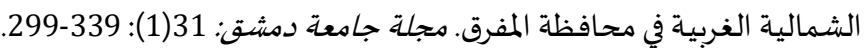
41. شراحيلي، جابر (2020). دور القيادة المدرسية في تحسين نواتج التعلم وفق تطور تصورات قادة المدارس ومشرفهيها. مجلة دراسات عبربية في التربية وعلم النفس: (118): 245-213.

42. شلش، باسم؛ وحرز الله، حسام (2017). الإشراف التربوي وعلاقته في التطور المهني لمعلمي الرياضيات في المرحلة الأساسية العليا في فلسطين.

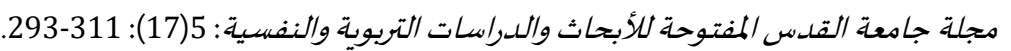
43. الشمراني، سعيد (2012). أولويات البحث في التربية العلمية بالمملكة العبية السعودية. مجلة جامعة الملك سعود-العلوم التربوية والدراسات الإسبامية: $24(1)$ (1): $199-10$ 44. الشمري، مطر (2004)، التنمية المهنية للقياد/ت التويوية بلدولة قطر في ضوء مدخل إدارة الجودة الشاملة (رسالة دكتوراه غير منشورة). كلية التربية، جامعة عين شمس، القاهرة، مصر.

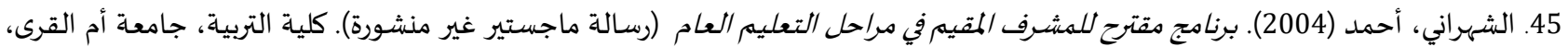
مكة المكرمة، السعودية. 46. الشهري، خالد (2018). واقع ممارسة قائد المدرسة الابتدائية الأهلية للعلاقات الإنسانية بمدينة الرياض. مجلة البحث العلمي في التوبية بجامعة عين شمس: 14(19): 348-307. 47. الشيخي، هاشم (2012). استراتيجية مقترحة لتحسين مستوى تحصيل طلبة المملكة العربية السعودية في الرياضيات في المسابقات الدولية TIMSS

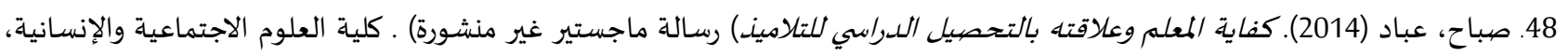
جامعة الشهيد حماه لخضر الوادي، الجزائر. 49. الصعيدي، منصيور (2016). تصهور مقترح لتطوير أداء معلمي الرياضيات بالمرحلة الإعدادية في ضوء المسورؤولية المهنية الذاتية لديهم، مجلة تربويات الرياضيات: 19(6): 228-279.

50. عامر، طارق (2012). النمو والتنمية المهنية للمعلمر" التدريب أثناء الخدمة. القاهرة، مصري دات دار الكتب والوثائق القومية المصرية.

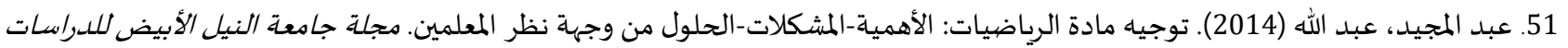
والبحوث: (4): 183-159. 52. عبد النعيم، محمد (2016). التخطيط الاستراتيجي لتطوير التوجيه الفني بالتعليم العام المصري: دراسة ميدانية بمحافظة سوهاج. مجلة دراسيات في التعليم الجامعي: (34): 354-434. 53. عتريس، محمد (2010). تفعيل دور مدير المدرسة في تحقيق التنمية المهنية للمعلمين للتعليم قبل الجامعي في ضواء مداتئ مدخل المدرسة كمجتمع

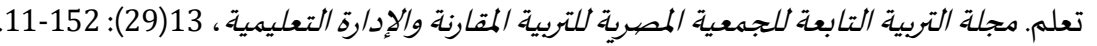

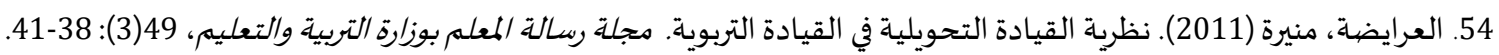
55. العساف، صالح (2012). المدخل إلى البحث في العلوم السلوكية. الرياض، السعودية: دار الزهرهاء.

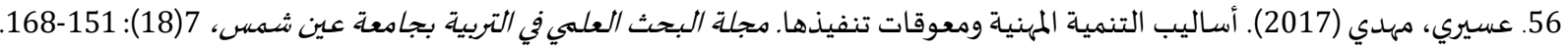
57. عطاري، عارف؛ عيسان، صالحة؛ ومحمود، ناريمان (2005). الإشراف التوبوي: نماذجه النظرية وتطبيقاته العلمية. الكويت: مكتبة الفلاح للنشر. 58. العلي، يسري (2014). درجة ممارسة مديري المدارس الأساسية والثانوية الخاصة في الاردن في دوره في تحقيق النمو المهني للمعلمين: دراسة

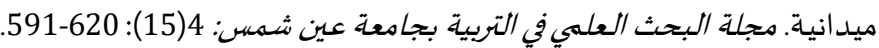




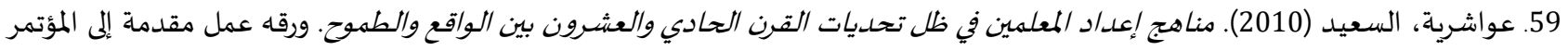

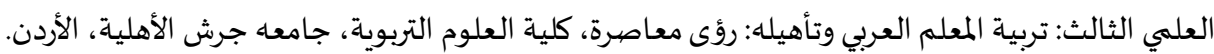

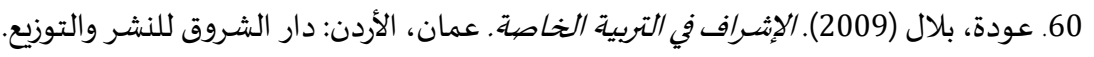

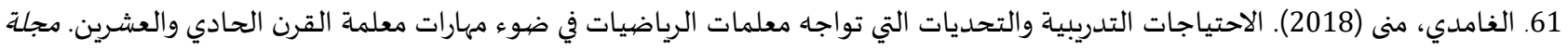
كلية التربية بجامعة طنطا: 70(2): 529-408،

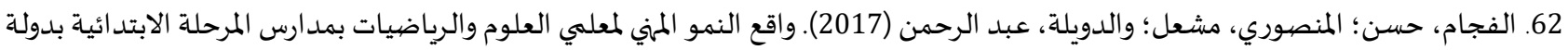

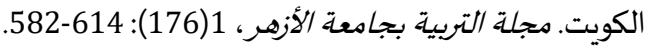

63. الفقياه، حسن (2005). إسهام مديري المدراس في تطوير تخطيط الدوروس للدى معلمي الفصول الأولية (رسالة ماجستير غير منشورة). كلية

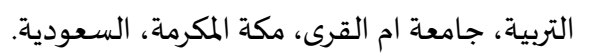

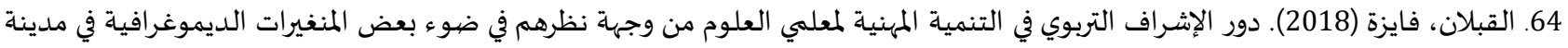

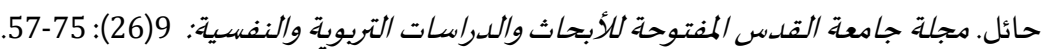
65. القحطاني، نوف (2018). دور القيادة المدرسية في التنمية المهنية لمعلمات العلوم الإدارية في المدارس الحكومية بمدينة الرياض. مجلة البحث

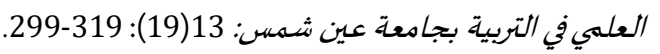
66. القعود، سارة (2003). دور المشـفات التويويات في تطوير أداء معلمات الطفولة المبكرة (رسالة ماجستير غير منشورة). كلية التربية، الرياض، جامعة الملك سعود، السعودية. 67. محسن، مصطفى (2010). الكتاب المدرسي وتوجهات المنهاج التربوي: نحو رؤية سوسيوثقافية لبعض معطيات الراهن ورهانات التطوير والإصلاح.

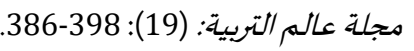
68. محمود، نصر الله (2005). تكوين معلم الرياضيات والوصهول إلى الجودة. المؤتمر العلمي الخامس-التغيرات العالمية والتربوية وتعليم الرياضيات،

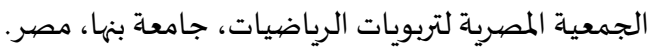
69. المطيري، بدرية؛ وسليمان، خالد (2019). دور الإشراف التربوي في التنمية المهنية لمعلمات المهارات النفسية والاجتماعية. المجلة الماتدولية الماتية للآداب والعلوم الإنسانية والاجتماعية: (18): 152-102.

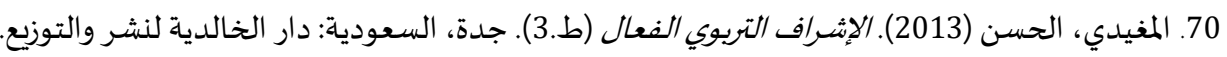
71. آل مغيرة، محمد (2017). مدى ممارسة مديري المدارس في مراحل التعليم العام لدورهم في تنمية المعلمين مهنياً. مجلة جامعاة الفيوم للعلوم التوبوية والنفسية: 3(7): 142-99. 72. المناحي، تركي (2010). واقع دور المثشف التويوي في تنمية الكفاءة المهنية لدى المعلمين: من وجهة نظر مديري مكاتب التوبية والتعليم ومعلهي الصيفوف الأولية في ملدينة الرياض (رسالة ماجستير غير منشورة). كلية العلوم الاجتماعية، جامعة الإمام محمد بن سعود الإسلامية، السعودية.

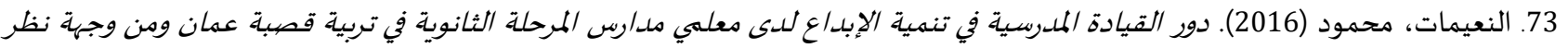

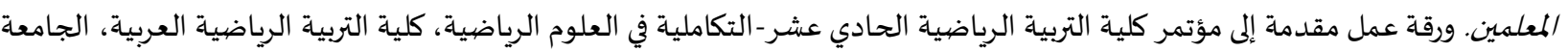
الأردنية، الأردن.

74. اليحيي، إبراهيم (2017). واقع التطوير المهني لمعلمي المرحلة الثانوية من وجها نظر المعلمين والمشرفين في مدينة الدوادمي. مجله كلية التوبية بجامعة أسيوط: 33(1): $101-56$. 75. اليعربية، زيانة (2018). تفعيل العمل الإشرافي المشترك بين المشرف التربوي والإدارة المدرسية في سلطنة عمان. مجلة التربية بجامعة الأزهر، .318-349:(178)1

ثانياً: المراجع الأجنبية:

1. Mudawali \& Mudzofir. (2017). Relationship Between Instructional Supervision and Professional Development: Perceptions of Secondary School Teachers, Aceh, Indonesia (unpublished Master Thesis). University of Tampere, Finland.

2. Mudzofir,D (2017). Relationship between instructional supervision and professional development: Perceptions of secondary school teachers and madrasah tsanawiyah (Islamic secondary school) teachers in Lhokseumawe, Aceh, Indonesia (unpublished Master Thesis). University of Tampere, Finland.

3. ThiHao, N. (2016). Teachers' Perceptions on Principals' Instructional Leadership Behaviors in Vietnam. Journal of Teacher Education. 1(1): 1-11. 
4. Ziyadin, S; Shash,N. b; Kenzhebekova, D. C, Yessenova, G. D \& Tlemissov, U. (2018). Data on the Role of Leadership in Developing Expertise in Teaching in Developing Country. Journal of Data in Brief, (18): 1127-1133. https://doi.org/10.1016/j.dib.2018.03.137

ثالثاً: المراجع الإلكترونية:

1. الألسكو، المنظمة العربية للتربية والثقافة والعلوم (2017). مجالات عمل المنظمة العربية للتربية والثقافة والعلوم. تم الاسترجاع: .http://www.alecso.org/nnsite/2017-09-06-08-37-39.htm/

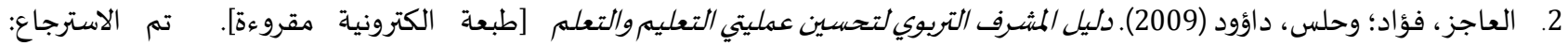
https://www.saudi-teachers.com/vb/t/154508/

3ttps://ecsme.ksu.edu.sa/ar: مركز التميز البحثي في تطوير تعليم العلوم والرياضيات (2020). تم الاسترجاع

4. وزارة التعليم بالمملكة العربية السعودية (1999-1998). دليل المشـف التويوي. الإدارة العامة للاشـراف التوبوي. [المنهل الثقافي]. تم الاسترجاع: .https://www.manhal.net/art/s/1330

5ttps:/www.education- وزارة التعليم بالمملكة العبية السعودية (2016-2015). الدليل التنظيهي للإشراف التربوي، تم الاسترجاع: .ksa.com/showthread.php?t=120774

6. وزارة التعليم بالمملكة العربية السعودية (2018). الخطة التنفينية لبرنامج التحول الوطني 2020. تم الاسترجاع: https:/cutt.us/6JfVm.

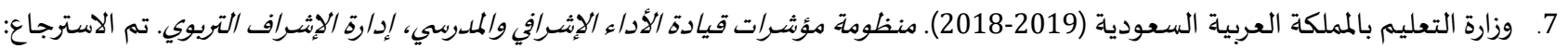
https://cutt.us/bgWKm

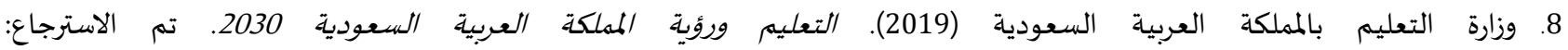
9 و وزارة التعليم بالمملكة العبية السعودية أ (2020-2019). وثيقة الدليل التنظيهي لمدارس التعليم العام -الإصبد/ر الرابع. الرياض. [مكتبة الإحساء التعليمة]. تم الاسترجاع: https:/www.alahsaa.net/wt/files/archives/11827.

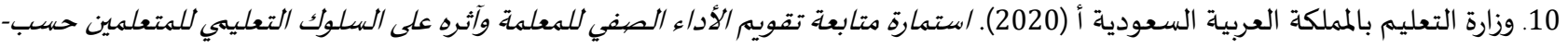
الزيارة الإشـرافية. مكتب تعليم جدة [موقع نظام نور]. تم الاسترجاع:https://noor.moe.gov.sa/Noor/Login.aspx. 11. وزارة التعليم بالمملكة العربية السعودية ب (2020-2019). منظوهة مؤشرات نواتج التعلم الأداء الإشـرافي والممدرسي، إدارة الإشـراف التوبوي. تم

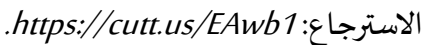
12. وزارة التعليم بالمملكة العربية السعودية. ب (2020). لائحة تنظيم المعهد الوطني للتطوير المنهي التعليهي. [جريدة أم القرى] تم الاسترجاع: .https://www.uqn.gov.sa/articles/1574322362515070500/

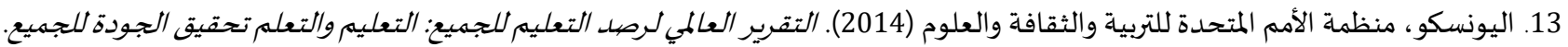
تم الاسترجاع:https://cutt.us/q8gDC. رابعاً: المؤتمرات واللقاءات والوثائق والتعاميم: 1. المؤتمر الأول لتعليم وتعلم الرياضيات (2015). STEM العلوم والتقنية والهندسة والرياضيات. مركز التميز البحثي في تطوير تعليم العلوم والرياضيات، الرياض. 2. المؤتمر السادس لتعليم وتعلم الرياضيات بكلية التربية (2019). مستقبل تعليم الرياضيات في المملكة العربية السعودية في ضوء الاتجاهات الحاديثة والتنافسية الدولية. الجمعية السعودية للعلوم الرياضية، جامعة أم القرى، مكة المكرمة.

3. الجمعية السعودية للعلوم التربوية والنفسية (2006). إعداد المعلمروتطويره في ضيوء المتغيرات المعاصرة. اللقاء السنوي الثالث عشر، الرياض.

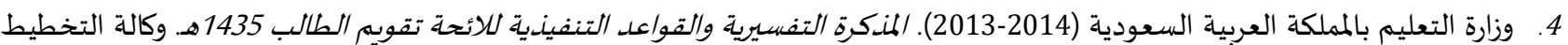
والتطوير، الإدارة العامة للتقويم. 


$$
\text { المجلة الدولية للدراسـات التربوية والنفسية }
$$

International Journal of Educational \& Psychological Studies (EPS)

Journal Homepage: https://www.refaad.com/views/EPSR/Home.aspx

www.refaad.com

ISSN: 2520-4149 (Online) 2520-4130 (Print)

\title{
The reality of educational leaders achieving the professional development of mathematics teachers from their point of view in government schools in Jeddah
}

\author{
Hanan Abdullah Sumayli \\ MA in Educational Leadership, Dar Al-Hekma University, KSA \\ seralhaia2015@gmail.com
}

Nouf Mohammed Albadi

Dar Al-Hekma University, KSA

Received:21/4/2021 Revised:9/5/2021 Accepted:27/5/2021 DOI : https://doi.org/10.31559/EPS2021.10.2.5

Abstract: The study aimed to identify the reality of educational leaders (the school leader, the educational supervisor) achieving the professional career of mathematics teachers from their point of view In public schools in the city of Jeddah, in the fields: work planning, classroom management, human relationships, evaluation, textbook and teaching methods, planning for teaching. It relied on the descriptive approach, and the questionnaire was used as a research tool. It was randomized to (657) female math teachers in government schools in Jeddah, Saudi Arabia, and the study reached the following results :The school leader achieves the professional development of mathematics teachers from their point of view in government schools in Jeddah with a high degree of investigation in the fields as a whole, with an arithmetic average (3.95) and in all of them in descending order: work planning with an arithmetic average (4.04), classroom management with an arithmetic average (4.03), human relations with an arithmetic average (3.81).The educational supervisor achieves the professional development of mathematics teachers from their point of view in the public schools in Jeddah with a high degree of investigation in the fields as a whole with an arithmetic average (3.92), and in all of them in descending order: evaluation with an arithmetic average (4.15), textbook and teaching methods with an arithmetic average (3.88), planning for teaching with an arithmetic average (3.71). In light of these results, recommendations were presented, the most important of which are: The Ministry of Education continues to train school leaders and educational supervisors in the areas of professional development of mathematics teachers. With the necessity of its work to reduce the administrative tasks of school leaders, and educational supervisors to calculate technical tasks, including professionally developing mathematics teachers.

Keywords: Educational leaders; School leader; Educational supervisor; Professional development; Mathematics teachers.

\section{References:}

1. Ahmd, Yasr (2018). Tqwym Waq' Ada' M'lmy Alryadyat Wathrh 'la Tnmyh Althsyl Walatjah Lda Tlab Alsf Alawl Althanwy Balmmlkh Al'rbyh Als'wdyh. Mjlh Trbwyat Alryadyat. 21(4): 86-127.

2. Adm, Mhmd: 'thman, Ebrahym؛ Wabkr, Sdyq (2017). Dwr Mdyr Almdrsh Fy Thqyq Altnmyh Almhnyh Lm'lmy Mrhlt Alt'lym Alasasy Walm'wqat Alty Twajh: Mhlyh Jbl Awlya' Nmwdjaan. Mjlt Drasat Trbwyh Wnfsyh: (97): 333-378.

3. Albdry, Tarq (2001). Ttbyqat Wmnahj Fy Alashraf Altrbwy. 'man, Alardn: Dar Alfkr.

4. Brkat, Zyad: Hrz Allh, Hsam (2010). Asbab Tdny Mstwa Althsyl Fy Madh Alryadyat Lda Tlbt Almrhlh Alasasyh Mn Wjht Nzr Alm'lmyn Fy Mhafzt Twlkrm. Wrqt 'ml Mqdmh Ela Alm'tmr Altrbwy Alawl, Mhafzt Alkhlyl, Flstyn.

5. Bshmany, Shkyb (2014). Drash Thlylyh Mqarnh Llsygh Almstkhdmh Fy Hsab Hjm Al'ynh Al'shwa'yh. Mjlt Jam't Tshryn Llbhwth Waldrasat Al'lmyh-Slslt Al'lwm Alaqtsadyh Walqanwnyh: 63(5): 85-100.

6. Alblwy, 'bd Allh (2010). Awlwyat Albhth Fy Mjal T'lym Wt'lm Alryadyat Fy Almmlkh Al'rbyh Als'wdyh. Mjlt Drasat Fy Almnahj Wtrq Altdrys Bjam't 'yn Shms: (155): 90-142.

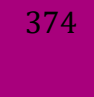


7. Alblwy, 'bd Allh؛ Walrajh, Nwal (2012). Waq' Alttwr Almhny Lm'lmy Wm'lmat Alryadyat Fy Almmlkh Al'rbyh Als'wdyh. Mjlt Rsalt Altrbyh W'lm Alnfs Bjam't Almlk S'wd: (38): 43-73.

8. Aldbyany, Mna (2014). Tjarb B'd Aldwl Fy E'dad Alm'lm Wtnmyth Mhnyaan Wemkanyh Alefadh Mnha Fy Almmlkh Al'rbyh Als'wdyh. Mjlt Klyt Altrbyh Balzqazyq: (85): 103-172.

9. Aldjany, Majdh (2011). Ab'ad Wthdyat Alnmw Almhny Llm'lmyn. Alm'tmr Alsnwy Althalth Almdars Alkhash: Afaq Alshrakh Byn Qta' Alt'lym Al'am Walkhas, Mrkz Dybwnw Lt'lym Altfkyr Wnqabh Ashab Almdars Alkhash Alardnyh Wshrkt Tyf Llkhdmat Alt'lymyh, 'man, Alardn.

10. Dwany, Kmal (2003). Aleshraf Altrbwy (Mfahym Wafaq). 'man, Alardn: Dar Wa'l Lltba'h Walnshr.

11. Alebrahym, Aftkar (2015). Dwr Aledarh Almdrsyh Walmshrfyn Altrbwyyn Fy Thsyn Alnmw Almhny Lm'lmy Almrhlh Alasasyh Fy Mdyryt 'man Alrab'h. Mjlt Drasat 'rbyh Fy Altrbyh W'lm Alnfs: (59): 149-172.

12. Hmdan, Mhmd (2010). Altnmyh Almhnyh Llm'lm Altdryb Lmjtm' Alm'rfh. Alm'tmr Aldwly Alkhams-Mstqbl Eslah Alt'lym Al'rby Lmjtm' Alm'rfh Tjarb Wm'ayyr Wr'a, Almrkz Al'rby Llt'elym Waltnmyh (Asd) Waljam'h Al'rbyh Almftwhh Balqahrh, Alqahrh, Msr.

13. Alhrby, 'bd Allh (2012). Dwr Alkfayat Alasasyh Llmshrf Altrbwy Fy Ttwyr Alnmw Almhny Lm'lm Al'lwm. Mjlt Drasat 'rbyh Fy Altrbyh W'lm Alnfs: 1(32): 193-210.

14. Aljrydah, Mhmd (2015). Drjh Altnsyq Byn Adwar Almshrfyn Altrbwyyn Wmdyry Almdars Fy Mhafzh Msqt Bsltnh 'man. Mjlt Jam't Alqds Almftwhh Llabhath Waldrasat Altrbwyh Walnfsyh: 3(9): 148-176.

15. Jytw, 'bd Alhq (2013). Msharkt Almshrf Altrbwy Lmdyr Almdrsh Fy Thsyn Alada' Almdrsy (Rsalt Majstyr Ghyr Mnshwrh). Klyt Altrbyh, Jam't Tybh, Almdynh Almnwrh, Als'wdyh.

16. Khlyl, 'sam (2014). Drjt Tqdyr M'lmy Almrhlh Alasasyh Alawla Lfa'lyh Aladwar Alty Yqwm Bha Mdyr Almdrsh Alhkwmyh Fy Mhafzt Ram Allh Walbyrh Fy Dw' B'd Almtghyrat. Mjlt Altrbyh Bjam't Alazhr:2 (158): 135-169.

17. Alkhtyb, Ebrahym: Walkhtyb, Aml (2003). Aleshraf Altrbwy-Flsfth-Asalybh-Ttbyqath. 'man, Alardn: Dar Qndyl Llnshr Waltwzy'.

18. Khyr Allh, Mtr (2018). Dwr Almshrf Altrbwy Fy Altnmyh Almhnyh Llm'lmyn Balmrhlh Althanwyh Bwlayh Ghrb Krdfan: Drash Mydanyh Mhlyh Babnwsh (Rsalt Majstyr Ghyr Mnshwrh). Klyt Altrbyh, Jam't Alnylyn, Alkhrtwm, Alswdan.

19. Alrbat, Bhyrh (2016). Aleshraf Almhny Altrbwy. Alryad, Als'wdyh: Dar Alzhra' Llnshr Waltwzy'.

20. Alrfa'y, S'd (2006). Ejra'at Aledarh Almdrsyh Fy Almmlkh Al'rbyh Als'wdyh (T.2). Jdh, Als'wdyh: Dar Khwarzm Al'lmyh Llnshr Waltwzy'.

21. Alrshaydh, Mhmd (2009). Mharat Fy Alqyadh Walashraf Altrbwy. 'man, Alardn: Dar Wa'l Llnshr.

22. Rshyd, Fkrt (2015). Al'waml Alm'dyh Ela Tdny Althsyl Aldrasy Fy Madt Alryadyat Lda Tlbt Almrhlh Almtwsth Fy Mdars Mdynt Alrmady Al'raqyh Mn Wjht Nzr Almdrsyn Walmdyryn (Rsalt Majstyr Ghyr Mnshwrh). Klyt Al'lwm Altrbwyh, Jam't Alshrq Alawst, 'man, Alardn.

23. Rsrs, Hsn (2013). Tswr Mqtrh Lttwyr Ada' M'lmy Alryadyat Bmdars Ghzh Fy Dw' Alm'ayyr Almhnyh Alm'asrh. Mjlt Aljam'h Aleslamyh Lldrasat Altrbwyh Walnfsyh: 21(3): 353-376.

24. Alrwyly, S'wd (2010). Mham Almshrf Altrbwy Fy Ttwyr Alnmw Almhny Lm'lmy Alryadyat Fy Almrhlh Almtwsth. 'alm Altrbyh: (30): 334-396.

25. Alrwyly, S'wd (2017) Dwr Almshrf Altrbwy Fy 'sr Alm'rfh Kma Ydrkh Alm'lmwn Walm'Imat Fy Mdynh 'r'r, Mjlt Jam't Alhdwd Alshmalyh Ll'lwm Alensanyh: 2(1): 27-55.

26. Alrwyly, Hna' (2010). Dwr Mdyrat Almdars Walmshrfat Altrbwyat Fy Altnmyh Almhnyh Lm'lmat Almrhlh Almtwsth Mn Wjht Nzr M'lmat Mntqh Aljwf Alt'lymyh Balmmlkh Al'rbyh Als'wdyh: Drash Mqarnh (Rsalt Majstyr Ghyr Mnshwrh). Klyt Altrbyh, Jam't Alyrmwk, Arbd, Alardn.

27. Tjar, Sbah (2013). 'waml Tdny Althsyl Alakadymy Lmadh Alryadyat Llsf Alrab' Bmrhlh Alasas Mn Wjht Nzr Alm'lmyn (Rsalt Majstyr Ghyr Mnshwrh). Klyt Aldrasat Al'lya, Jam't Alswdan Ll'lwm Waltknwlwjya, Alkhrtwm, Alswdan.

28. Alzhrany, Khlf (2010). Esham Mdyr Almdrsh Walmshrf Altrbwy Almnsq Fy B'd Mjalat Alnmw Almhny Lm'lmy Almrhlh Alabtda'yh Bmhafzty Jdh Walmkhwah (Rsalt Majstyr Ghyr Mnshwrh). Klyt Altrbyh, Jam't Am Alqra, Mkh Almkrmh, Als'wdyh.

29. Alzhrany, Nwrh (2008). 'laqh Alnmt Alqyady Lmdyrat Almdars Balrwh Alm'nwyh Lm'lmat Almrhlh Alabtda'yh Bmhafzt Jdh (Rsalt Majstyr Ghyr Mnshwrh). Klyt Altrbyh, Jam't Am Alqra, Mkh Almkrmh, Als'wdyh.

30. Zydan, Alsyd (2018). Altnmyh Almhnyh Llm'Im Watjahatha Alhdythh Sbylna Lttwyr Alt'lym Qbl Aljam'y. Mjlt Klyt Altrbyh Bjam't Bwr S'yd. (24): 370-410.

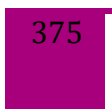

المجلة الدولية للدراسـات التربوية والنفسية- المجلد10، العدد2- 2021، ص: 345-375 